University of Louisville

ThinkIR: The University of Louisville's Institutional Repository

Electronic Theses and Dissertations

$12-2013$

\title{
Identification of carbon black removed from elastomeric components in contact with potable water.
}

William Calvin Hunter 1989-

University of Louisville

Follow this and additional works at: https://ir.library.louisville.edu/etd

\section{Recommended Citation}

Hunter, William Calvin 1989-, "Identification of carbon black removed from elastomeric components in contact with potable water." (2013). Electronic Theses and Dissertations. Paper 657.

https://doi.org/10.18297/etd/657

This Master's Thesis is brought to you for free and open access by ThinkIR: The University of Louisville's Institutional Repository. It has been accepted for inclusion in Electronic Theses and Dissertations by an authorized administrator of ThinkIR: The University of Louisville's Institutional Repository. This title appears here courtesy of the author, who has retained all other copyrights. For more information, please contact thinkir@louisville.edu. 


\title{
IDENTIFICATION OF CARBON BLACK REMOVED FROM ELASTOMERIC
} COMPONENTS IN CONTACT WITH POTABLE WATER

\author{
By \\ William Calvin Hunter III \\ B.S., University of Louisville, 2012
}

\begin{abstract}
A Thesis
Submitted to the Faculty of the

University of Louisville

J. B. Speed School of Engineering

As Partial Fulfillment of the Requirements

For the Professional Degree

MASTER OF ENGINEERING

Department of Chemical Engineering
\end{abstract}

December 2013 


\title{
IDENTIFICATION OF CARBON BLACK REMOVED FROM ELASTOMERIC
} COMPONENTS IN CONTACT WITH POTABLE WATER

\author{
Submitted By: \\ William Calvin Hunter III \\ A Thesis Approved on \\ (Date)
}

By the Following Reading and Examination Committee:

Gerold A. Willing, Thesis Director

James C. Watters

Thomas D. Rockaway 


\section{ACKNOWLEGDEMENTS}

First of all, I'd like to thank my family for all the support they've given me over the years. Through their love and freedom, I've felt confident in the decisions I've made

and know that they support me in my endeavors. Without them, I would not be the person I am today.

I would like to thank Dr. Willing for trusting me and giving me this opportunity. He has been the greatest asset to the University of Louisville and the Chemical Engineering Program. His detailed knowledge in all the subjects taught and his open door policy has allowed countless students to succeed. I appreciate all the help I've received from him over the years and cannot thank him enough.

I would like to thank my reading and examination committee. Dr. Rockaway, Dr. Watters, and Dr. Willing have taken a great deal of effort and time to read this thesis and test my knowledge on the material. No great deed comes without a challenge and without them this thesis would not have been possible.

I'd like to thank Raja Nagisetty. His knowledge and help in the lab was invaluable throughout the duration of this study. His willingness to answer questions was very beneficial to my work.

I'd like to thank my Chemical Engineering Family. Carmen Miralda, Logan Waller, Patrick Kroeger, and Patrick Baker have been with me since day one and have never given up. Through late night study sessions or help on a homework problem, I've been able to learn more about Chemical Engineering than I ever could have on my own. They never expected anything in return for their help and would always be willing to help 
no matter the time. Without them, I would not have survived the Chemical Engineering program. 


\begin{abstract}
Monochloramine is primarily used as a disinfectant in the drinking water distribution industry. The degradation of styrene butadiene rubber (SBR), natural rubber (NR), and ethylene propylene diene monomer-peroxide cured (EPDM-P) by monochloramine was first reported in a study published by the American Water Works Association (AWWA) in 2007. The study exposed samples of various types of rubber, including SBR, NR, and EPDM-P, to monochloramine solutions at varying concentrations and temperatures for 30 days. This study provided the basis for the present research, as at the medium temperatures and concentrations used in the study, $45^{\circ} \mathrm{C}$ and 30 parts per million ( $\mathrm{ppm}$ ), the rubbers displayed standard long term degradation in a short time frame. This research was continued to better understand the impacts on the rubber during long term degradation.

The experiment was set up into thirty day test periods. During these test periods, solutions containing different rubber types, temperatures, and concentrations were tested. The rubber types tested were SBR, NR, and EPDM-P. The temperatures used for the experiment were $23^{\circ} \mathrm{C}$ and $45^{\circ} \mathrm{C}$. The lower temperature used was a control while the
\end{abstract}


higher temperature characterized long term degradation. The concentrations of chloramine solution used were $1 \mathrm{ppm}$ and $30 \mathrm{ppm}$. The lower concentration was the control while the higher characterized long term degradation. The experiment found the degraded rubber particle size in solution, the amount of degraded rubber particles in solution, and the particle size range over time. Results indicated that the rubber matrix was highly affected by changes in concentration of monochloramine and temperature. The chloramine solution caused the bonds in the rubber matrix to break, releasing carbon black particles into the chloramine suspension. Both concentration and temperature are large contributors to diffusion into the rubber and the degradation rate of the rubber. However, temperature has a positive exponential proportionality while concentration has a positive linear proportionality. In conclusion, both temperature and concentration play large roles in the monochloramine diffusion into the rubber and degradation rates of the elastomer bonds. Temperature and concentration similarly contributed in determining the carbon black particle sizes being released from the degraded rubber matrix. 
TABLE OF CONTENTS

ACKNOWLEGDEMENTS .................................................................................. ii

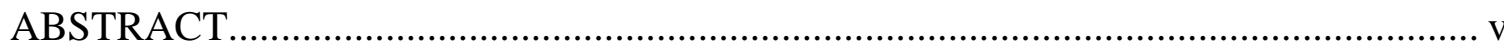

LIST OF FIGURES …................................................................................. ix

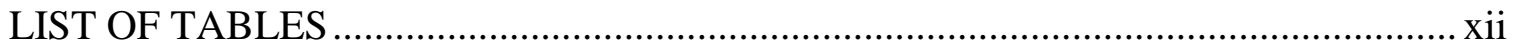

I. INTRODUCTION …………………………………………………………….. 1

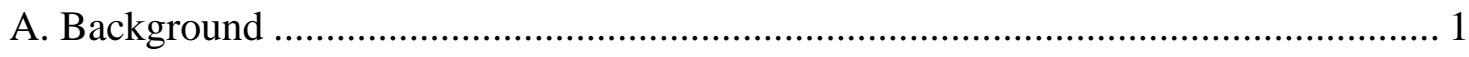

B. AWWA Rubber Degradation Study ………….................................................... 2

C. Rubber Formulation and Carbon Black......................................................................... 4

D. Time-Temperature Chloramine Superposition ..................................................... 8

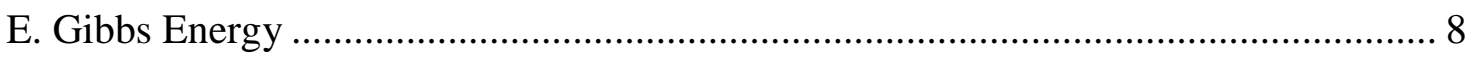

F. Chloramine Degradation Reaction Rate ……………............................................ 15

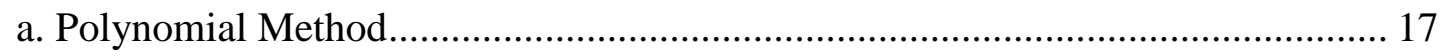

b. Integral Method ………….......................................................................... 19

G. Reaction Kinetics of Elastomer Degradation ......................................................... 22

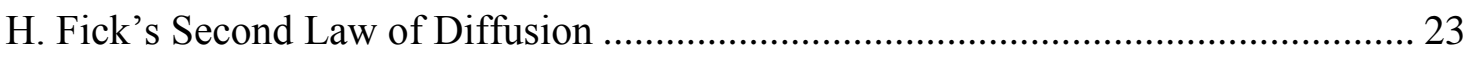

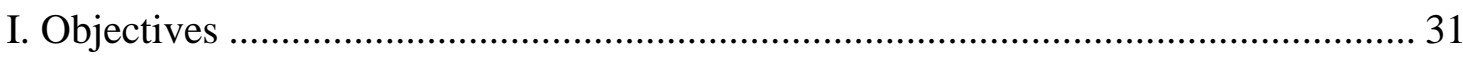

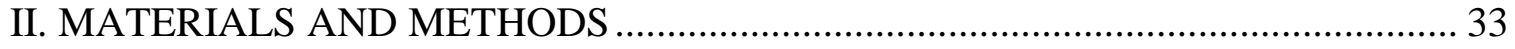

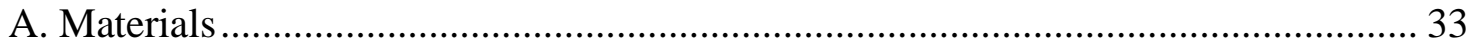

B. Brookhaven 90 Plus/Bi-mas Multi Angle Particle Sizing Device............................. 36

C. Monochloramine Synthesis Materials and Procedure .............................................. 37

D. Monochloramine Concentration Measurement ..................................................... 39

E. 30 Day Degradation Test Experimental Procedure ……………………………….... 40

a. Preparation ................................................................................................ 40

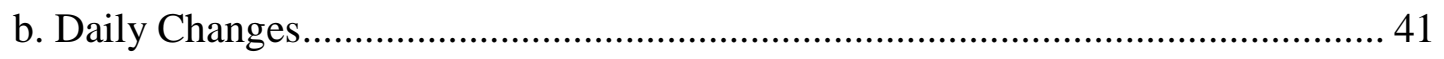




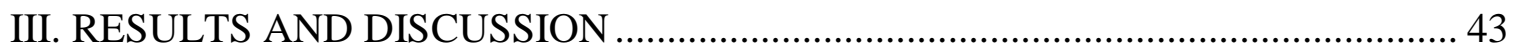

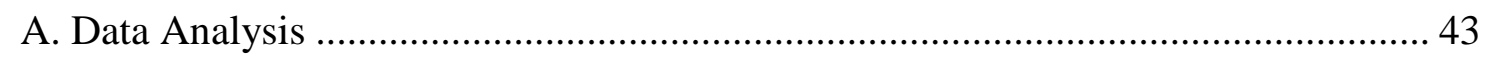

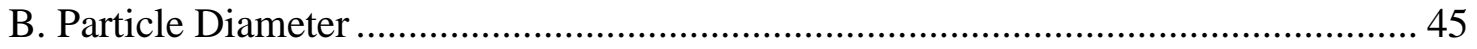

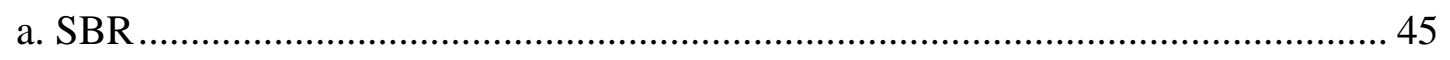

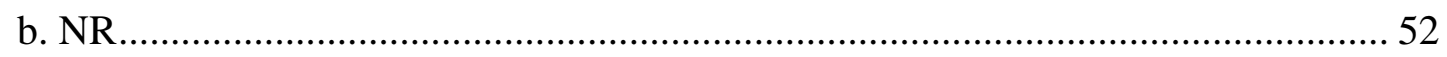

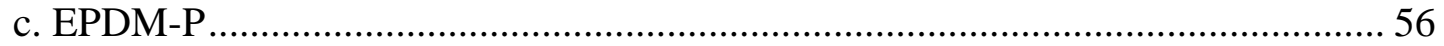

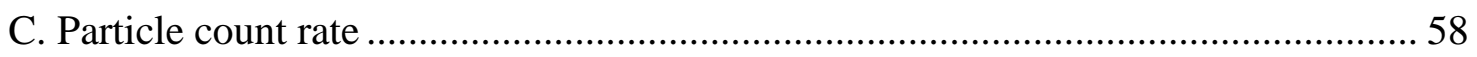

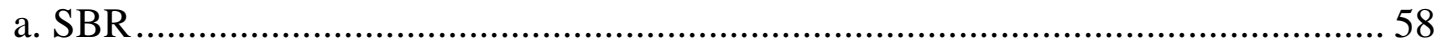

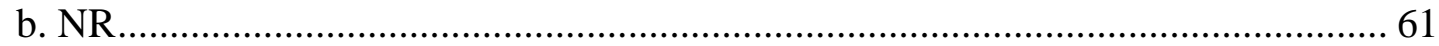

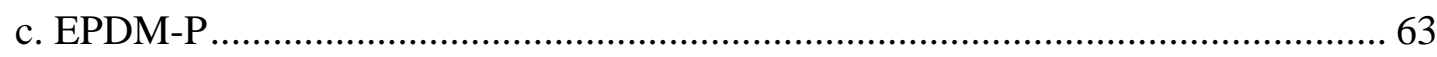

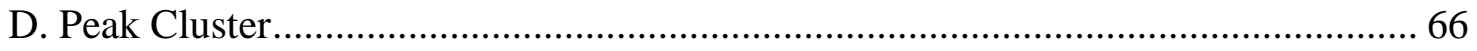

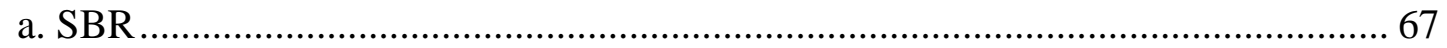

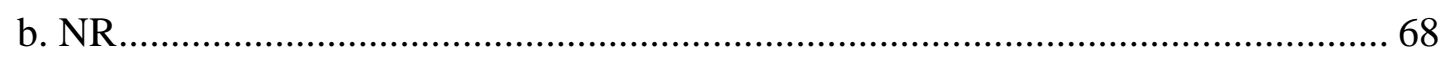

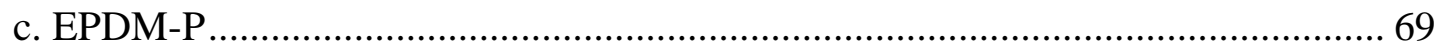

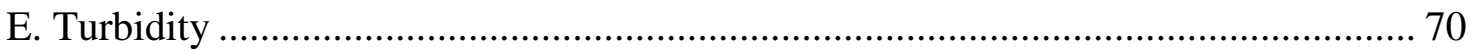

F. Comparisons to Previous Research........................................................... 74

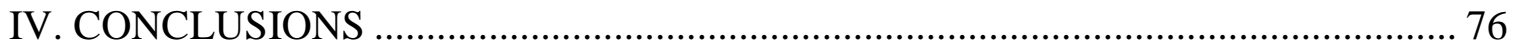

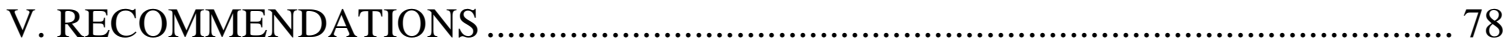

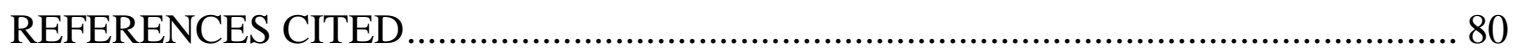

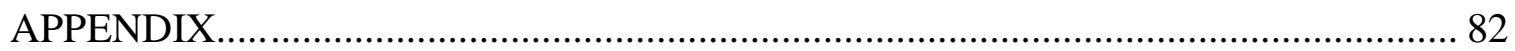

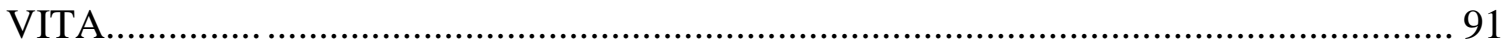




\section{LIST OF FIGURES}

Figure 1. Second Digit Classification in ASTM System (Donnet, 1976).......................... 6

Figure 2. Distribution Diagram for Chloramine Species with pH (EPA Guidance Manual. 1999). 14

Figure 3 - Monochloramine Decomposition Profile ....................................................... 17

Figure 4 - Determination of Reaction Order and Rate Constant ..................................... 18

Figure 5 - Integral Method First Order Plot............................................................... 20

Figure 6. Model depicting one dimensional contact between chloramine solution and natural rubber.

Figure 7. Diffusivity Coefficient for natural rubber at different Temperatures and Chloramine Concentrations (Nagisetty, 2009) 28

Figure 8. Chloramine Concentration Profile in natural rubber for a 30 day exposure time at different temperatures. (Nagisetty, 2009) 30

Figure 9. Styrene Butadiene Rubber Sample (Kroeger, 2013). 33

Figure 10. Rubber Samples on Glass Tree (left) and Sample Containers in Hot Water Bath (right) 35

Figure 11. SBR Interaction plot of Time and Temperature on Particle Diameter............ 47

Figure 12. SBR Interaction plot of Time and Concentration on Particle Diameter.......... 49

Figure 13. SBR Interaction plot of Time, Temperature, and Concentration on Particle

Diameter. 50

Figure 14. NR Interaction plot of Time and Temperature on Particle Diameter. 52

Figure 15. NR Interaction plot of Time and Concentration on Particle Diameter. 53 
Figure 16. NR Interaction plot of Time, Temperature, and Concentration on Particle

Diameter. 54

Figure 17. EPDM-P Interaction plot of Time, and Temperature on Particle Diameter.... 56

Figure 18. EPDM-P Interaction plot of Time, and Concentration on Particle Diameter.. 56 Figure 19. EPDM-P Interaction plot of Time, Temperature, and Concentration on Particle

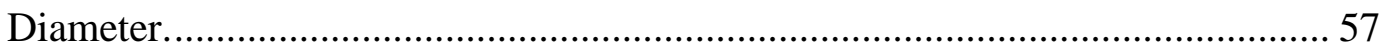

Figure 20. Daily SBR particles in solution without adjustment. ................................... 58

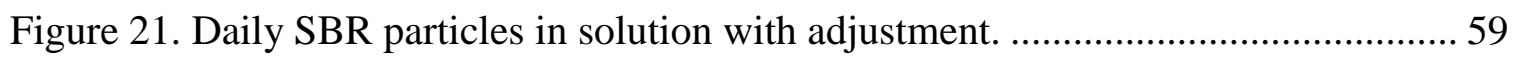

Figure 22. SBR Interaction plot of Time, Temperature, and Concentration on Diluted

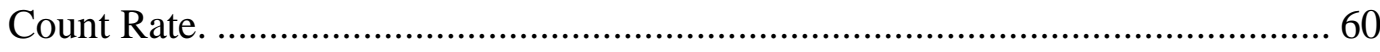

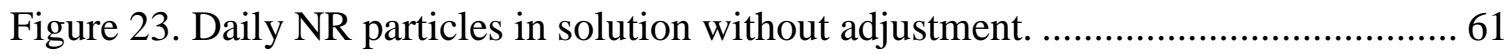

Figure 24. Daily NR particles in solution with adjustment. ....................................... 62

Figure 25. NR Interaction plot of Time, Temperature, and Concentration on Diluted

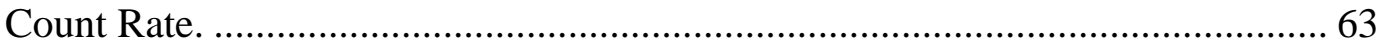

Figure 26. Daily EPDM-P particles in solution without adjustment. ............................. 64

Figure 27. Daily EPDM-P particles in solution with adjustment. ................................. 65

Figure 28. EPDM-P Interaction plot of Time, Temperature, and Concentration on Diluted

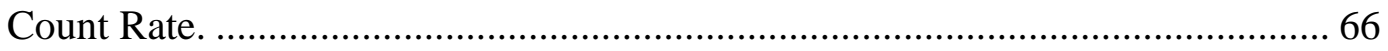

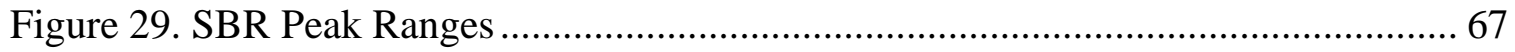

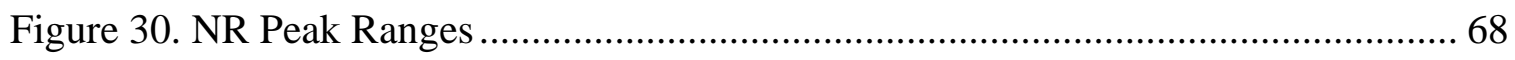

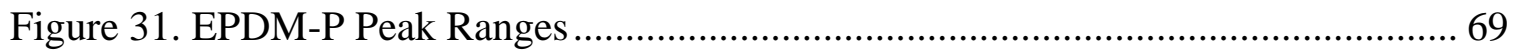


Figure 32. Turbidity at $1 \mathrm{ppm}$ and $23^{\circ} \mathrm{C}$ (Solution was changed on Day 9 to switch from DI water to Distilled) .......................................................................... 70

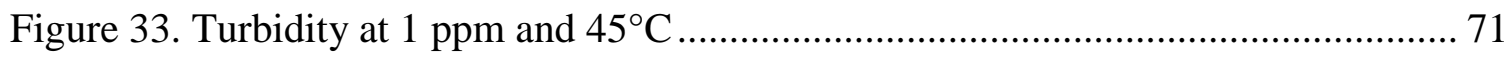

Figure 34. Turbidity at $30 \mathrm{ppm}$ and $23^{\circ} \mathrm{C}$ (Solution was changed on Day 9 to switch from

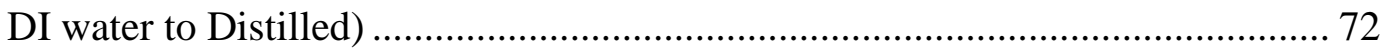

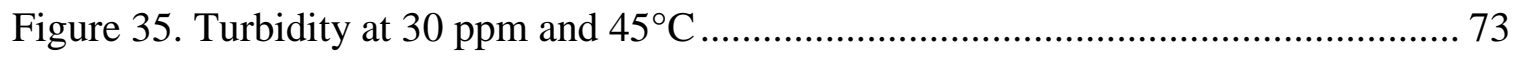




\section{LIST OF TABLES}

TABLE I._TIME TO 99 PERCENT CONVERSION OF CHLORINE TO

MONOCHLORAMINE

TABLE II_POLYNOMIAL METHOD: REACTION RATE_CONSTANT

TEMPERATURE DEPENDENCE

TABLE III_COMPARISON OF POLYNOMIAL AND INTEGRAL_METHOD

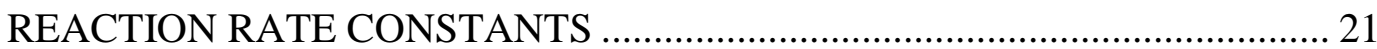

TABLE IV_ACTIVATION ENERGY AND PRE-EXPONENTIAL FACTOR............. 21

TABLE V_SBR COMPOSTION IN PARTS-PER HUNDRED (PHR) ......................... 34

TABLE VI_NR COMPOSTION IN PARTS-PER HUNDRED (PHR).......................... 34

TABLE VII_EPDM-P COMPOSITION IN PARTS-PER HUNDRED (PHR)............... 34

TABLE VIII_CHEMICALS USED IN MONOCHLORAMINE SYNTHESIS.............. 38

TABLE IX_CHEMICALS USED IN MEASURING MONOCHLORAMINE

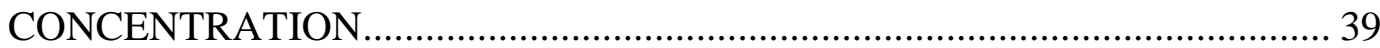

TABLE X_SUMMARY OF STARTING/AVERAGE CONCENTRATIONS ............... 41

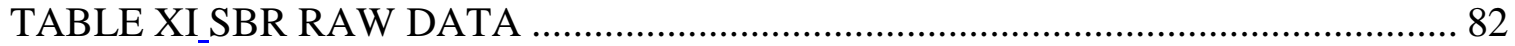

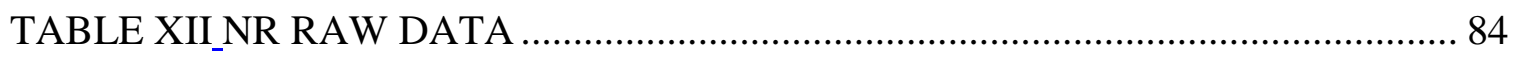

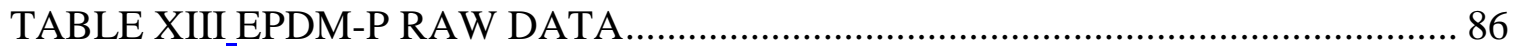

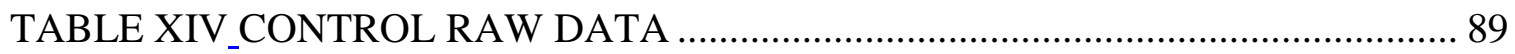




\section{INTRODUCTION}

\section{A. Background}

Since the early 1900s, chlorine had been used as the primary disinfectant of water sources to prevent the spread of water borne disease. However, recent studies have shown the formation of carcinogens in the drinking water as a product of the chlorine reacting in the system. Due to these studies, many water processing plants have switched to chloramines as a water disinfectant source instead of chlorine. Although certain carcinogens are still formed as by-products of the disinfection reaction, the rate and quantity of this formation is still being researched. (Department of Health, 2008)

This switch to chloramines has led to an increase in degradation of rubber compounds used in the water industry. This leads to shorter lifespans of these rubber compounds and causes the water company to replace these parts at a relatively higher frequency. This degradation is caused by the chloramines in solution diffusing into the rubber compounds and breaking the sulfur cross-links between the elastomer molecules. The chloramines diffusing into the rubber can also cause swelling; which can prevent rubber in valves from operating properly. (Nagisetty, 2009) 
The phrasing chloramines can be ambiguous. There are actually three types of chloramines depending on the number of chlorine atoms connected to the nitrogen atom. The main chloramine used in this study is monochloramine $\left(\mathrm{NH}_{2} \mathrm{Cl}\right)$ and is referred to as chloramine for the rest of this paper. The other two possible chloramines are dichloramine $\left(\mathrm{NHCl}_{2}\right)$ and nitrogen trichloride $\left(\mathrm{NCl}_{3}\right)$. Dichloramine and nitrogen trichloride are formed at $\mathrm{pH}$ levels which are avoided for this experiment. Although all three types of chloramines have been shown to degrade rubber compounds, monochloramine has the quickest degradation rate of all three chloramines. The focus of this study is to understand how the rubber is degraded over long term exposure. Thus monochloramine was used for this experiment since it shows the highest rubber degradation over short intervals. (Kroeger, 2013)

\section{B. AWWA Rubber Degradation Study}

For most of the twentieth century, elastomeric compounds have been used in the drinking water distribution industry. Materials such as natural rubber (NR), styrene butadiene rubber (SBR), and neoprene rubber have been used in gaskets and hoses in equipment at water treatment facilities. In most cases, this equipment is expected to have a long lifespan from 50 to 100 years. Free chlorine has been used as a disinfectant in water treatment plants for most of the twentieth century as well; however, it has fallen out of favor in recent years due to concerns that it forms hazardous byproducts when it reacts with certain organic compounds. A study conducted in 1975 by the Environmental Protection Agency (EPA) found four types of trihalomethanes (chloroform, 
bromodichloromethane, dibromodichloromethane, and bromoform) were present in drinking water as a result of the chlorination. A subsequent study by the National Cancer Institute (NCI) found that chloroform caused cancer in laboratory animals. Hence, due to these concerns, the EPA established maximum concentration standards for trihalomethanes in 1979. (Kirmeyer et al, 2003)

Since the establishment of the EPA trihalomethane standards, water distribution facilities have begun using chloramine as an alternative to free chlorine. Chloramine forms from a reaction of ammonia and chlorine and is present as monochloramine $\left(\mathrm{NH}_{2} \mathrm{Cl}\right)$, dichloramine $\left(\mathrm{NHCl}_{2}\right)$, and nitrogen trichloride $\left(\mathrm{NCl}_{3}\right)$. The amine group provides stability to the chlorine atom, thus limiting the reactions that produce trihalomethanes and increasing the time that the molecule is active in the drinking water system; this additional benefit allows water distribution facilities to add less chloramine to the water supply for the same level of disinfection. The use of chloramines in water treatment has steadily grown since the 1970s and a 2002 survey found that 46 percent of treatment facilities had converted from free chlorine to chloramine. (Nagisetty, 2009)

Almost immediately after the inclusion of chloramines into water treatment processes, elastomer gaskets and hoses that were in contact with chloramine solutions began to degrade and fail, thus prompting a study by the American Water Works Association (AWWA) Research Foundation into the effects of chloramine on several different types of elastomers used in drinking water facilities. The AWWA reported on six types of rubber: NR, neoprene rubber, ethylene propylene diene monomer peroxide cured (EPDM-P), SBR, ethylene propylene diene monomer sulfur cured (EPDM-S), and 
nitrile rubber. These six types of rubber have various applications in the water distribution industry. Rubber samples were exposed to monochloramine at a range of concentrations and temperatures over a period of 30 days and the results were formulated using the time-temperature superposition principle. The study found that all six types of rubber that were tested were affected by monochloramine with EPDM-P and EPDM-S being least sensitive and neoprene rubber and NR being most sensitive. SBR showed moderate sensitivity. (Rockaway et al., 2007)

\section{Rubber Formulation and Carbon Black}

Rubber is formulated predominately from an elastomer, carbon black and extending oil. The basic component of the rubber is the elastomer and the rubber type varies depending on the type of elastomer being produced. Carbon black is the largest additive and is used as a reinforcing material and also gives tire rubber its black color. The oils are added as processing aids or placticizers. Antioxidants and antiozonants are added to improve the resistance to aging, heat, oxygen, and ozone. Zinc oxide and stearic acid are activators for the vulcanization process, while retarders are used to delay the onset of vulcanization to ensure adequate processing time. Primary and secondary accelerators are used to regulate cure time, rate and state. Finally, sulfur is used in the vulcanization step to cross link the polymer molecules. (Hsieh, 1994) The vulcanization process causes the rubber to form and hold together. This increases the rubber durability but could also lead to larger carbon black aggregates forming on the outer surface of the rubber. 
Carbon black provides reinforcement to the elastomer and is mainly produced for that purpose. This improvement can alter the rubber modulus, hardness, tensile strength, abrasion resistance, and tear resistance as well as other properties related to the performance of the rubber. The carbon black reinforces the elastomer by acting as a filler particle. The carbon black is added during the synthesis process and adheres to the voids of the elastomer. By filling the voids within the vulcanized elastomer structure, the overall structure of the rubber is stronger. (Donnet, 1976)

The American Society of Testing and Materials (ASTM) has adopted a four digit naming and identification system that has been generally accepted. In this system, the first letter indicates the curing rate, $\mathrm{S}$ for the slow curing acidic channel blacks and $\mathrm{N}$ for the normal curing neutral and basic blacks. The second digit indicates the particle size range and the last two digits are arbitrarily assigned based on the manufacturer. (Donnet, 1976) 


\begin{tabular}{|l|l|l|l|}
\hline Second Digit & $\begin{array}{l}\text { Particle Diameter } \\
(\mathrm{nm})\end{array}$ & Old Code & Type of Black \\
\hline 0 & $1-10$ & -- & -- \\
\hline 1 & $11-19$ & SAF & Super Abrasion Furnace \\
\hline 2 & $20-25$ & ISAF & $\begin{array}{l}\text { Intermediate Super Abrasion } \\
\text { Furnace }\end{array}$ \\
\hline 3 & $26-30$ & $\begin{array}{l}\text { HAF, } \\
\text { EPC/MPC }\end{array}$ & $\begin{array}{l}\text { High Abrasion Furnace, } \\
\text { Easy Processing } \\
\text { Channel/Medium Processing } \\
\text { Channel }\end{array}$ \\
\hline 4 & $31-39$ & FF & Fine Furnace \\
\hline 5 & $40-48$ & FEF & Fast Extrusion Furnace \\
\hline 6 & $49-60$ & GPF, HMF & $\begin{array}{l}\text { General Purpose Furnace, High } \\
\text { Modulus Furnace }\end{array}$ \\
\hline 7 & $61-100$ & SRF & Semi Reinforcing Furnace \\
\hline 8 & $101-200$ & FT & Fine Thermal \\
\hline 9 & $201-500$ & MT & Medium Thermal \\
\hline
\end{tabular}

Figure 1. Second Digit Classification in ASTM System (Donnet, 1976)

The rubbers tested in this study were classified as shown below:

- $\quad \mathrm{SBR}$ as SRF-N767

- $\quad \mathrm{NR}$ as SRF-N762

- $\quad$ EPDM-P as SRF-N762

Based on the ASTM classification system, all three types of rubber are classified the same way. The carbon black used in the rubber is all Semi Reinforcing Furnace carbon black with initial particle diameter between 61-100 $\mathrm{nm}$. All three rubbers use the same type of carbon black to be reinforced however the strengthening process is different. 
In the gas furnace process that pertains to all three rubbers used in this study, a diffusion flame is created by burning part of the gas with added air. The rest of the gas is thermally decomposed in the flame, forming the desired carbon black. Yields for this process are of the order 25-40\%. (Donnet, 1976)

It is common for the carbon black to aggregate or form together in or outside of the elastomer given the right conditions. While the rubber is being synthesized, the size of the voids between the elastomer bonds determines the degree of aggregation. If the void is large enough, multiple carbon black particles may fit within the void. As the rubber is degraded, carbon black is detached and released in suspension. Since carbon black is an insoluble organic compound, these particles can be classified into one of two categories depending on the affinity of the dispersed phase for the dispersion medium. In this case, the dispersed phase is the solid carbon black particles and the dispersion medium is the very dilute in water chloramine solution. These categories are lyophilic and lyophobic.

In lyophilic colloidal suspensions, the dispersion particles have high affinity for the dispersion medium similar to that of powdered gelatin to water. This traps the dispersion medium in such a way that the overall viscosity increases. The other category is lyophobic which is what is observed in this study. In lyophobic suspensions, the dispersed particles have poor affinity to the dispersing medium and there is no significant change to the viscosity of the solution. The dispersed particles are therefore highly susceptible to coagulation. This coagulation causes the turbidity of the water to increase. 
This shows that as the degradation of the rubber increases, the turbidity should increase proportionally. (Sarai, 2002)

\section{Time-Temperature Chloramine Superposition}

Elastomer material performance predictions rely to some extent on the "relaxation/creep" properties of the individual chains in the elastomer matrix. By increasing the elastomer exposure temperature, researchers can increase the speed at which these "relaxation/creep" properties of the elastomer chains degrade and effectively move further along the time scale. By measuring property changes over a set time period at several different temperatures, it becomes possible to superimpose all the data sets onto a reference temperature and produce a master degradation curve. The process of combining the individual time and temperature curves through superposition to form a master degradation curve is called "time-temperature superposition."(Nagisetty, 2009)

The same concept can be applied to chloramine concentration. By increasing the chloramine concentration exposed to the elastomer, researchers can increase the speed at which these "relaxation/creep" properties of the elastomer chains degrade and effectively move further along the time scale. This theory allows researchers to perform long term degradation experiments in a shorter time frame.

\section{E. Gibbs Energy}

The Gibbs Energy is an indication of how spontaneous a reaction is in your system and is useful in determining the direction of a reaction and the equilibrium 
composition. "Gibbs energy differs from the thermodynamic quantities enthalpy and entropy in another significant way: it has no physical reality as a property of matter, whereas enthalpy and entropy can be related to the quantity and distribution of energy in a collection of molecules. The free energy is simply a useful construct that serves as a criterion for change and makes calculations easier" (Lower, 2010). Gibbs energy can be expressed in terms of enthalpy and entropy as seen in Equation 1.

$$
\mathrm{G}=\mathrm{H}-\mathrm{TS}
$$

Where $\mathrm{G}$ is the Gibbs energy, $\mathrm{H}$ is the enthalpy, $\mathrm{T}$ is temperature, and $\mathrm{S}$ is entropy. Equation 1 is useful but given that Gibbs, enthalpy, and entropy are state functions, taking the derivative of Equation 1 is considerably more useful. Assuming the system is at constant temperature and simplifying Equation 1 gives Equation 2.

$$
\Delta \mathrm{G}=\Delta \mathrm{H}-\mathrm{T} \Delta \mathrm{S}
$$

Using Equation 2, the spontaneity of reactions in a system can be determined. When $\Delta \mathrm{G}$ is negative, the overall entropy in the system and surroundings increases and the reaction occurs. When $\Delta \mathrm{G}$ is positive, the overall entropy in the system and surroundings decreases. Since that does not happen spontaneously, the reaction is likely to proceed in reverse where any products decompose to the reactants. When $\Delta \mathrm{G}$ is 0 , the system is in equilibrium and both reactions occur but tend to balance each other out. 
As previously mentioned the chloramines enter the rubber matrix and cause the rubber to degrade over time. However, it is useful to know what actually makes the chloramine solution being used by the water company. The components in the chloramine solution are a 0.7:1.1:1000 ratio of sodium hypochlorite $(\mathrm{NaOCl})$ : ammonium hydroxide $\left(\mathrm{NH}_{4} \mathrm{OH}\right)$ : DI water $\left(\mathrm{H}_{2} \mathrm{O}\right)$.

Sodium hypochlorite in water disassociates almost immediately. The reaction equations to form this compound are shown below:

$$
\begin{array}{cc}
\mathrm{OH}^{-}(\mathrm{aq})+\mathrm{Na}^{+}(\mathrm{aq}) \leftrightarrow \mathrm{NaOH}(\mathrm{aq}) & \Delta \mathrm{G}_{\mathrm{rxn}}=39.76 \mathrm{~kJ} / \mathrm{mol} \\
\mathrm{H}^{+}(\mathrm{aq})+\mathrm{OCl}^{-}(\mathrm{aq}) \leftrightarrow \mathrm{HOCl}(\mathrm{aq}) & \Delta \mathrm{G}_{\mathrm{rxn}}=-43.10 \mathrm{~kJ} / \mathrm{mol} \\
\underline{\mathrm{H}_{2}} \underline{\mathrm{O}(\mathrm{l}) \leftrightarrow \mathrm{H}^{+}(\mathrm{aq})+\mathrm{OH}^{-}(\mathrm{aq})} & \Delta \mathrm{G}_{\mathrm{rxn}}=79.86 \mathrm{~kJ} / \mathrm{mol} \\
\mathrm{H}_{2} \mathrm{O}(\mathrm{l})+\mathrm{OCl}^{-}(\mathrm{aq})+\mathrm{Na}^{+}(\mathrm{aq}) \leftrightarrow \mathrm{NaOH}(\mathrm{aq})+\mathrm{HOCl}(\mathrm{aq}) & \Delta \mathrm{G}_{\mathrm{rxn}}=76.52 \mathrm{~kJ} / \mathrm{mol}
\end{array}
$$

All values for $\Delta \mathrm{G}_{\mathrm{rxn}}$ were found in the CRC Handbook of Chemistry and Physics, 2005.

Here Reactions 1-3 are disassociation reactions of the compounds and Reaction 4 is the final overall reaction. It is important to notice that $\mathrm{NaOCl}$ is not in the final reaction product. This is due to the fact that sodium hypochlorite dissociates in water. So instead of $\mathrm{NaOCl}$, the final product is aqueous $\mathrm{Na}^{+}$and $\mathrm{OCl}^{-}$.

Written next to each of the reactions is the $\Delta \mathrm{G}_{\mathrm{rxn}}$. As previously mentioned, positive values for $\Delta \mathrm{G}_{\mathrm{rxn}}$ mean the reaction will favor the reactants and not the products. 
This is good since the reaction for chloramine requires $\mathrm{Na}^{+}$and $\mathrm{OCl}^{-}$. The reaction favoring the reactants is further proven with Equation 3 (Smith, 2005):

$$
K_{e q}=\exp \left(\frac{-\Delta G}{R T}\right)
$$

Where $\mathrm{K}_{\mathrm{eq}}$ is the equilibrium constant, $\mathrm{G}$ is the Gibbs energy, $\mathrm{R}$ is the gas constant, and $\mathrm{T}$ is the temperature. The equilibrium constant can also be written as (Perry and Green, 2008):

$$
K_{e q}=\frac{[C]^{c}[D]^{d}}{[A]^{a}[B]^{b}}
$$

And

$$
a A+b B \leftrightarrow c C+d D
$$

Where a,b,c, and d are stoichiometric coefficents. A, B, C, and D are the reactants and products. $[\mathrm{A}],[\mathrm{B}],[\mathrm{C}]$, and $[\mathrm{D}]$ are the concentrations of the reactants and products.

The equilibrium constant can be calculated using Equations 3. Equations 4 and 5 demonstrate how the overall concentration of the solution affects the equilibrium constant. Standard values for the equilibrium constant are usually around 1. When the equilibrium constant equals 1 , the reaction favors neither the reactants or the products and 
the reaction is considered to be at steady state. When the equilibrium constant is less than 1 , the reaction favors the reactants and when it is greater than 1 , the reaction favors the products.

The overall equilibrium constant for Reaction 4 is 2.3E-14 (CRC Handbook of Chemistry and Physics, 2005). From a chemistry viewpoint, this means the reaction favors the reactants just like the Gibbs energy represented. However, from a mathematical viewpoint, the equilibrium constant is much less than 1 . Thus the reaction strongly favors the reactants. Looking at Equation 4, in order for the equilibrium constant to be so low, the concentration of reactants must be relatively large compared to the concentration of the products.

The second reactant used in the preparation of chloramine solution is ammonium hydroxide $\left(\mathrm{NH}_{4} \mathrm{OH}\right)$. However, similar to sodium hypochlorite, ammonium hydroxide dissociates in water. This can be seen in the reactions below.

$$
\begin{array}{cc}
\mathrm{NH}_{3}(\mathrm{aq})+\mathrm{H}^{+}(\mathrm{aq}) \leftrightarrow \mathrm{NH}_{4}^{+}(\mathrm{aq}) & \Delta \mathrm{G}_{\mathrm{rxn}}=-52.80 \mathrm{~kJ} / \mathrm{mol} \\
\underline{\mathrm{H}}_{2} \underline{\mathrm{O}(\mathrm{l}) \leftrightarrow \mathrm{H}^{+}(\mathrm{aq})+\mathrm{OH}^{-}(\mathrm{aq})} & \Delta \mathrm{G}_{\mathrm{rxn}}=79.86 \mathrm{~kJ} / \mathrm{mol} \\
\mathrm{NH}_{3}(\mathrm{aq})+\mathrm{H}_{2} \mathrm{O}(\mathrm{l}) \leftrightarrow \mathrm{NH}_{4}^{+}(\mathrm{aq})+\mathrm{OH}^{-}(\mathrm{aq}) & \Delta \mathrm{G}_{\mathrm{rxn}}=27.06 \mathrm{~kJ} / \mathrm{mol}
\end{array}
$$

Once again, the Gibbs energy value is positive meaning the reaction favors the reactants. The overall equilibrium constant is $1.5 \mathrm{E}-5$. This value is still way below 1 ; however this reaction does have a higher mobility between products and reactants. Yet the reactants are still heavily favored. 
The reaction to form the chloramine solution is simple. Combining and mixing the two previous solutions together, the chloramine solution forms. This is shown in the reaction steps below.

$$
\begin{aligned}
& \mathrm{NaOH}(\mathrm{aq})+\mathrm{HOCl}(\mathrm{aq}) \leftrightarrow \mathrm{H}_{2} \mathrm{O}(\mathrm{l})+\mathrm{OCl}^{-}(\mathrm{aq})+\mathrm{Na}^{+}(\mathrm{aq}) \quad \Delta \mathrm{G}_{\mathrm{rxn}}=-76.52 \mathrm{~kJ} / \mathrm{mol} \\
& \mathrm{NH}_{3}(\mathrm{aq})+\mathrm{H}_{2} \mathrm{O}(\mathrm{l}) \leftrightarrow \mathrm{NH}_{4}^{+}(\mathrm{aq})+\mathrm{OH}^{-}(\mathrm{aq}) \quad \Delta \mathrm{G}_{\mathrm{rxn}}=27.06 \mathrm{~kJ} / \mathrm{mol} \\
& \mathrm{OH}^{-}(\mathrm{aq})+\mathrm{Na}^{+}(\mathrm{aq}) \leftrightarrow \mathrm{NaOH}(\mathrm{aq}) \quad \Delta \mathrm{G}_{\mathrm{rxn}}=39.76 \mathrm{~kJ} / \mathrm{mol} \\
& \underline{\mathrm{OCl}-(\mathrm{aq})+\mathrm{NH}_{4}} \underline{+(\mathrm{aq}) \leftrightarrow \mathrm{NH}_{2}} \underline{\underline{\mathrm{Cl}}(\mathrm{aq})+\mathrm{H}_{2}} \underline{\underline{\mathrm{O}}(\mathrm{l})} \quad \Delta \mathrm{G}_{\mathrm{rxn}}=88.23 \mathrm{~kJ} / \mathrm{mol} \\
& \mathrm{NH}_{3}(\mathrm{aq})+\mathrm{HOCl}(\mathrm{aq}) \leftrightarrow \mathrm{NH}_{2} \mathrm{Cl}(\mathrm{aq})+\mathrm{H}_{2} \mathrm{O}(\mathrm{l}) \quad \Delta \mathrm{G}_{\mathrm{rxn}}=78.53 \mathrm{~kJ} / \mathrm{mol}
\end{aligned}
$$

Although the Gibbs energy is positive, the reaction goes to completion in less than a second. This is represented in the Table I. The Gibbs energy being positive represents the slow degradation of chloramine to $\mathrm{NH}_{3}$ and $\mathrm{HOCl}$ over time.

TABLE I.

TIME TO 99 PERCENT CONVERSION OF CHLORINE TO MONOCHLORAMINE.

\begin{tabular}{cc}
\hline $\mathrm{pH}$ & Time (seconds) \\
\hline 2 & 421 \\
4 & 147 \\
7 & 0.2 \\
8.3 & 0.069 \\
12 & 33.2 \\
\hline
\end{tabular}

(EPA Guidance Manual, 1999) 
The experimental $\mathrm{pH}$ is 8.3 using a $\mathrm{pH} 7$ buffer and the $\mathrm{pH}$ of the water system is roughly 7 . From Table I, the time for chloramines to form is about 0.2 seconds or less. Continuing from before, since the reaction to chloramine is so short; the Gibbs energy corresponds to the degradation of chloramine. This degradation can be sped up at higher temperatures and higher initial chloramine concentrations.

The $\mathrm{pH}$ of the solution also plays a large role in the type of chloramine formed. This is shown in Figure 2:

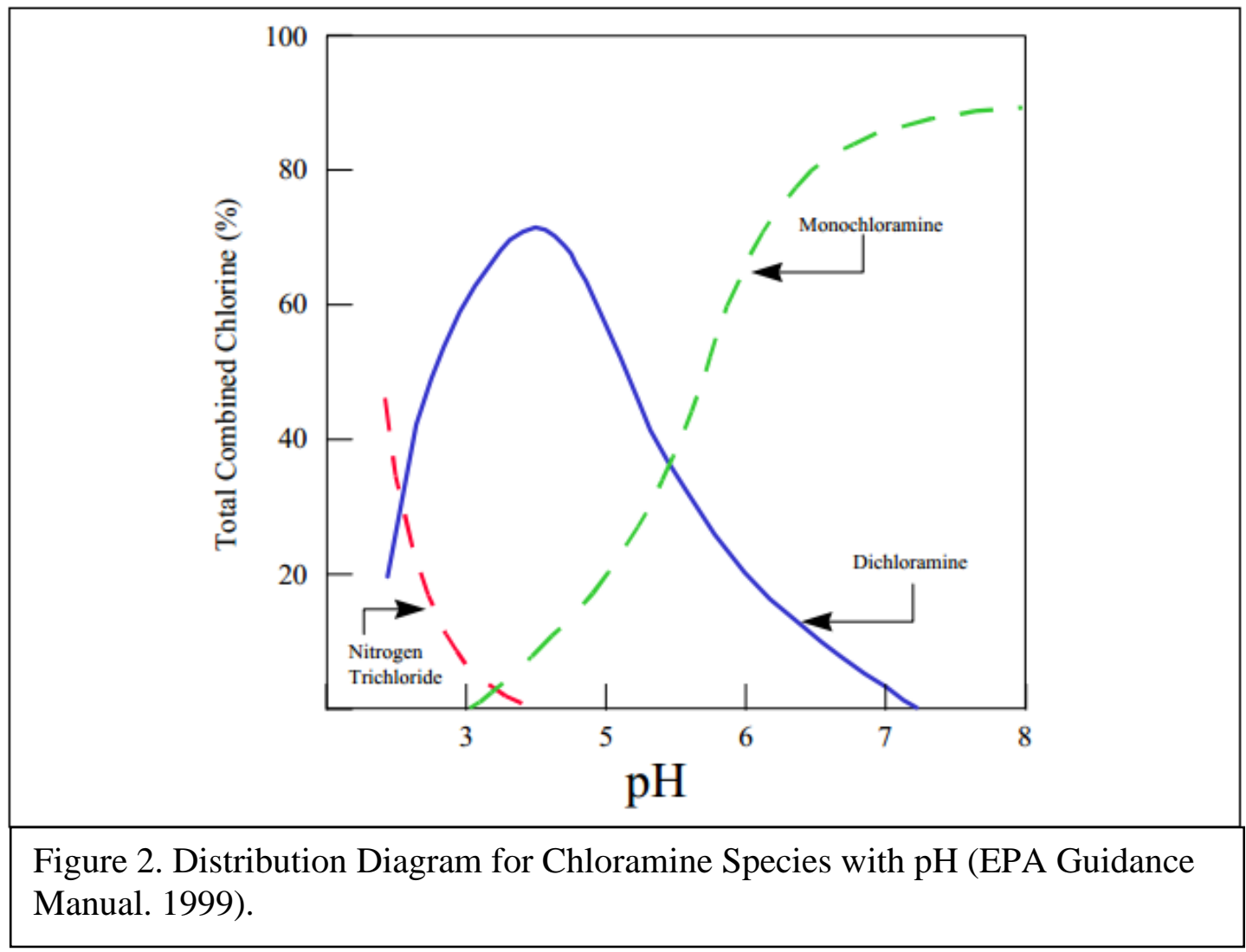

The $\mathrm{pH}$ can determine which chloramine species is formed. The lower the $\mathrm{pH}$, the more free $\mathrm{H}^{+}$ions will be available in solution. This means instead of the hydrogen bonding 
with the nitrogen and chlorine, the hydrogen ions will remain suspended in solution. This means the nitrogen will bond with the free chlorine ions instead to become stable. Thus at lower $\mathrm{pH}$, the solution will form more dichloramine and nitrogen trichloride. Alternatively, at more neutral $\mathrm{pH}$ concentrations of about 7 or 8.3 , the solution is more likely to form monochloramine.

Based on the previous reactions, figure, and table, the solution is expected to start out as monochloramine and water. The $\mathrm{pH}$ of the solution will eliminate all dichloramine and nitrogen trichloride. However, monochloramine isn't completely stable. Over time it is expected to slowly degrade into ammonia and hypochlorous acid. As the experiment progresses, the amount of ammonia and hypochlorous acid in the solution will increase as the monochloramine concentration is kept constant.

\section{F. Chloramine Degradation Reaction Rate}

The objective of this section is to determine the stability of monochloramine at different temperatures by determining the rate law, reaction order, reaction rate constant, and activation energy. This is achieved by measuring the rate of chloramine decomposition over the course of several hours at different temperatures. The chloramine solution is unstable at standard conditions. This causes the chloramine components to slowly decompose into ammonia and hypochlorous acid. The goal of this section is to determine the rate of this decomposition. This would allow an average concentration over 24 hours to be met. The first step is to postulate the chemical equation that describes 
monochloramine decomposition. A simplified version of the monochloramine decomposition equation is

$$
\mathrm{NH}_{2} \mathrm{Cl} \rightarrow \text { products }
$$

The actual mechanism is more complicated; however, this equation is adequate to serve the intended purpose of determining the rate of decomposition of monochloramine. From Equation 6, a rate law is assumed to take the form

$$
-r_{\mathrm{NH}_{2} \mathrm{Cl}}=k \mathrm{C}_{\mathrm{NH}_{2} \mathrm{Cl}}^{\alpha}
$$

The parameters are then determined experimentally by reacting monochloramine at different temperatures and tracking the concentration decrease over time. Raw concentration data is measured in $\mathrm{ppm}$ and then converted to mol/L by the conversion

$$
1 \text { ppm Monochloramine }=1.9425 \times 10^{-5} \frac{\mathrm{mol}}{\mathrm{L}}
$$

Two different methods were used to determine the rate law parameters of the decomposition of monochloramine. A method similar to the polynomial method is first. Then the data is compared versus the integral method to evaluate the rate law parameters and compare the effectiveness of the different methods. 
a. Polynomial Method

For the polynomial method, the data is plotted and fitted with a trendline, as shown in Figure 3.

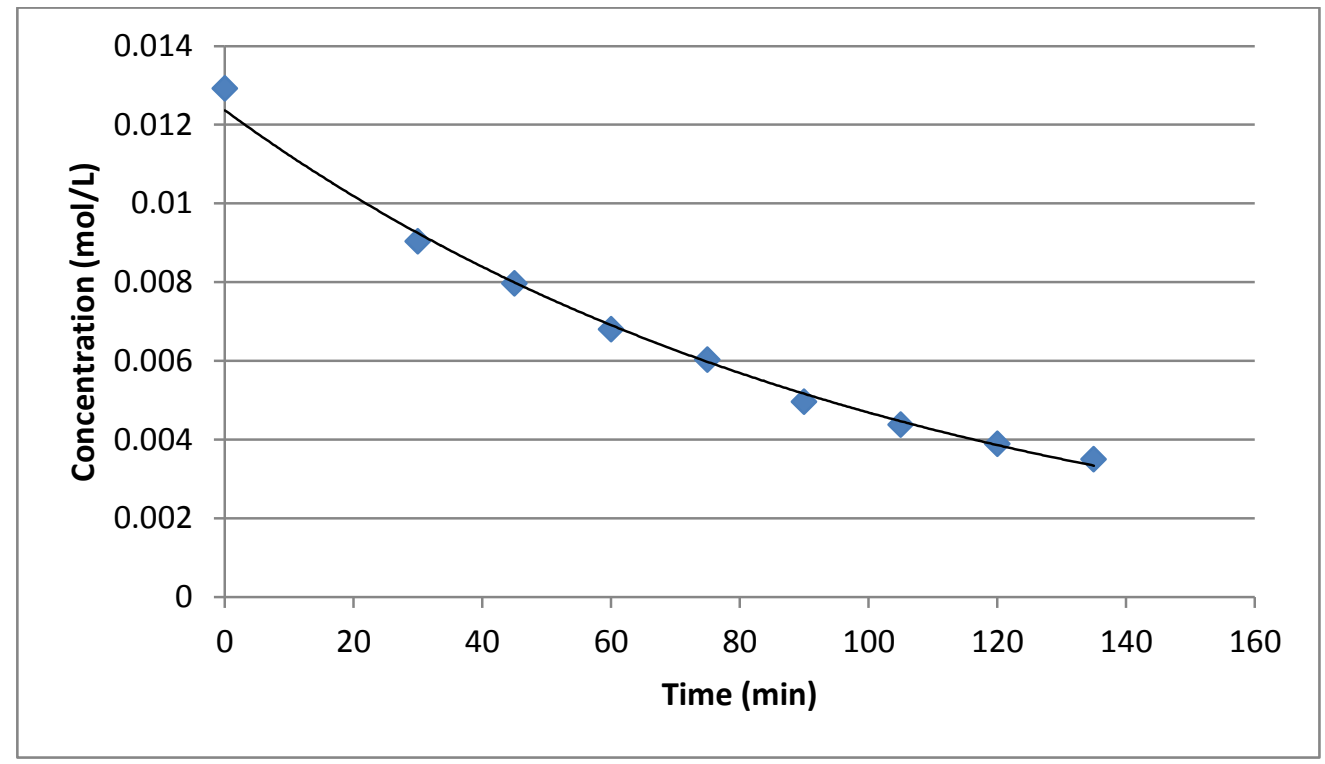

Figure 3 - Monochloramine Decomposition Profile

$$
\begin{aligned}
& \text { Trendline Equation }=C_{\mathrm{NH}_{2} \mathrm{Cl}} \\
& =0.01237 \exp (-0.00971 t) \\
& -\frac{d C_{\mathrm{NH}_{2} \mathrm{Cl}}}{d t}=-(-0.00971)(0.01237) \exp (-0.00971 t)
\end{aligned}
$$

The trendline is differentiated with respect to time to determine the reaction rates at times corresponding to measured concentrations. The reaction rate is then plotted as a function 
of the measured concentration values and a trendline is fitted to determine the reaction rate constant and the order of reaction as seen in Figure 4.

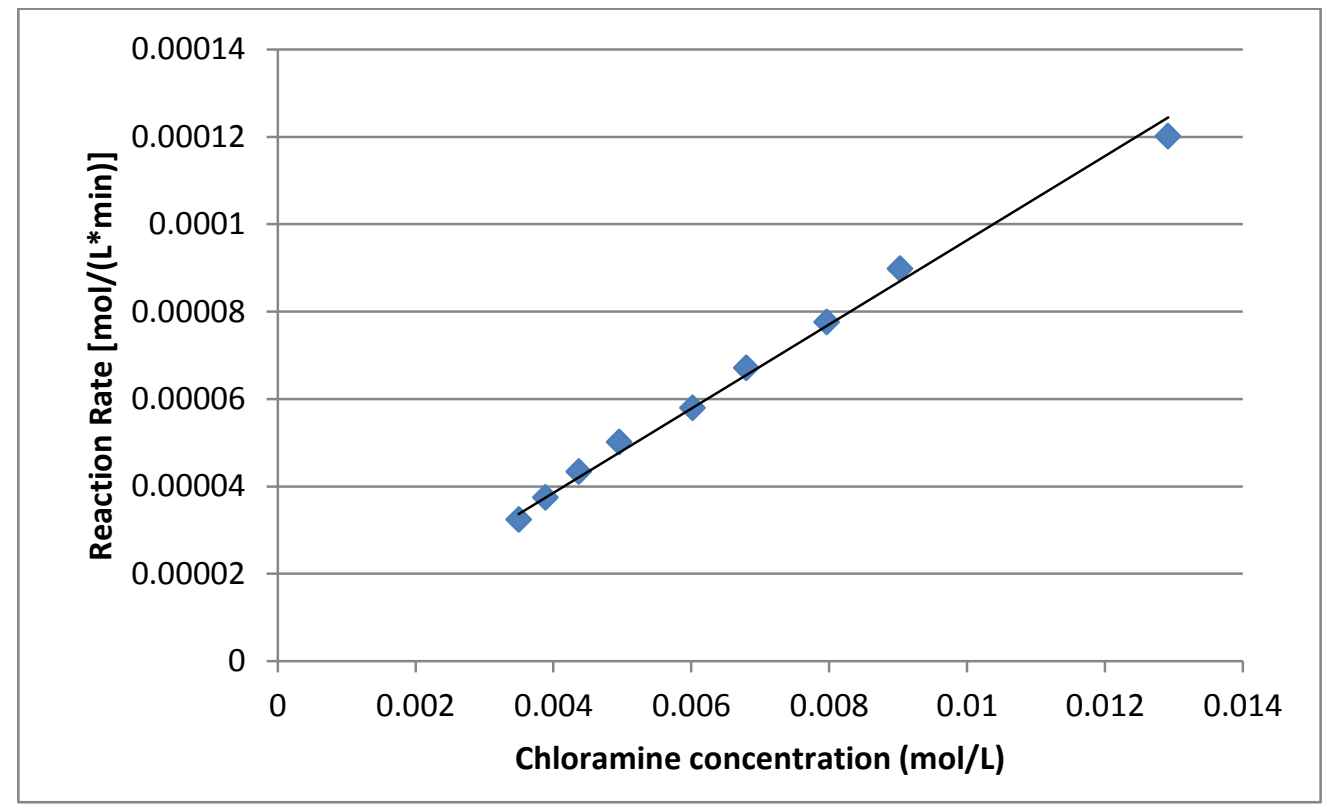

Figure 4 - Determination of Reaction Order and Rate Constant

$$
\text { Trendline Equation }=-r_{\mathrm{NH}_{2} \mathrm{Cl}}=0.009632 \mathrm{C}_{\mathrm{NH}_{2} \mathrm{Cl}}
$$

Thus, by Equation 11, the reaction is first order in monochloramine and the reaction rate constant is approximately $0.0096 \mathrm{~min}^{-1}$. This process is performed for concentration profiles at two other temperatures to determine the dependence of the rate constant on temperature. The results are presented in Table II. 
TABLE II

POLYNOMIAL METHOD: REACTION RATE

CONSTANT TEMPERATURE DEPENDENCE

\begin{tabular}{cc}
\hline TEMPERATURE $\left({ }^{\circ} \mathbf{C}\right)$ & $\mathbf{k}\left(\mathbf{m i n}^{-1}\right)$ \\
\hline $\mathbf{4 5}$ & 0.001748 \\
$\mathbf{7 0}$ & 0.009632 \\
$\mathbf{9 2}$ & 0.061912 \\
\hline
\end{tabular}

\section{b. Integral Method}

The results from the integral method correlate strongly with results from the polynomial method. Both methods determined the reaction was first order. The data was plotted three different times in Microsoft Excel to determine if the reaction was zero, first, or second order. For zero order, concentration, Ca vs. time was plotted. For first order, $\ln \left(\mathrm{Ca}_{0} / \mathrm{Ca}\right)$ vs. time was plotted. Finally, $1 / \mathrm{Ca}$ vs. time was plotted to determine second order. A line of best fit was assigned to each set of data. The data set which had the highest $\mathrm{R}^{2}$ values determined the reaction order. When fitted to a first order system, all three temperatures indicated high correlation, proving the reaction is first order. The reaction rate constant, $\mathrm{k}$ was also similar for the two methods. The reaction rate constants are logical since they follow heuristics and increase as the temperature increases. The first order plot and a comparison of the reaction rate constants are presented below in Figure 5 and Table III, respectively. 


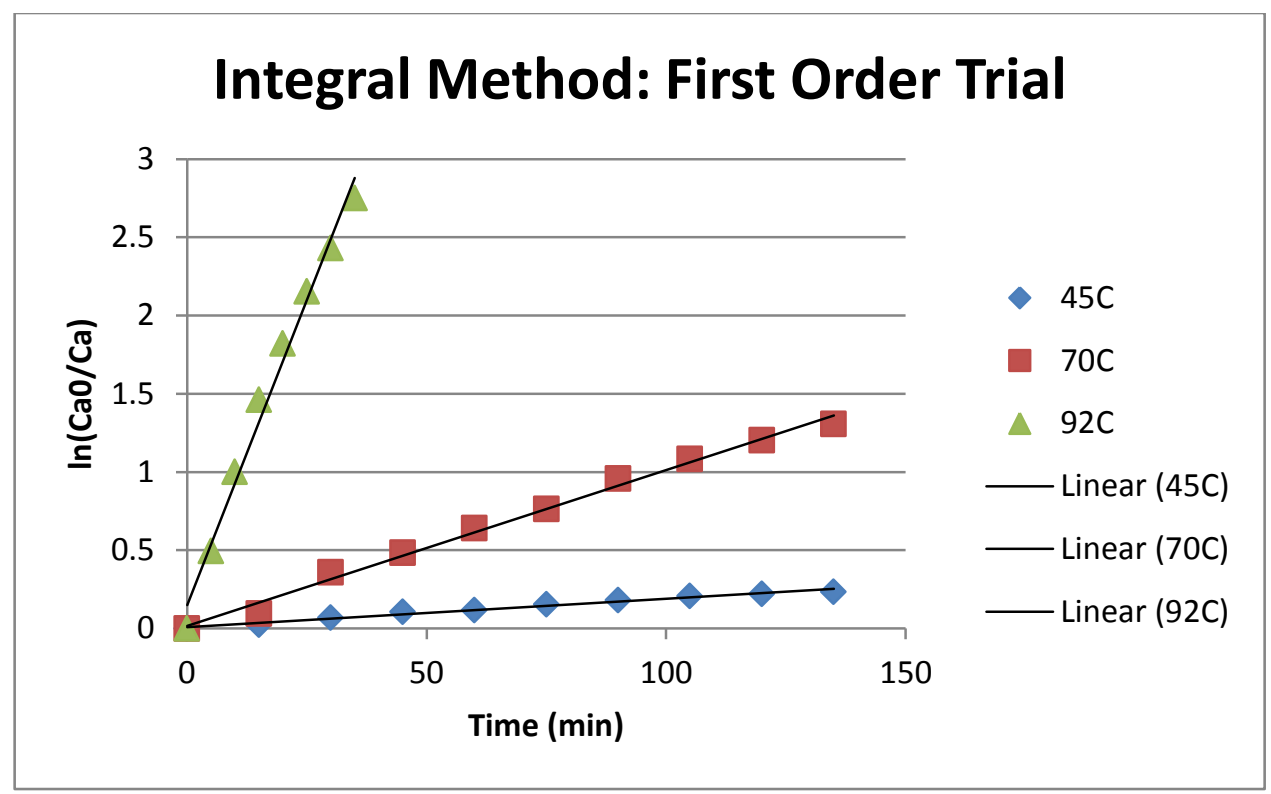

Figure 5 - Integral Method First Order Plot

$$
\begin{gathered}
\ln \frac{C a o}{C a}=0.0018 t+0.0092\left(\mathrm{R}^{2}=0.982\right) \text { at } 45^{\circ} \mathrm{C} \\
\ln \frac{C a o}{C a}=0.01 t+0.0159\left(\mathrm{R}^{2}=0.993\right) \text { at } 70^{\circ} \mathrm{C} \\
\ln \frac{C a o}{C a}=0.078 t+0.1492\left(\mathrm{R}^{2}=0.987\right) \text { at } 92^{\circ} \mathrm{C}
\end{gathered}
$$


TABLE III

COMPARISON OF POLYNOMIAL AND INTEGRAL

METHOD REACTION RATE CONSTANTS

\begin{tabular}{ccc}
\hline Temperature & $\begin{array}{c}\text { Polynomial } \\
\text { Method }\end{array}$ & Integral Method \\
$\mathrm{T}\left({ }^{\circ} \mathrm{C}\right)$ & $\mathrm{k}\left(\mathrm{min}^{-1}\right)$ & $\mathrm{k}\left(\mathrm{min}^{-1}\right)$ \\
\hline $45^{\circ} \mathrm{C}$ & 0.00174 & 0.0018 \\
$70^{\circ} \mathrm{C}$ & 0.0096 & 0.01 \\
$92^{\circ} \mathrm{C}$ & 0.0619 & 0.078 \\
\hline
\end{tabular}

Using the data from Table III, the activation energy, $\mathrm{E}_{\mathrm{a}}$, and the pre-exponential factor, $\mathrm{k}_{\mathrm{o}}$, can be calculated using the Arrhenius equation $\left(k=k_{o} \exp \left[\frac{-E_{a}}{R T}\right]\right)$. These values are found in Table IV.

TABLE IV

ACTIVATION ENERGY AND PRE-EXPONENTIAL FACTOR

\begin{tabular}{|c|c|}
\hline Factor & Value \\
\hline $\mathrm{E}_{\mathrm{a}}$ & $72745 \mathrm{~J} / \mathrm{mol}$ \\
\hline $\mathrm{k}_{\mathrm{o}}$ & $1.405 \times 10^{9} \mathrm{~min}^{-1}$ \\
\hline
\end{tabular}




\section{G. Reaction Kinetics of Elastomer Degradation}

Previous studies have determined the elastomer degradation rate can be generally modeled by the Arrhenius rate equation, shown in Equation 15 .

$$
\mathrm{k}=k_{o} \exp \left[-\frac{E_{a}}{R T}\right]
$$

Where $\mathrm{k}$ is the elastomer degradation rate constant, $\mathrm{k}_{\mathrm{o}}$ is the pre-exponential factor at standard conditions, $E_{a}$ is the activation energy, $R$ is the universal gas constant, and $T$ is the absolute temperature in Kelvin.

For this elastomer degradation study, concentration and temperature were used to accelerate the degradation. Thus, taking into account the Arrhenius equation, the temperature effects, and the concentration effects, the degradation rate function was anticipated to take the form shown in Equation 16.

$$
-r_{A}=k_{o} e^{-E_{a} / R T} * C_{A}^{a}
$$

Where $r_{A}$ is the elastomer degradation rate, $k_{o}$ is the initial degradation rate, $E_{a}$ is the activation energy, $\mathrm{R}$ is the universal gas constant, $\mathrm{T}$ is absolute temperature in Kelvin, $\mathrm{C}_{\mathrm{A}}$ is chloramine concentration with "a" as a constant (material dependent). Equation 16 is dependent on temperature and concentration and can be broken apart into two terms. Equation 17 is the temperature dependent term and Equation 18 is the concentration dependent term. 


$$
\begin{gathered}
k_{o} e^{-E_{a} / R T} \\
C_{A}^{a}
\end{gathered}
$$

Observing Equations 16 through 18, it is easy to state how temperature and concentration affect the reaction rate of the elastomer. Any changes in temperature will alter the elastomer reaction rate in an exponential manner. Whereas, the term "a" for the reactions in this experiment is at one. This makes any changes in concentration linearly proportional to the elastomer degradation rate (Rockaway et al, 2007).

\section{H. Fick's Second Law of Diffusion}

Fick's second law of diffusion is useful in calculating and determining the factors that affect the amount of diffusion of a liquid into a solid. The overall goal for the water industry is to reduce the diffusion rate and increase the lifetime of their rubber components.

The diffusion of chloramine solution into the rubber compound can be explained through Fick's $2^{\text {nd }}$ law of diffusion shown in Equation 19 below:

$$
\frac{\partial c_{A}}{\partial t}=D\left(\frac{\partial^{2} c_{A}}{\partial x^{2}}+\frac{\partial^{2} c_{A}}{\partial y^{2}}+\frac{\partial^{2} c_{A}}{\partial z^{2}}\right)
$$


Here $c_{A}$ is the concentration of the chloramine solution diffusing into the rubber compound, $\mathrm{t}$ is the time, $\mathrm{D}$ is the diffusion coefficient, and $(\mathrm{x}, \mathrm{y}, \mathrm{z})$ refer to the direction of diffusion on the Cartesian coordinate system.

Fick's $2^{\text {nd }}$ law of diffusion is based on three observations and is used to define unsteady state diffusion in a system: 1)Mass transfer by ordinary molecular diffusion occurs because of a concentration gradient. 2)The mass-transfer rate is proportional to the

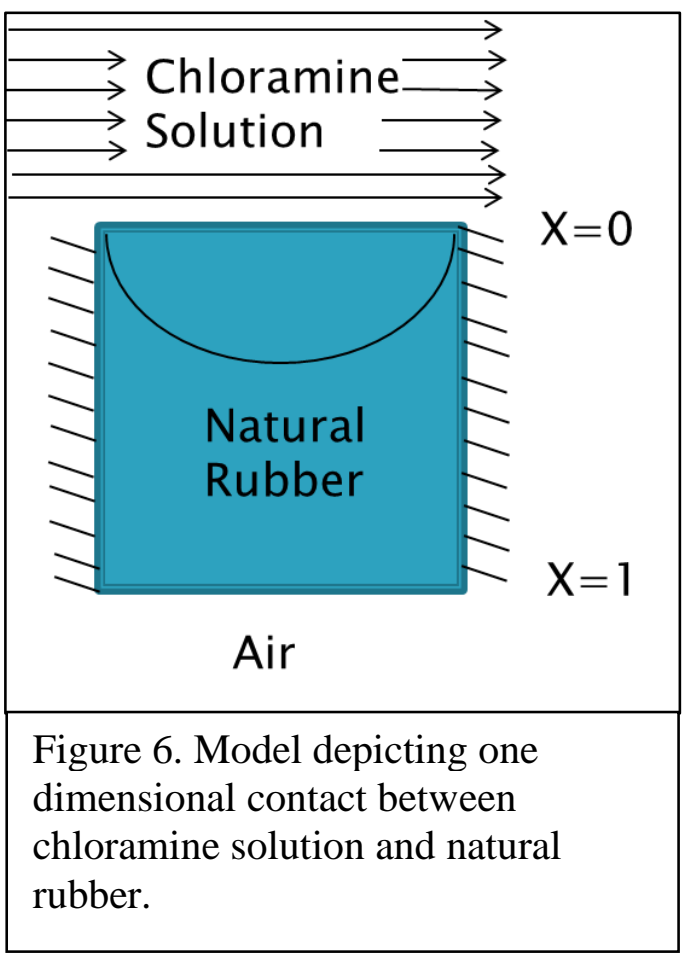
area normal to the direction of mass transfer. 3)Net transfer stops when concentrations are uniform. (Seader, 2011)

The concentration of the chloramine solution over time plays a large role in the diffusion rate. As explained by Fick's observations through the $2^{\text {nd }}$ law, the diffusion rate is proportional to the gradient in the system. That means the driving force of the diffusion is the gradient formed from the chloramine concentration in solution versus the chloramine concentration inside the rubber.

Fick's $2^{\text {nd }}$ law of diffusion helps model the diffusion of chloramine solution into the rubber compound but it can be simplified. As seen in Figure 6, the chloramine solution only contacts the rubber in one dimension. This is similar to the experimental arrangement. The rubber samples have high surface area in the x-direction and relatively 
small surface areas in the $y$ and z-directions. Thus, Fick's $2^{\text {nd }}$ law can be reduced to only the $\mathrm{x}$-direction as shown in Equation 20:

$$
\frac{\partial c_{A}}{\partial t}=D\left(\frac{\partial^{2} c_{A}}{\partial x^{2}}\right)
$$

The change in the diffusion coefficient, D, with respect to temperature can be modeled with the Arrhenius equation: $D=D_{o} e^{-E_{a} / R T}$, making $\mathrm{D}$ the temperature dependent term. The second order chloramine concentration at rubber depth: $\left(\frac{\partial^{2} c_{A}}{\partial x^{2}}\right)$, is the concentration dependent term. (Perry and Green, 2008)

Since the diffusion is one dimensional, Fick's $2^{\text {nd }}$ law can be solved using Fourier Integrals, boundary conditions, and initial conditions. The boundary conditions are:

$$
\begin{aligned}
& C(0, t)=30 \mathrm{ppm} \\
& C(1, t)=0 \mathrm{ppm}
\end{aligned}
$$

The initial condition for the system is:

$$
\mathrm{C}(\mathrm{x}, 0)=\left\{\begin{array}{c}
30 \text { ppm at } x=0 \\
0 \text { ppm at } x>0
\end{array}\right.
$$

Where $C(x, t)$ is the function of concentration at depth of rubber penetration $(x)$ and time (t). The function can be separated into two functions as seen below in Equation 24. 


$$
C(x, t)=F(x) G(t)
$$

By taking the derivative of $\mathrm{G}(\mathrm{t})$ and the second derivative of $\mathrm{F}(\mathrm{x})$, they can be substituted back into Equation 20. This gives Equation 25:

$$
\frac{G^{\prime}}{D G}=\frac{F \prime \prime}{F}
$$

The left side of Equation 25 depends only on time and the right side only on penetration depth. In order for Equation 25 to satisfy Equation 24, Equation 25 must also equal an arbitrary constant.

$$
\frac{G \prime}{D G}=\frac{F \prime \prime}{F}=-P^{2}
$$

By solving the first and second parts of Equation 26 equal to $-\mathrm{P}^{2}$, Equations 27 and 28 can be derived.

$$
\begin{aligned}
& F^{\prime \prime}+P^{2} F=0 \\
& G^{\prime}+D P^{2} G=0
\end{aligned}
$$

Where solutions are $F(x)=A \cos (P x)+B \sin (P x)$ and $G(t)=\exp \left(-D^{2} t\right)$. Using these solutions and Equations 27 and 28 in a Fourier Integral yields Equation 29. 


$$
C(x, t)=\int_{0}^{1} C(x, t ; P) d P=\int_{0}^{1}[A \cos (P x)+B \sin (P x)] \exp \left(-D P^{2} t\right) d P
$$

Equation 29 provides the solution to Fick's $2^{\text {nd }}$ law of diffusion. However, the two arbitrary constants A and B are still unknown. Using the initial condition from Equation 23, these constants can be solved for using:

$$
\begin{aligned}
& A=\frac{1}{\pi} \int_{0}^{1} f(v) \cos (P v) d v \\
& B=\frac{1}{\pi} \int_{0}^{1} f(v) \sin (P v) d v
\end{aligned}
$$

Here $v$ is a differentiable variable introduced by using a Fourier Transform. By substituting Equations 30 and 31 back into Equation 29 and doing some rearranging, a final solution with fewer unknown constants is arrived at.

$$
C(x, t)=\frac{1}{\pi} \int_{0}^{1} f(v)\left[\int_{0}^{1} \exp \left(-D P^{2} t\right) \cos (P x-P v) d P\right] d v
$$

However without experimental data, the arbitrary constant $\mathrm{P}$ is still unknown. With a few more substitutions, the constant $\mathrm{P}$ can be divided out of the equation. Thus the final form of Fick's $2^{\text {nd }}$ law of diffusion in one dimension is (Kreyszig, 2011):

$$
C(x, t)=\frac{1}{2 \sqrt{(\pi D t)}} \int_{0}^{1} f(v) \exp \left(\frac{-(x-v)^{2}}{4 D t}\right) d v
$$


This final equation shows how the chloramine solution diffuses into the rubber compound over time. Experimental results for the diffusivity coefficient (D) at several temperatures have already been found. Using this experimental diffusivity coefficient, the concentration profile within the rubber compound can be graphed. Presented below in Figure 7 and 8 are the diffusivity coefficient for natural rubber at different temperatures and chloramine concentrations and the chloramine concentration profile for a 30 day exposure time to natural rubber.

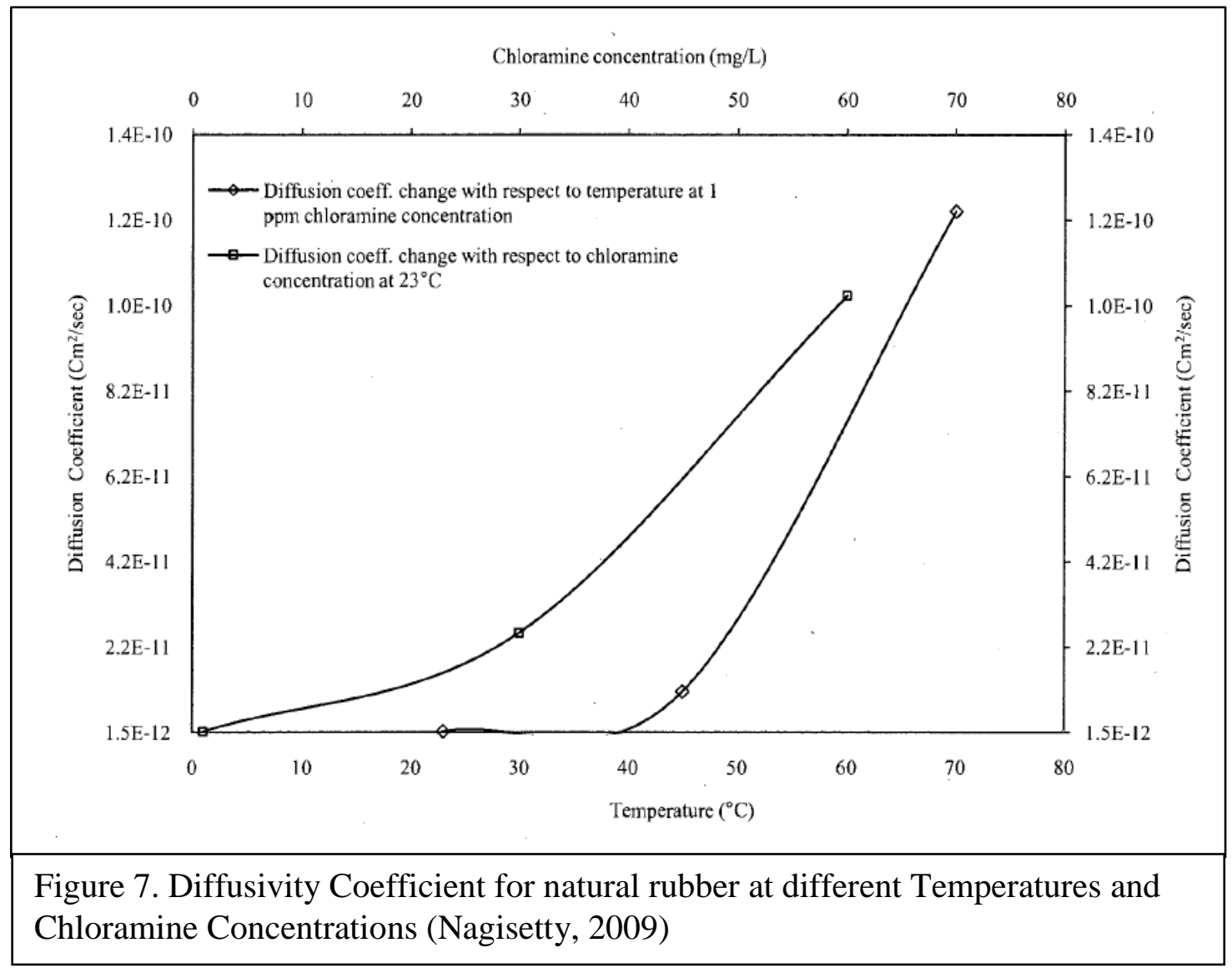


Figure 7 demonstrates the variables that affect the diffusion rate of the chloramine solution into the natural rubber compound. Based on the figure, the two main components are temperature and the chloramine concentration. As the temperature increases, the diffusion rate increases. This is expected since the temperature affects the energy within the system. It takes energy for the chloramines to penetrate the rubber compound. In order to reduce the degradation and improve the lifespan of the rubber equipment used by the water company, the temperature of the system should remain low. By utilizing this relation, water systems that use chloramine disinfectant can expect higher chloramine degradation during warmer seasons and less chloramine degradation during the cooler seasons.

Referring back to the three observations of Fick's $2^{\text {nd }}$ Law of Diffusion, Fick's $2^{\text {nd }}$ law refers to a concentration gradient that causes the liquid to diffuse into the solid. By increasing the chloramine concentration, it is apparent that the diffusion rate into the rubber will increase due to the increase in the concentration gradient. 


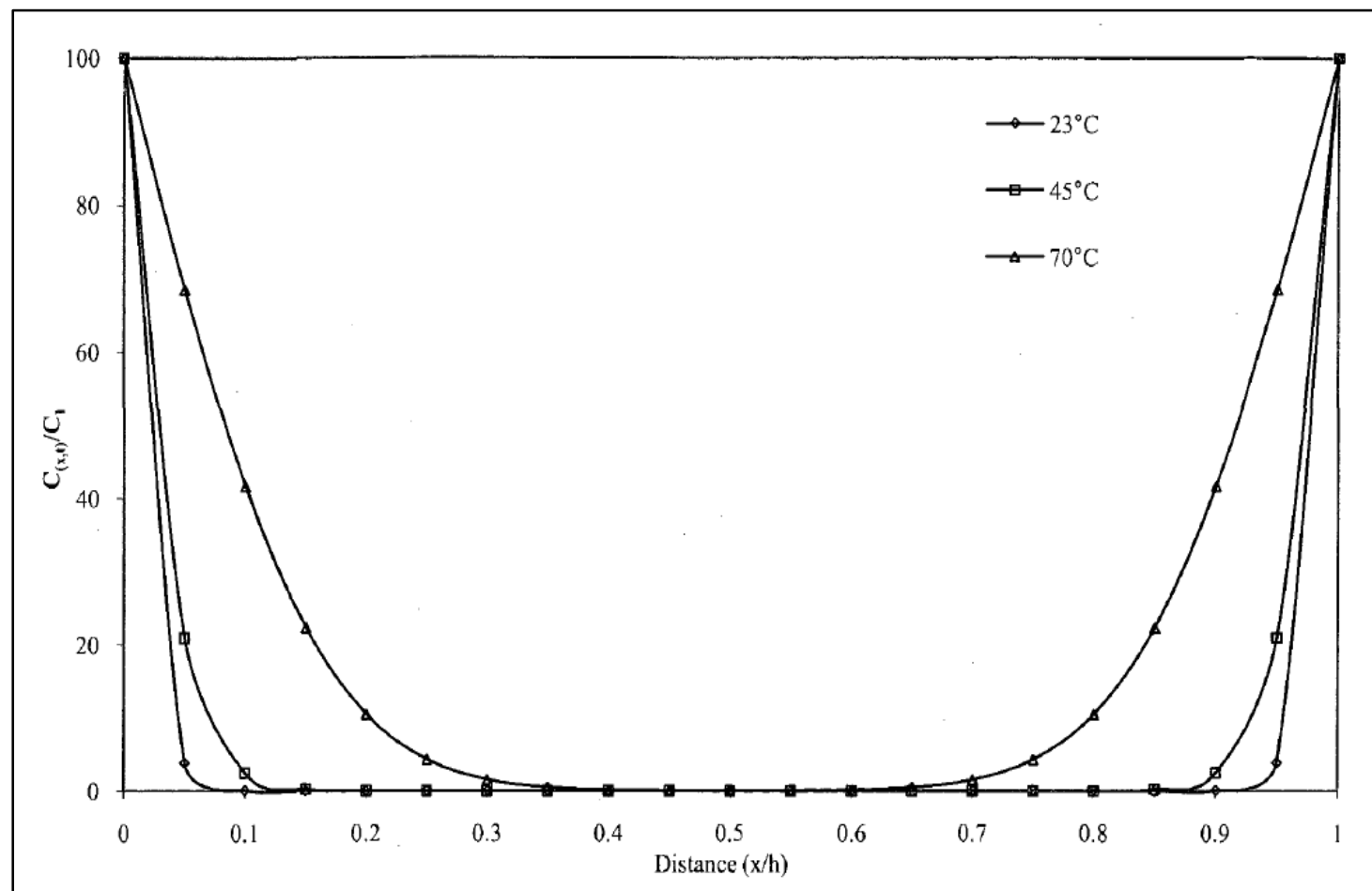

Figure 8. Chloramine Concentration Profile in natural rubber for a 30 day exposure time at different temperatures. (Nagisetty, 2009)

Figure 8 demonstrates the extent of diffusion into natural rubber and the chloramine concentration at the different depths into the rubber. Figures 6 and 8 are a one dimensional analysis of chloramine solution diffusing into natural rubber; Figure 6 depicts the diffusion only in the positive direction while Figure 8 is for diffusion into a solid in both the positive and negative direction. Figure 8 is a more accurate depiction of what is being observed in the experiment. 


\section{Objectives}

There were two main goals for this study. The first was to determine the particle size of the degraded rubber suspended in solution. The second objective was to determine the rate at which carbon black particles are suspended in solution. These were accomplished using the Brookhaven 90 Plus/BI-MAS Particle Sizing Equipment. This device allows quantitative analysis of the particle size distribution within a sample. The operation of this device is further defined in the Materials, Equipment, and Methodology section. Along with testing the particle size, turbidity readings were taken to better define the rate of rubber degradation.

To determine the rate of the rubber degradation and the health risks it entails, studies have been conducted. Normally the rubber compounds take several years to fully break down and fail. However, this study was conducted at an accelerated rate. To do this, an elevated temperature and concentration were used to replicate long term aging affects. A temperature of $23^{\circ} \mathrm{C}$ was used as a control while $45^{\circ} \mathrm{C}$ was used as the elevated temperature. A concentration of $1 \mathrm{ppm}$ chloramine was used as a control while $30 \mathrm{ppm}$ chloramine was used as the elevated concentration.

The temperature was held constant for a 30 day testing period using a warm water bath. However, the concentration of the chloramine solution would not stay constant at the temperature of the experiment. Instead a starting concentration of $35 \mathrm{ppm}$ chloramine solution was used and concentrated every 24 hours. This gave the experiment an average chloramine concentration of $30 \mathrm{ppm}$ over a 24 hour period.

Three types of rubber were being investigated. These rubber types are natural rubber (NR), styrene butadiene rubber (SBR), and ethylene propylene diene monomer- 
peroxide (EPDM-P) cured. These are three commonly used rubbers that may come into contact with the chloramine water sanitized by the metro sewer department. The size of the carbon black released from the rubber can be compared to the size of the carbon black used by the manufacturer to make the rubber. By comparing the two sizes, it can be determined whether the carbon black is being eroded away from the rubber sample or the bonds between the rubber particles are being broken. If the degraded rubber particles are similar in size distribution to the manufacturer particle size, then the bonds are being broken. Otherwise, the rubber particles are being eroded away. 


\section{MATERIALS AND METHODS}

\section{$\underline{\text { A. Materials }}$}

The rubber samples used for this experiment were obtained from the Ashtabula Rubber Company in Ashtabula, Ohio. The rubber was sent as square pieces size $15 \mathrm{~cm} x$ $15 \mathrm{~cm} \times 4 \mathrm{~mm}$. Figure 9 shows the initial rubber square used before being cut into sample pieces and Table V through Table VII presents the composition of the rubber in parts per hundred. All rubber composition data was received from the Ashtabula Rubber Company and can be found in the AWWA study done in 2007.

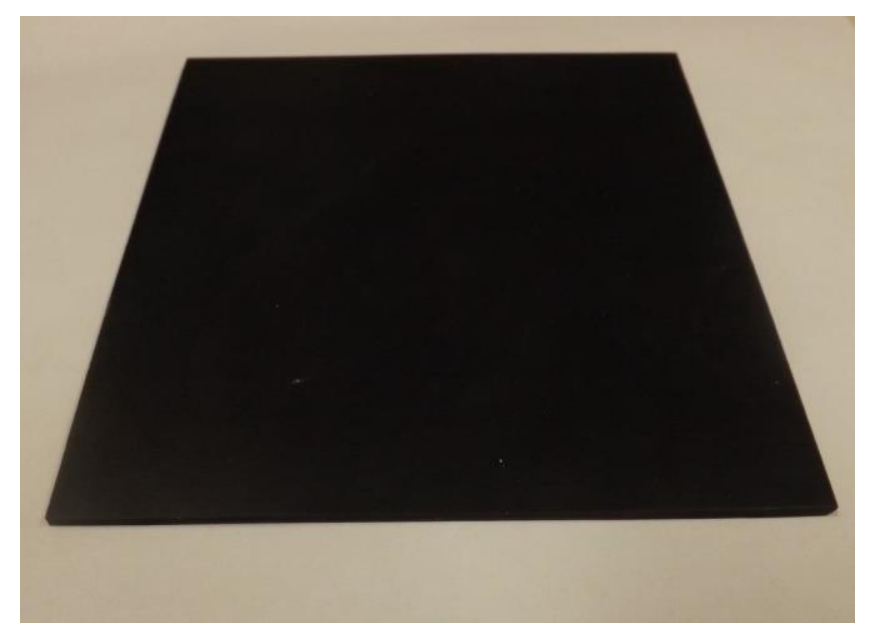

Figure 9. Styrene Butadiene Rubber Sample (Kroeger, 2013). 
TABLE V

SBR COMPOSTION IN PARTS-PER HUNDRED (PHR)

\begin{tabular}{|c|c|c|}
\hline Ingredient & PHR & Function \\
\hline SBR 1502 & 100 & $\begin{array}{c}\text { Styrene butadiene rubber base } \\
\text { polymer }\end{array}$ \\
\hline SRF N767 & 90 & Carbon Black \\
\hline Sun 4240 & 10 & Extending Oil \\
\hline Sulfur & 1 & Primary Vulcanizing Agent \\
\hline Zinc Oxide & 5 & Curing System additive (activator) \\
\hline Stearic acid & 1 & Curing System additive \\
\hline Santocure & 1 & Accelerant \\
\hline
\end{tabular}

TABLE VI

NR COMPOSTION IN PARTS-PER HUNDRED (PHR)

\begin{tabular}{|c|c|c|}
\hline Ingredient & PHR & Function \\
\hline SMR CV 60 & 100 & Standard Malaysia rubber (latex) \\
\hline SRF N762 & 70 & Carbon Black \\
\hline Sun 4240 (or equiv.) & 2 & Extending Oil \\
\hline Sulfur & 2.5 & Primary Vulcanizing Agent \\
\hline Zinc Oxide & 5 & $\begin{array}{c}\text { Curing System additive } \\
\text { (activator) }\end{array}$ \\
\hline Santocure & 0.7 & Accelerant- Thiazole Based \\
\hline
\end{tabular}

TABLE VII

EPDM-P COMPOSITION IN PARTS-PER HUNDRED (PHR)

\begin{tabular}{|c|c|c|}
\hline Ingredient & PHR & Function \\
\hline DSM Keltan 27 & 100 & $\begin{array}{c}\text { Ethylene-propylene diene } \\
\text { copolymer }\end{array}$ \\
\hline SRF N762 & 75 & Carbon Black \\
\hline Sun 2280 & 20 & Extending Oil \\
\hline Zinc Oxide & 5 & Curing Agent \\
\hline Dicup 4OKE & 10 & Accelerant \\
\hline
\end{tabular}


During the rubber degradation experiments, the large rubber pieces were cut into smaller rectangles size $9.5 \mathrm{~cm} \times 2.5 \mathrm{~cm} \times 4 \mathrm{~mm}$. These pieces were then hole-punched and placed on a glass tree. Ten rectangular samples were placed on each of the glass trees. Each glass tree only held one type of rubber at a time. The glass trees were placed in metal cans containing chloramine solution. The metal cans were placed in a hot water bath to ensure a constant temperature. The experiment was run in two phases. The first phase was at room temperature. Six metals cans were placed in a water bath at $23^{\circ} \mathrm{C}$. Figure 10 shows the metal cans in the water bath marked with the appropriate type of rubber and chloramine concentration. This setup was repeated for the $45^{\circ} \mathrm{C}$ experiment.

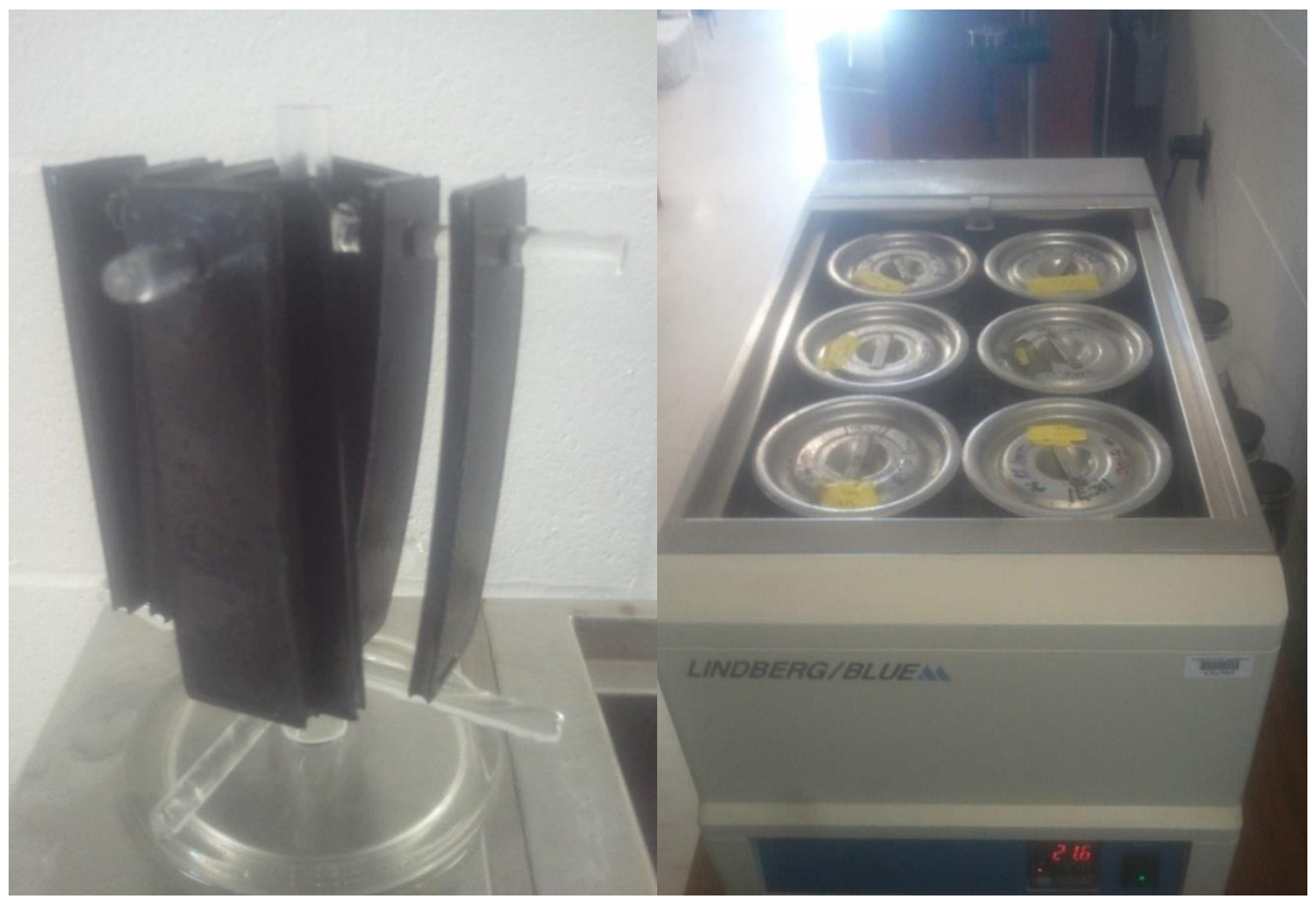

Figure 10. Rubber Samples on Glass Tree (left) and Sample Containers in Hot Water Bath (right) 


\section{B. Brookhaven 90 Plus/Bi-mas Multi Angle Particle Sizing Device}

All experimental samples were tested using the Brookhaven 90 Plus/Bi-mas Multi Angle Particle Sizing Device. This device analyzes the samples using Quasi Elastic Light Scattering (QELS) techniques. This allows for quick analysis, small sample size, measurement time independent of particle density, and no harm to the sample. Some of the advantages of the device include: 1) Delay time intervals that are not linearly spaced. This allows broad distributions to be sampled properly. 2) An algorithm which removes signals affected by dust. 3) Unimodal fits to an assumed lognormal size distribution. 4) Automatic repetition of measurements with statistical averaging.

The device operates by sending a laser beam through the sample to a receiver. The device then records any changes in the average intensity of the laser as a function of angle, changes in polarization, changes in wavelength, and fluctuations about the average intensity. The random motion of small particles in a liquid gives rise to fluctuations in the time intensity of the scattered light. The fluctuating signal is processed by forming the autocorrelation function $\mathrm{C}(\mathrm{t})$, with $\mathrm{t}$ being the time delay. As $\mathrm{t}$ increases correlation is lost, and the function approaches the constant background term, B. For short times the correlation is high. In between these two limits the function decays exponentially for a monodisperse suspension of rigid, globular particles and is given by Equation 34 .

$$
C(t)=A e^{-2 \Gamma t}+B
$$

Where $\mathrm{A}$ is an optical constant determined by the instrument design, and $\Gamma$ is related o the relaxation of the fluctuations by,

$$
\Gamma=D q^{2}
$$


The value of $\mathrm{q}$ is calculated from the scattering angle, $\theta$ (equal to $90^{\circ}$ ), the wavelength of the laser light, $\lambda_{\mathrm{o}}$ (equal to $0.635 \mu \mathrm{m}$ ), and the refractive index, $\mathrm{n}$ (equal to 1.33), of the suspending liquid. The equation relating these quantities is

$$
q=\frac{2 \pi n}{\lambda_{o}} 2 \operatorname{Sin}\left(\frac{\theta}{2}\right)
$$

The translational diffusion coefficient, D, can then be calculated using Equation 35. Particle size is related to D for simple shape like a sphere by Equation 37.

$$
D=\frac{k_{B} T}{3 \pi \eta(t) d}
$$

Here $\mathrm{k}_{\mathrm{B}}$ is the Boltzmann constant $\left(1.38054 \times 10^{-16} \mathrm{ergs} / \mathrm{deg}\right), \mathrm{T}$ is the temperature in Kelvin, $\eta(\mathrm{t})$ is the viscosity of the liquid in which the particle is moving in centipoise, and $\mathrm{d}$ is the particle diameter. (Brookhaven Instruments Corporation, 1995)

Assumptions for this calculation are spherical particles and particle movement independent of one another. The device then plots particle diameter against the number of particles. These plots were used during calculation of the particle diameter, particle count rate, and peak range.

\section{Monochloramine Synthesis Materials and Procedure}

Chloramine is synthesized by reacting ammonia and chlorine in an aqueous solution. Monochloramine is preferentially formed in alkaline conditions at a $\mathrm{pH}$ between 8 and 9 with the most favored conditions at $8.3 \mathrm{pH}$. For this research, monochloramine is synthesized using the ASTM D 6284 method. Aqueous sodium hypochlorite and ammonium hydroxide are added to Distilled water and mixed. The $\mathrm{pH}$ is adjusted to the desired range of $8-9$ by adding drops of phosphoric acid. A pH buffer solution is added 
after the desired $\mathrm{pH}$ is reached to keep the $\mathrm{pH}$ stable. The chemicals, manufacturers, and catalog numbers used in monochloramine synthesis are found in Table VIII.

\section{TABLE VIII}

\section{CHEMICALS USED IN MONOCHLORAMINE SYNTHESIS}

\begin{tabular}{|c|c|c|c|}
\hline Chemical & Weight Percent & Manufacturer & Catalog/Lot \# \\
\hline $\begin{array}{c}\text { Sodium } \\
\text { Hypochlorite }\end{array}$ & $5-6 \%$ & Fisher Scientific & 123335 \\
\hline $\begin{array}{c}\text { Ammonium } \\
\text { Hydroxide }\end{array}$ & $3.5 \%$ & Lab Chem & C035-01 \\
\hline Phosphoric Acid & $85 \%$ & Acros-Oganics & A0311067 \\
\hline pH 9 Buffer & & Ricca Chemical & $1590-32$ \\
\hline
\end{tabular}

The concentration in parts-per-million ( $\mathrm{ppm}$ ) is used in this research to quantify the amount of monochloramine to one million grams of water. The following is the procedure used to synthesize monochloramine:

1. Measure out desired volume of Distilled water (e.g. $1000 \mathrm{ml})$ and place and stir continuously in a beaker.

2. Add $5.5 \times 10^{-6} \mathrm{ml} \mathrm{NaOCl} /\left(\mathrm{ml} \mathrm{H}_{2} \mathrm{O} \cdot \mathrm{ppm}\right.$ monochloramine desired $)$ to beaker (e.g. $5.5 \mathrm{ml}$ of $\mathrm{NaOCl}$ per $1000 \mathrm{ml}$ of water for a desired concentration of 300 ppm).

3. Add $9.6 \times 10^{-6} \mathrm{ml} \mathrm{NH}{ }_{4} \mathrm{OH} /\left(\mathrm{ml} \mathrm{H}_{2} \mathrm{O} \cdot \mathrm{ppm}\right.$ monochloramine desired $)$ to beaker (e.g. $9.6 \mathrm{ml}$ of $\mathrm{NH}_{4} \mathrm{OH}$ per $1000 \mathrm{ml}$ of water for a desired concentration of 300 ppm).

4. While stirring and measuring $\mathrm{pH}$, add phosphoric acid drop wise until $\mathrm{pH}$ of 8.6 is reached. 
5. Add $0.1 \mathrm{ml}$ of $\mathrm{pH} 9$ buffer per $\mathrm{ml} \mathrm{H}_{2} \mathrm{O}$

\section{Monochloramine Concentration Measurement}

The concentration of monochloramine is measured using ASTM D 2240 method. This method involves titrating a solution of water, monochloramine, potassium iodide, and a $\mathrm{pH} 4$ buffer solution with phenylarsine oxide and measuring the electrical conductivity of the solution until the iso-electric point is reached. The chemicals used in the titration are listed in Table IX along with the manufacturer and lot/catalog numbers.

\section{TABLE IX}

\section{CHEMICALS USED IN MEASURING MONOCHLORAMINE}

CONCENTRATION

\begin{tabular}{|c|c|c|}
\hline Chemical & Manufacturer & Lot/Cat \# \\
\hline $\mathrm{pH} 4$ Buffer & Fisher Scientific & 110220 \\
\hline Potassium Iodide & Fisher Scientific & 111860 \\
\hline Phenylarsine Oxide & Fisher Scientific & 123660 \\
\hline
\end{tabular}

The titrimeter used to measure the monochloramine concentration is a Fisher Scientific Titrimeter 397 (Serial \#: 306N0002, Cat \#: 09-313-140). An Accumet electrode (Cat \#: 13-620-149) was used in the titrimeter. The procedure for measuring the concentration of monochloramine is as follows: 
1. Measure $98 \mathrm{ml}$ of D.I. water in a beaker.

2. Add $2 \mathrm{ml}$ of monochloramine solution to $98 \mathrm{ml}$ of water in beaker.

3. Add $1 \mathrm{ml}$ each of potassium iodide and $\mathrm{pH} 4$ buffer solution to beaker containing water and monochloramine.

4. Place beaker on the titrimeter, place stir bar in beaker and turn on stirrer, then lower electrode into the solution.

5. Add phenylarsine oxide to the beaker until adding additional phenylarsine oxide does not cause the needle to move.

6. Interpret monochloramine concentration as $0.1 \mathrm{ml}$ of phenylarsine oxide added is equal to a 10 ppm monochloramine solution.

\section{E. 30 Day Degradation Test Experimental Procedure}

The tests for the 30 day degradation took place over two separate 30 day periods.

The first 30 day test involved all the samples at $23^{\circ} \mathrm{C}$. A water bath was used to keep all samples containers at a constant temperature throughout the experiment duration.

\section{a. Preparation}

Six metal containers were used to hold the rubber. Each container contained 10 sample strips of SBR, NR, or EPDM-P. These samples were held up on a glass tree to allow maximum surface area contact with the chloramine solution. Each container was labeled with the type of rubber and chloramine concentration (e.g. Container 1-SBR 30 ppm). Each container was then filled with $1500 \mathrm{ml}$ of chloramine solution at either 30 ppm or $1 \mathrm{ppm}$ at $\mathrm{pH} 8.3$. 


\section{b. Daily Changes}

Since the chloramine concentration degrades over time, the solution concentration must be altered daily. Previous studies have shown the degradation rate of the chloramine solution at different temperatures. Table $\mathrm{X}$ shows the starting concentrations needed to average the desired concentration.

TABLE $X$

SUMMARY OF STARTING/AVERAGE CONCENTRATIONS

\begin{tabular}{|c|c|c|c|c|c|c|}
\hline Temperature & $\begin{array}{c}\text { Daily } \\
\text { Average } \\
\text { Concentration }\end{array}$ & $\begin{array}{c}\text { Daily Starting } \\
\text { Concentration }\end{array}$ & $\begin{array}{c}\mathrm{pH} 9 \\
\text { Buffer }\end{array}$ & $\mathrm{NaOCl}$ & $\mathrm{NH}_{4} \mathrm{OH}$ & $\begin{array}{c}\text { Bulk } \\
\text { Solution } \\
\text { Exchanged } \\
\text { Daily }\end{array}$ \\
\hline$\left({ }^{\circ} \mathrm{C}\right)$ & $(\mathrm{ppm})$ & $(\mathrm{ppm})$ & $\begin{array}{c}\mathrm{Cc} / 9 \\
\text { liters }\end{array}$ & $\begin{array}{c}\mathrm{Cc} / 9 \\
\text { liters }\end{array}$ & $\begin{array}{c}\mathrm{Cc} / 9 \\
\text { liters }\end{array}$ & $\begin{array}{c}\text { (ml of 300 } \\
\text { ppm } \\
\text { solution })\end{array}$ \\
\hline 45 & 30 & 35 & 36 & 6.3 & 9.9 & 55 \\
\hline 23 & 30 & 32 & 36 & 5.0 & 7.9 & 22 \\
\hline 45 & 1 & 1.25 & 36 & 0.23 & 0.35 & 2.5 \\
\hline 23 & 1 & 1.20 & 36 & 0.20 & 0.32 & 2 \\
\hline
\end{tabular}

(Nagisetty, 2009)

A bulk solution was used to concentrate each sample solution. This bulk solution was made at 300 ppm daily.

1. Prepare and test the chloramine concentration of the bulk solution.

2. Test the chloramine concentration of the sample solutions

3. Calculate the amount of bulk solution required to replace the sample solution to achieve the desired starting concentration. 


$$
\begin{aligned}
& \text { Solution Volume }(m l) * \text { Solution Conc }(p p m)+\text { Bulk Volume }(m l) \\
& \text { * Bulk Conc }(p p m)=\text { Final Volume }(m l) * \text { Starting Conc }(p p m)
\end{aligned}
$$

Where the Final Volume is $1500 \mathrm{ml}$ and Solution Volume $(\mathrm{ml})+$ Bulk Volume $(\mathrm{ml})=$ Final Volume(ml).

4. Remove the bulk volume amount from the sample solution and replace with the bulk solution. (e.g. Remove $50 \mathrm{ml}$ from the $1500 \mathrm{ml}$ sample solution and replace with $50 \mathrm{ml}$ of the bulk solution to achieve the desired starting concentration.)

5. Take the removed sample solution and test for turbidity and use in the particle sizing analyzer. 


\section{RESULTS AND DISCUSSION}

\section{$\underline{\text { A. Data Analysis }}$}

Samples for this experiment were run on the Brookhaven 90 Plus/Bi-mas Multi Angle Particle Sizing Device. The device operates by sending a laser beam through the sample to a receiver. The size and number of particles can then be calculated based on the time and angle difference between sending the laser in a vacuum to the actual experimental time and angle.

In order to determine what is in the sample, the refractive index must be known for the particles and the suspended medium. The refractive index is a dimensionless number that describes how light, or any other radiation, changes in acceleration through that medium. The refractive index for water is 1.33 , meaning light travels 1.33 times slower through water than in a vacuum. (Perry and Green, 2008) The refractive index can have a real and imaginary coefficient based on how it distorts the light. The refractive index used for carbon black in this experiment was $1.84+0.85 i$ as suggested by Brookhaven. 
Due to how the Particle Sizing Device operates, two types of errors could occur. The first is over counting the particles. In this case, the device can actually count the same particle multiple times as long as the particle stays within view of the laser path. The second type is under counting. In this case, the particle in suspension may never enter into the path of the lasers. Thus the particle never gets counted. Both are small errors that could cause slight misrepresentation of the particles in solution and were taken into account when analyzing the results.

Another point to mention is the capabilities of the particle analyzing device. As the experiment progressed, the solution kept at $30 \mathrm{ppm}$ and $45^{\circ} \mathrm{C}$ indicated particle sizes outside the operating range of the particle sizing analyzer. Due to this, most of the data for those samples were eliminated. The exact cause of this malfunction is unknown. However, it is likely due to what was in the solution. As the experiment progressed, the chloramine solution broke the elastomer sulfur bonds of the rubber. This caused the carbon black to be released into solution but also caused the degraded sulfur bonds to be released. It is possible that the concentration of degraded elastomer increasing over time could cause a noticeable change in the clarity of light through the solution. This would cause the turbidity of the solution to increase and change the refractive index needed to properly operate the particle sizing device. Since the refractive index of 1.33 was kept constant throughout the experiment, there is a small degree of error being introduced as the experiment progressed.

The results for the particle diameter, particle count rate, and peak range were analyzed using an ANOVA statistical analysis. ANOVA is an analysis for variance. It is a 
test of the hypothesis that the variation in an experiment is no greater than that due to normal variation of individual characteristics and errors in the measurement (Washington State University, 2000). When referring to high interaction between factors and responses, it is simply stating that the change in response is outside the range of standard variation and error and that the factor is the cause. Standard ANOVA tests use a confidence interval of $95 \%$. Meaning there is a $95 \%$ or greater chance that the change in response outside normal range is due to the factor.

\section{B. Particle Diameter}

The factor levels tested in this experiment are: 1) rubber type, 2) time (days), 3) concentration of chloramine solution (ppm), and 4) temperature of chloramine solution $\left({ }^{\circ} \mathrm{C}\right)$. An ANOVA test was used to determine which factor levels affected the response levels the greatest. The test was run with a $95 \%$ confidence interval to ensure high correlation.

The particle diameter was calculated by the Brookhaven 90 Plus/Bi MAS Multi Angle Particle Sizing Device and a range of particle diameters were found for any given day. To allow analysis of the data, a weighted average of the particle diameter was used in the ANOVA.

\section{a. SBR}

ANOVA on the SBR data indicated a strong correlation between particle size and the interaction of concentration and temperature of the chloramine solution. This means 
the largest contributor to the particle sizes observed in the SBR samples were the temperature and concentration interaction. The temperature and concentration interaction is defined as how the factors of temperature and concentration must work together in order to observe correlation with particle size.

This result was expected. As discussed earlier, the carbon black particles aggregate together and are synthesized as grouped particles into the rubber for structural support. The particle sizes observed show little to no degradation of the carbon black. Instead it is likely the chloramine solution is degrading the sulfur bonds in the rubber matrix holding the carbon black in the rubber. As the sulfur bonds are broken, gaps within the rubber allow the smallest of the carbon black aggregates to be released into solution. As the degradation continues, the gaps in the rubber become larger allowing more carbon black to be released. Either the carbon black is released as aggregates and the size of the aggregates increases as the degradation continues or the carbon black is released as single particles that aggregate in solution upon standing. Figure 11 shows an interaction plot showing the factor levels of time and temperature and their effect on particle diameter. 


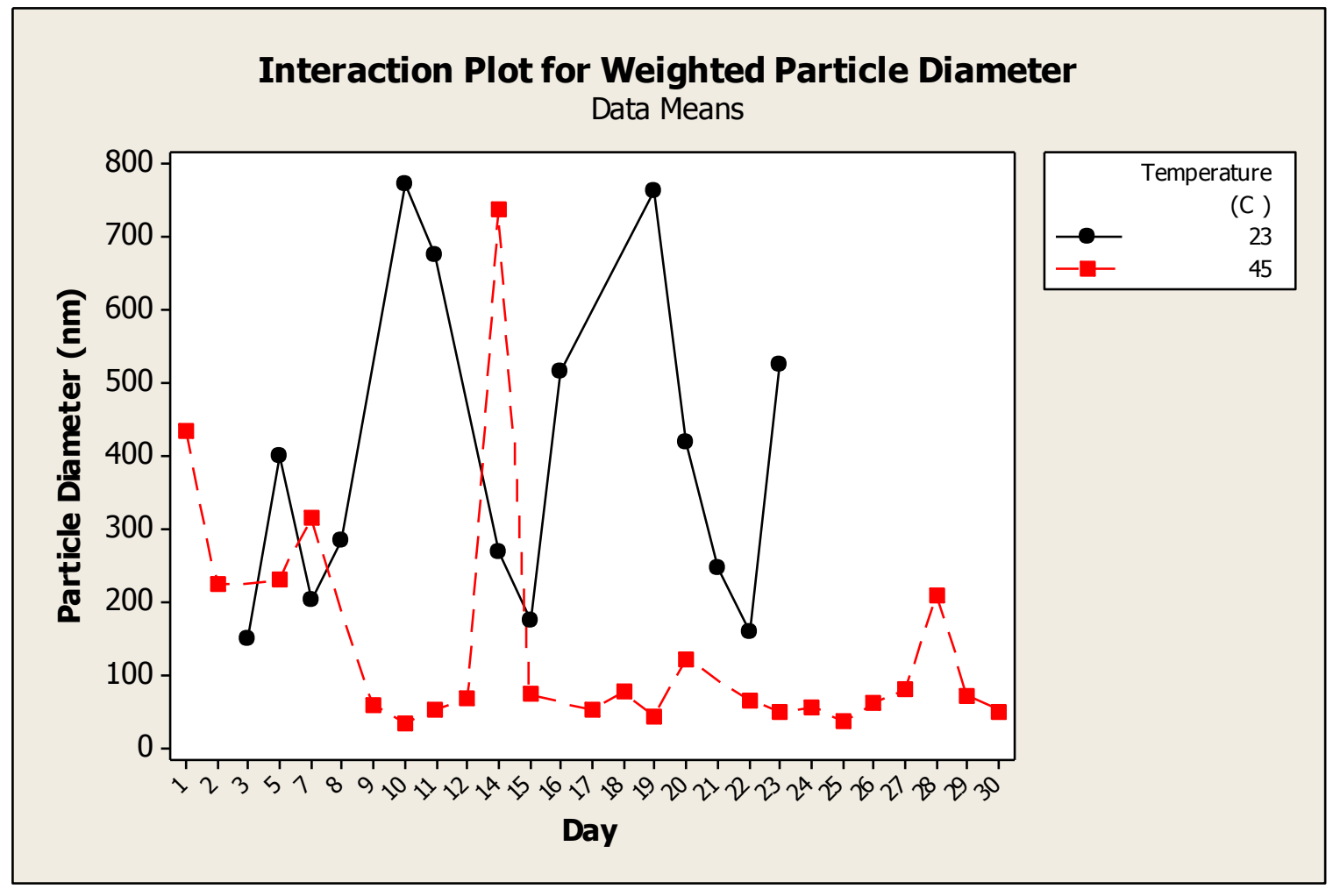

Figure 11. SBR Interaction plot of Time and Temperature on Particle Diameter.

The interaction plot for time and temperature shows quite clearly how temperature affects the particle diameter. The solid line shows lower temperature effects on the particle diameter. This line has a large range at which particle diameters are seen compared to the higher temperature particle diameters that stay fairly consistent from day 9 to 30 other than the one data point at day 15. This shows higher temperatures actually correlate to smaller particle sizes. This can be explained in one of two ways. The first theory is the higher temperature increases the diffusion of the chloramine solution into the rubber and the rate of reaction between the elastomer and chloramine solution. This higher diffusion and reactions causes all the smaller carbon black aggregates to be removed from the rubber and to be suspended in solution. Since the particle diameter is 
weighted based on size and quantity in solution, the larger particles are not seen due to the high quantity of smaller particles. The second theory is the larger carbon black aggregates in solution are being attacked and broken apart by the chloramine solution. This would cause the higher temperature samples to degrade or erode the carbon black aggregates quicker.

The first theory is supported by Fick's second law and the reaction kinetics as discussed in the Introduction section. By increasing the temperature of the system, it is safe to assume the diffusion into the rubber matrix and the elastomer reaction rate will increase exponentially. The equation for Fick's second law of diffusion and the reaction kinetics are:

$$
\begin{aligned}
\frac{\partial c_{A}}{\partial t} & =D\left(\frac{\partial^{2} c_{A}}{\partial x^{2}}\right) \\
-r_{A} & =k C_{A}^{a}
\end{aligned}
$$

Both the diffusion coefficient, $\mathrm{D}$, and the reaction coefficient, $\mathrm{k}$, change with respect to the Arrhenius equation. This causes an exponential increase in diffusion and reaction rate with respect to temperature. The Arrhenius equation for diffusion and the reaction coefficient, respectively, are:

$$
\begin{gathered}
D=D_{o} e^{-E_{a} / R T} \\
k=k_{o} e^{-E_{a} / R T}
\end{gathered}
$$

The second theory is less supported. Previous studies by the AWWA Research Foundation found that the chloramine solution showed no signs of breaking apart the carbon black aggregates. (Rockaway et al., 2007) The carbon black aggregates have a 
tendency to agglomerate into larger units, which may be re-dispersed by shear forces, but re-agglomerate upon standing. (Donnet, 1976)

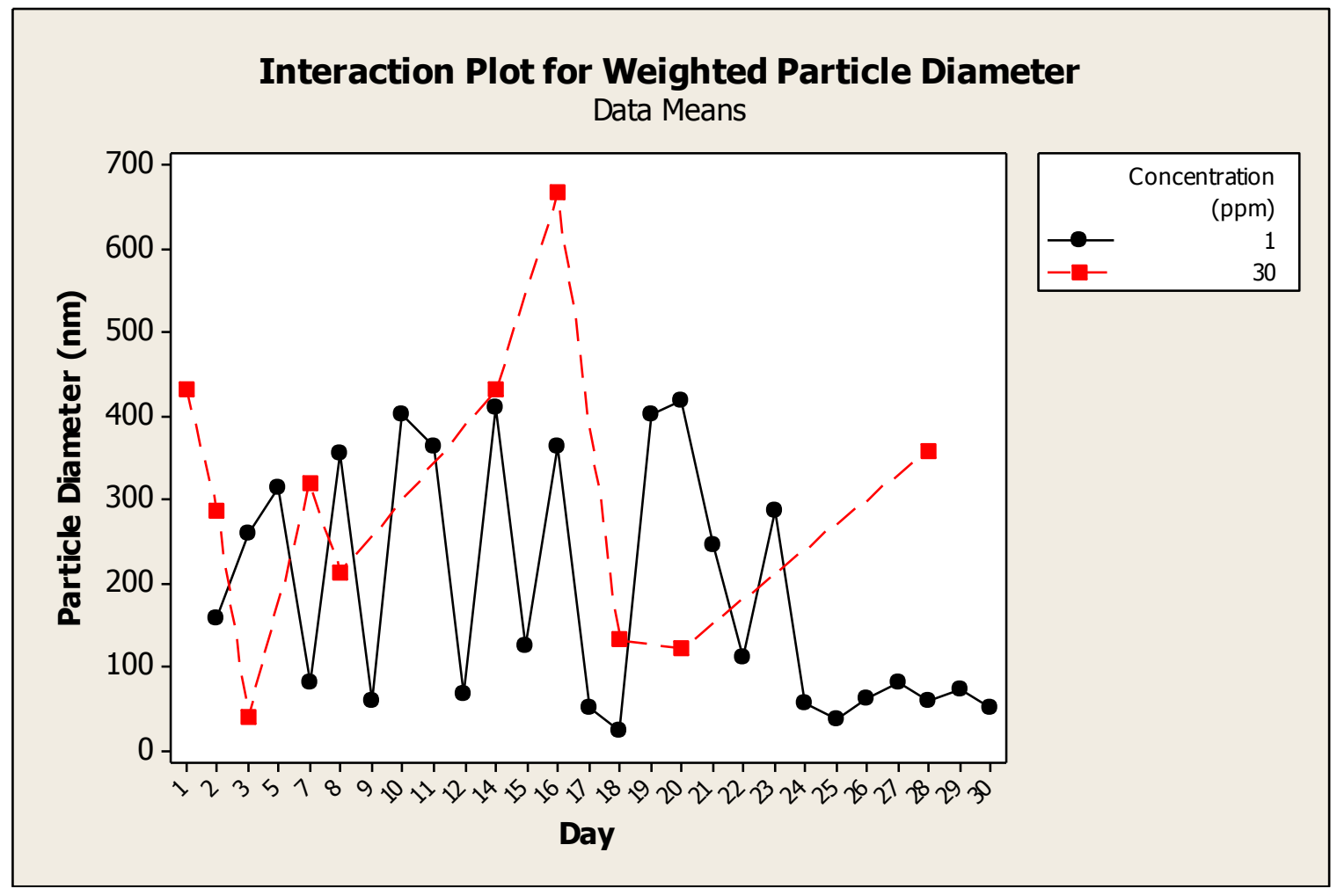

Figure 12. SBR Interaction plot of Time and Concentration on Particle Diameter.

Figure 12 is an interaction plot for time and concentration of chloramine solution. From this plot, it is noticeable that the lower concentration solutions exhibited a much lower particle diameter range compared to the higher concentration solutions. The exact reason for this is unknown. However, lower concentrations would decrease diffusion into the rubber. Thus the solution would take longer to remove the larger particles from the rubber matrix. The higher concentration solution would have a higher diffusion. This would expedite the removal of larger particles from the rubber matrix and lead to a larger particle diameter range. 
Referring back to the reaction rate equation and Fick's second law of diffusion, the concentration has a linear effect on diffusion and reaction rate. By comparing Figure 11 and 12 , one can see that the temperature plays a larger role in determining particle size. This is expected since temperature effects diffusion and reaction rate exponentially while concentration effects diffusion and reaction rate linearly.

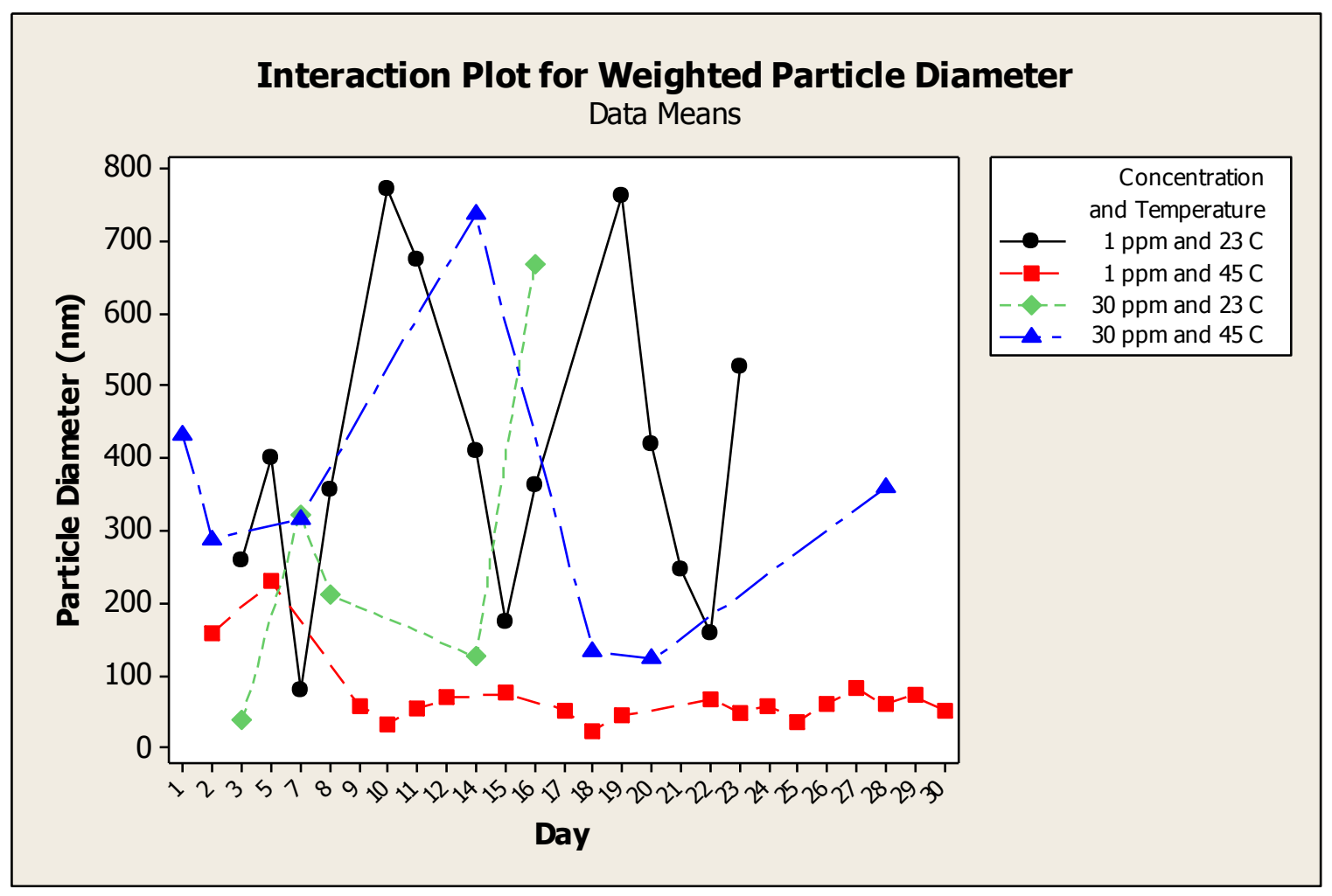

Figure 13. SBR Interaction plot of Time, Temperature, and Concentration on Particle Diameter.

Figure 13 shows an interaction plot outlining the particle diameter for each combination of the experimented concentration and temperatures. The particle diameter values shown in Figure 13 are weighted averages from day the sample was taken.

Working in order from lowest to greatest, the first data to investigate is a solution of $1 \mathrm{ppm}$ concentration and base temperature of $23^{\circ} \mathrm{C}$. This data shows the highest 
fluctuation in particle diameter and would have the lowest diffusion rate into the rubber sample. The high fluctuation in particle diameter is likely due to the low diffusion and reaction rate. The solution is unable to penetrate deep into the rubber and the low concentration and temperature would cause low degradation of the rubber. That leads to less rubber particles in the solution as a whole so the weighted average particle diameter can vary greatly on a daily basis.

The second data to investigate is a solution of $1 \mathrm{ppm}$ concentration and base temperature of $45^{\circ} \mathrm{C}$. This data shows the lowest fluctuation of particle diameters. This is likely caused by the increase in temperature at low concentrations. As discussed before, changes in temperature play a larger role in the diffusion and elastomer reaction rate. The increase in temperature would allow higher diffusion into the rubber however; the low concentration over a 30 day period would only allow the smallest of the particles to be removed from the rubber matrix.

The third data to investigate is a solution of $30 \mathrm{ppm}$ concentration and base temperature of $23^{\circ} \mathrm{C}$. This data has fewer data points and does not exceed day 15 . This is due to the higher amounts of outliers or unusable information from the particle size analyzer. The points that are present have similar range to the $1 \mathrm{ppm}$ at $23^{\circ} \mathrm{C}$. This is likely due to the low impact concentration changes play compared to temperature on the diffusion and elastomer reaction rate.

The final data to investigate is a solution of $30 \mathrm{ppm}$ concentration and base temperature of $45^{\circ} \mathrm{C}$. This data exhibits the second highest fluctuation of particle diameters. This is due to the high amounts of elastomer degradation and diffusion in the 
rubber. The high concentration and temperature allows the solution to penetrate deep into the rubber matrix and remove the carbon black. This allows high amounts of small and large rubber to be suspended in solution, thus causing a higher fluctuation in the weighted particle diameter.

b. NR

Running an ANOVA on the NR samples, there is a strong correlation between particle size diameter and the concentration of the chloramine solution. This means the greatest contributor to determining the particle size removed from the rubber is chloramine concentration.

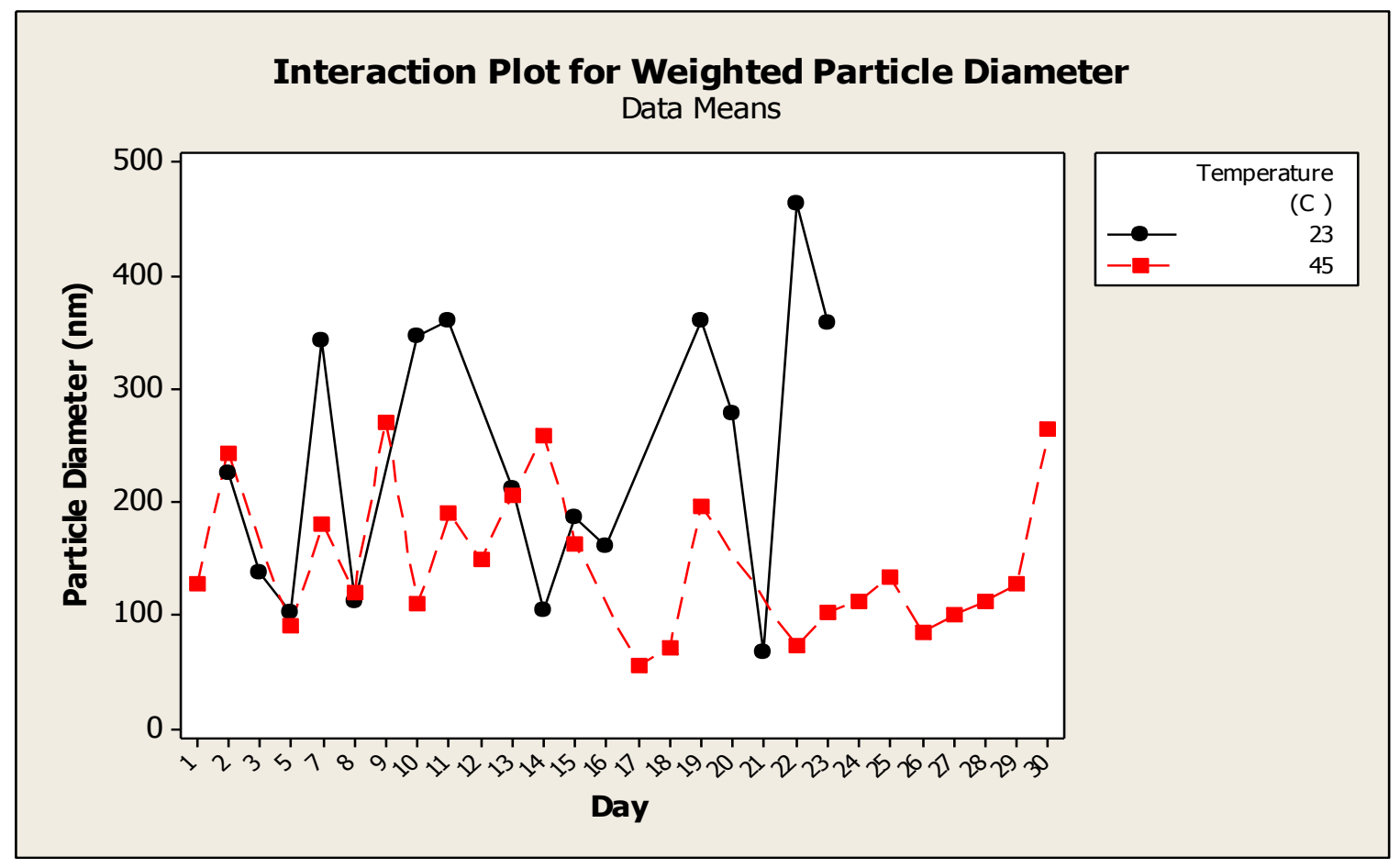

Figure 14. NR Interaction plot of Time and Temperature on Particle Diameter. 
From the ANOVA performed on the data, temperature has a minimal role on the weighted particle diameter. This is seen in Figure 14 with both temperatures having similar fluctuation in particle diameter. The lower temperature at $23^{\circ} \mathrm{C}$ does have a slightly higher fluctuation in particle diameter then the samples at $45^{\circ} \mathrm{C}$. Although temperature affects the diffusion and elastomer degradation rate, NR has low resistance to degradation. Thus the changes in temperature are not as noticeable as they were with SBR.

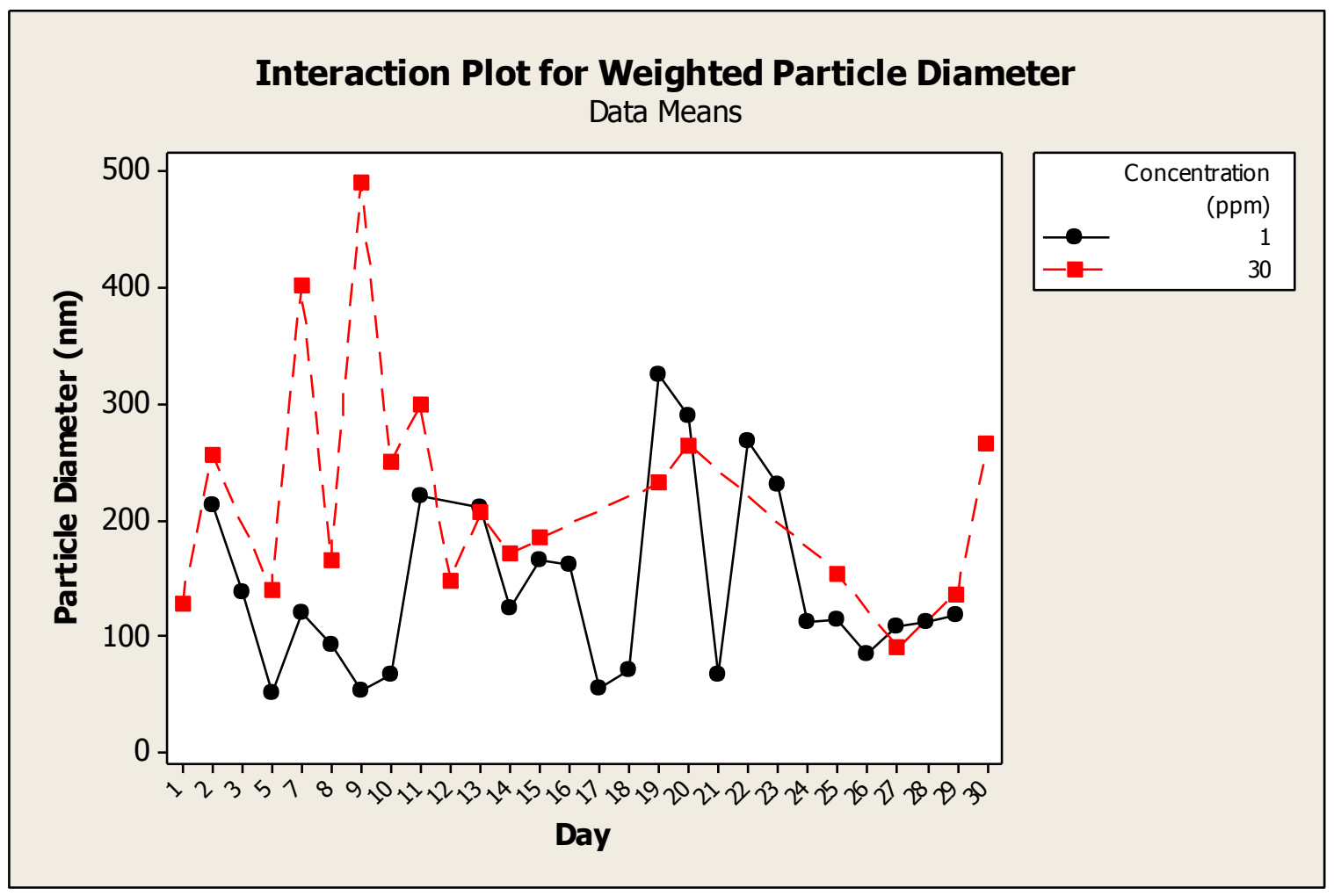

Figure 15. NR Interaction plot of Time and Concentration on Particle Diameter.

From the ANOVA performed on the data, concentration has a larger role on the weighted particle diameter than temperature. This is demonstrated in Figure 15. The higher concentration has a much larger particle diameter fluctuation over time. This 
indicates that NR's high sensitivity to chloramine degradation would allow concentration to influence the particle diameters better. The higher particle size range at greater concentrations point out the elastomer is degrading quicker, thus allowing larger carbon black particles to be released into the solution.

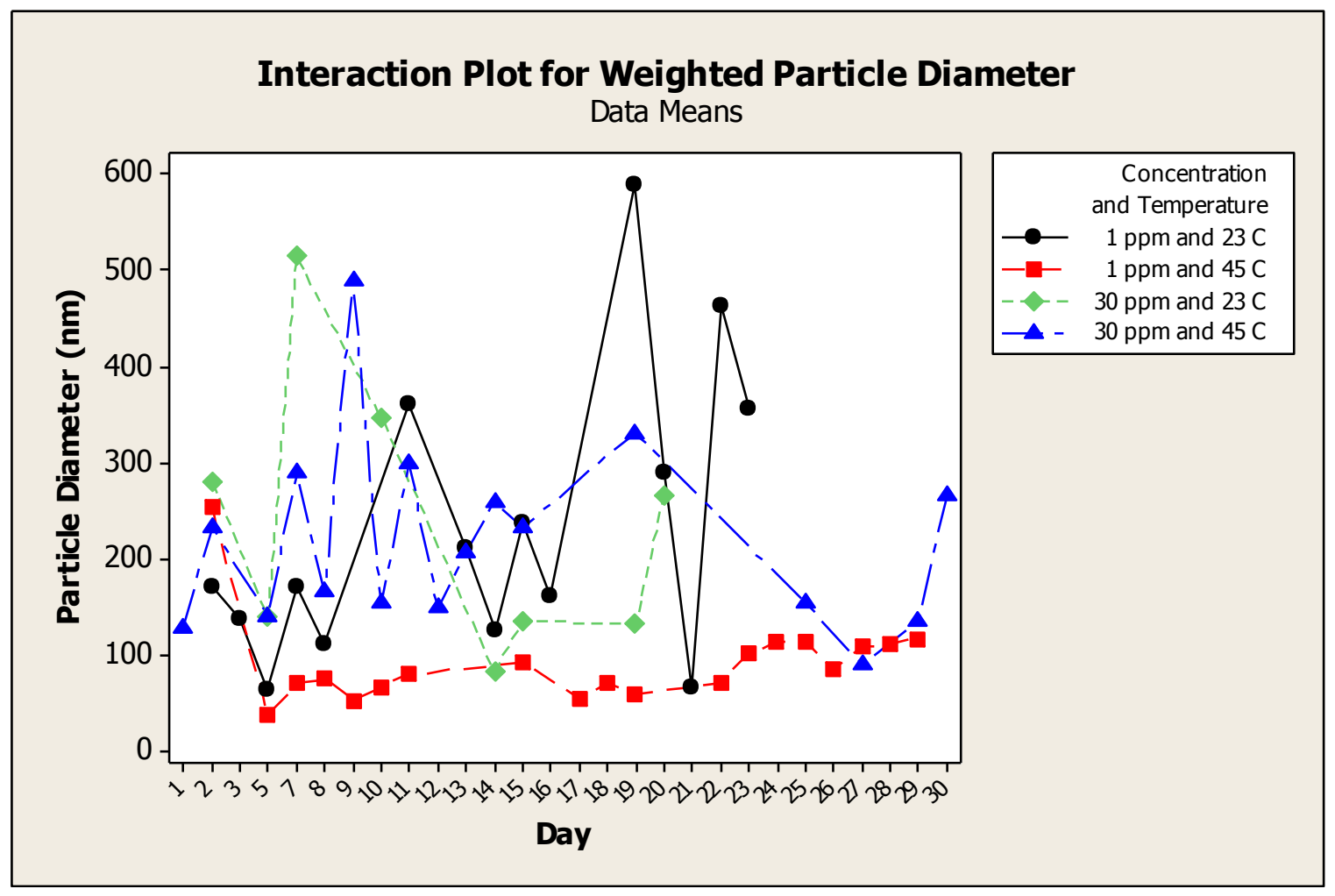

Figure 16. NR Interaction plot of Time, Temperature, and Concentration on Particle Diameter.

Figure 16 shows an interaction plot outlining the particle diameter ranges for each combination of the experimented concentration and temperatures. Working in order from lowest to greatest, the first data to investigate is a solution of $1 \mathrm{ppm}$ concentration and base temperature of $23^{\circ} \mathrm{C}$. This data shows the highest fluctuation in particle diameter and would have the lowest diffusion rate into the rubber sample. The high fluctuation in particle diameter is likely due to the low diffusion rate and elastomer reaction rate. The 
solution is unable to penetrate deep into the rubber and the low concentration and temperature would cause low degradation of the rubber. That leads to less rubber particles in the solution as a whole so the weighted average particle diameter can vary greatly on a daily basis.

The second data to investigate is a solution of $1 \mathrm{ppm}$ concentration and base temperature of $45^{\circ} \mathrm{C}$. This data shows the lowest fluctuation of particle diameters. This is likely caused by the increase in temperature at low concentrations. As discussed before, changes in temperature play a larger role in the diffusion and elastomer reaction rate. The increase in temperature would allow higher diffusion into the rubber however; the low concentration over a 30 day period would only allow the smallest of the particles to be removed from the rubber matrix.

The third data to investigate is a solution of $30 \mathrm{ppm}$ concentration and base temperature of $23^{\circ} \mathrm{C}$. This data exhibits the second highest fluctuation of particle diameters. The points have similar range to the $30 \mathrm{ppm}$ at $45^{\circ} \mathrm{C}$.

The final data to investigate is a solution of $30 \mathrm{ppm}$ concentration and base temperature of $45^{\circ} \mathrm{C}$. This data exhibits similar diameter fluctuation as $30 \mathrm{ppm}$ and $23^{\circ} \mathrm{C}$. Mentioned before, the NR is highly sensitive to chloramine degradation and is highly influenced by concentration. By changing the temperature but keeping the same concentration, it is expected for the particle sizes to be similar for NR. 


\section{c. EPDM-P}

EPDM-P indicated little to no correlation between factor changes and the particle diameter. This result was also expected given EPDM-Ps resistance to degradation.

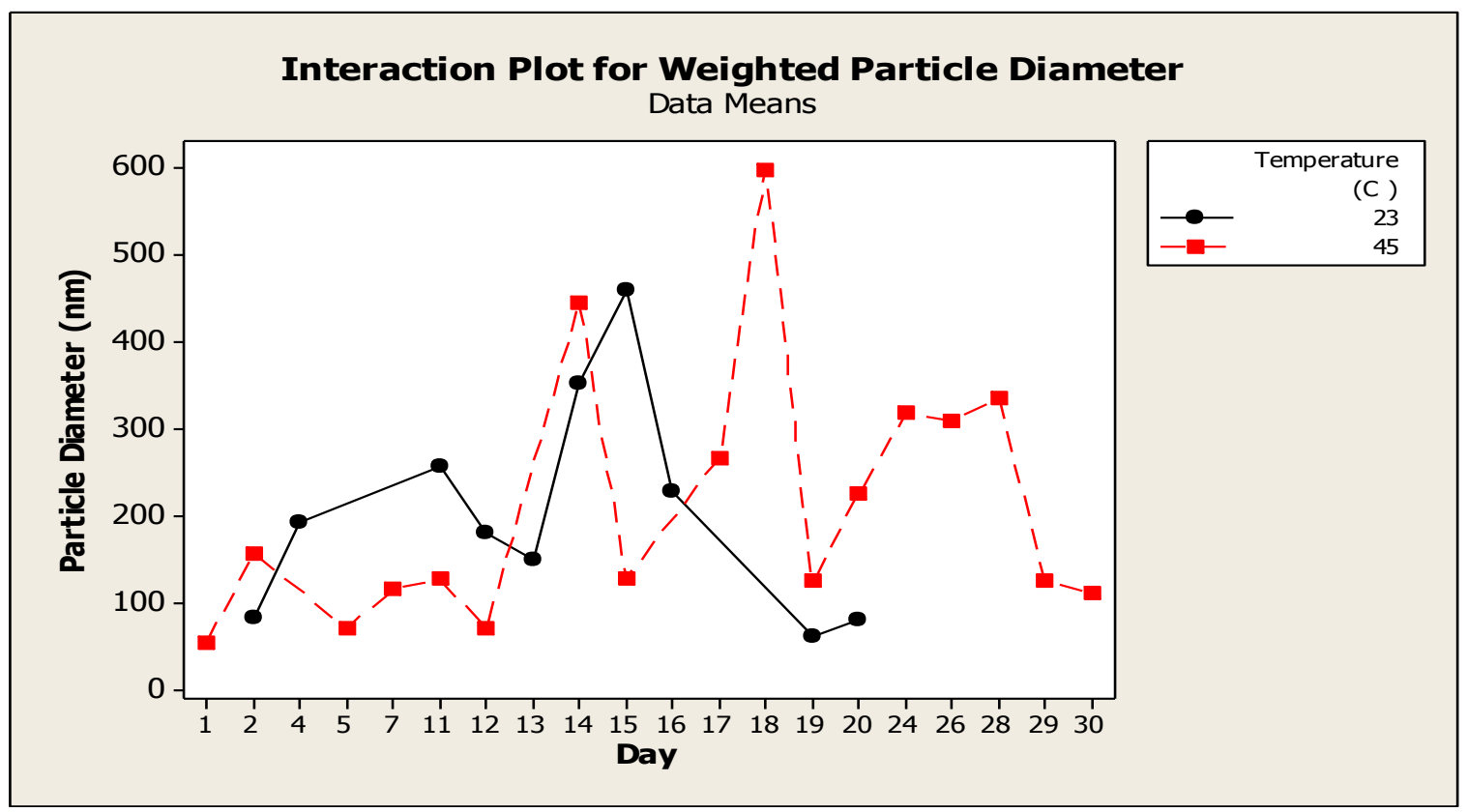

Figure 17. EPDM-P Interaction plot of Time, and Temperature on Particle Diameter.

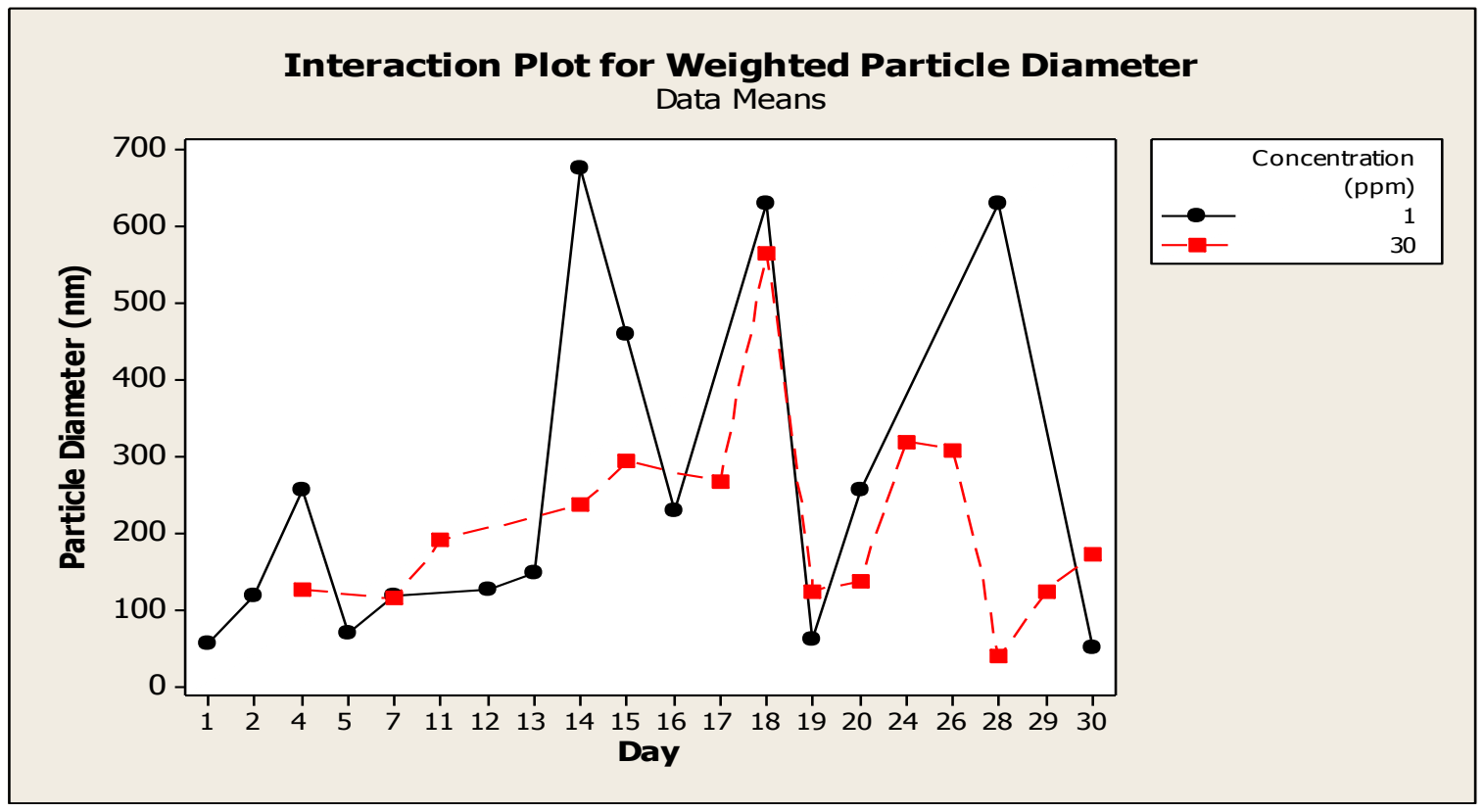

Figure 18. EPDM-P Interaction plot of Time, and Concentration on Particle Diameter. 


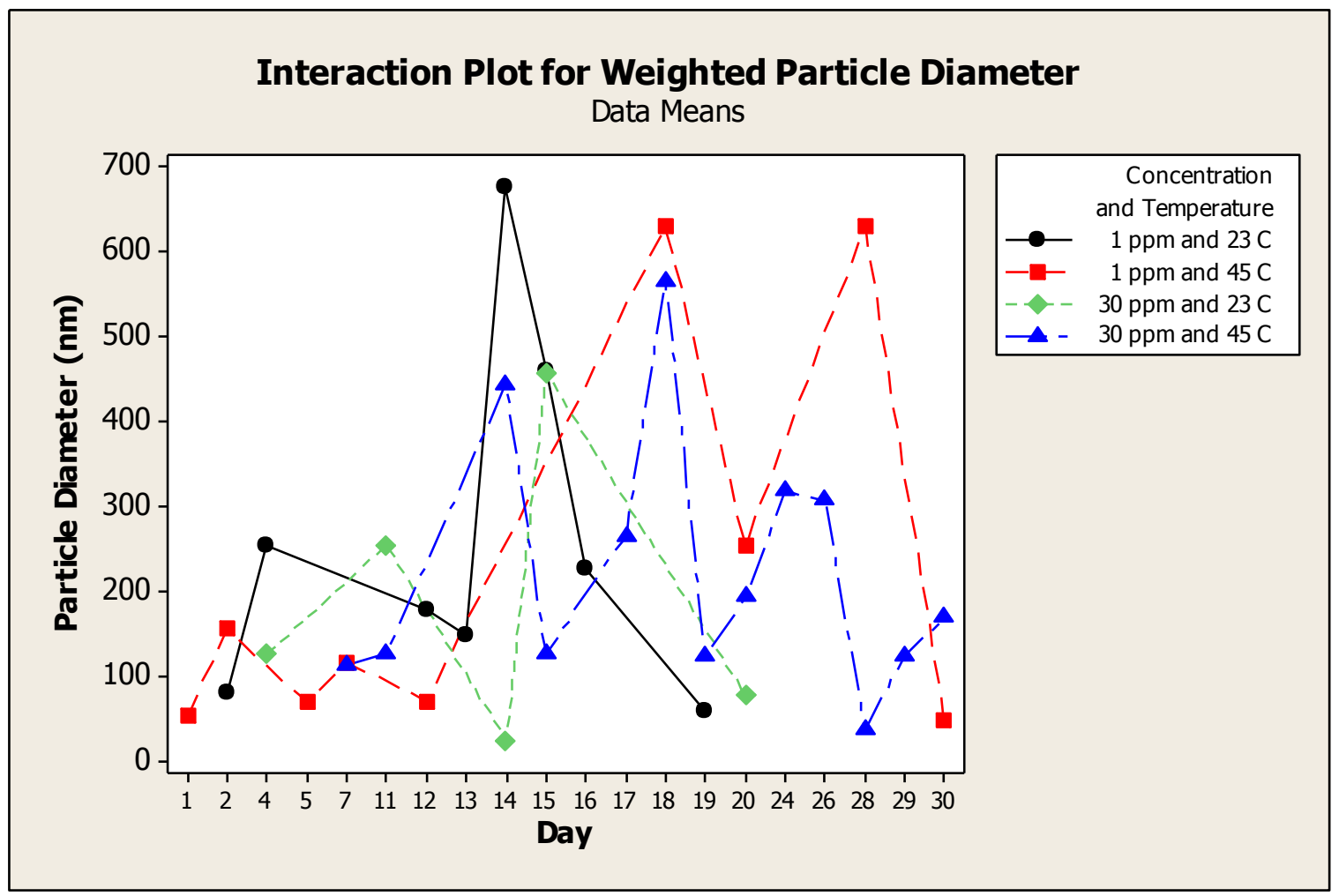

Figure 19. EPDM-P Interaction plot of Time, Temperature, and Concentration on Particle Diameter.

Figures 17, Figure 18, and Figure 19 show interaction of time, temperature, and concentration on the particle diameter. All three plots show little to no change in the fluctuation of particle diameter. This is due to EPDM-Ps high resistance to degradation. EPDM-P is highly resistant due to its peroxide curing treatment. The peroxide curing method strengthens the rubber compound. Previous studies have shown EPDM-P showing no change in breaking stress, breaking strain, and hardness over the first 1000 days (Nagisetty, 2009).Higher concentrations, higher temperatures, and/or a longer testing period would be needed to see the changes in particle diameter similar to the results seen from SBR or NR. 


\section{$\underline{\text { C. Particle count rate }}$}

\section{a. SBR}

SBR indicated high correlation between factor changes and the count rate of particles. This result was expected given the methodology of the experiment. The chloramine solution was not changed every day. Instead a higher concentrated bulk solution was prepared at about 300 ppm daily. Part of the sample chloramine solution was removed and then was replaced by the higher concentrated bulk solution to reach the required $35 \mathrm{ppm}$. This means the solution on a given day would include the particles suspended in solution from that particular day along with particles from previous days since the solution was never fully exchanged. This led to a slight increase in the number of particles over time. Thus it is no surprise that the ANOVA indicated high correlation between the day and the count rate of particles.

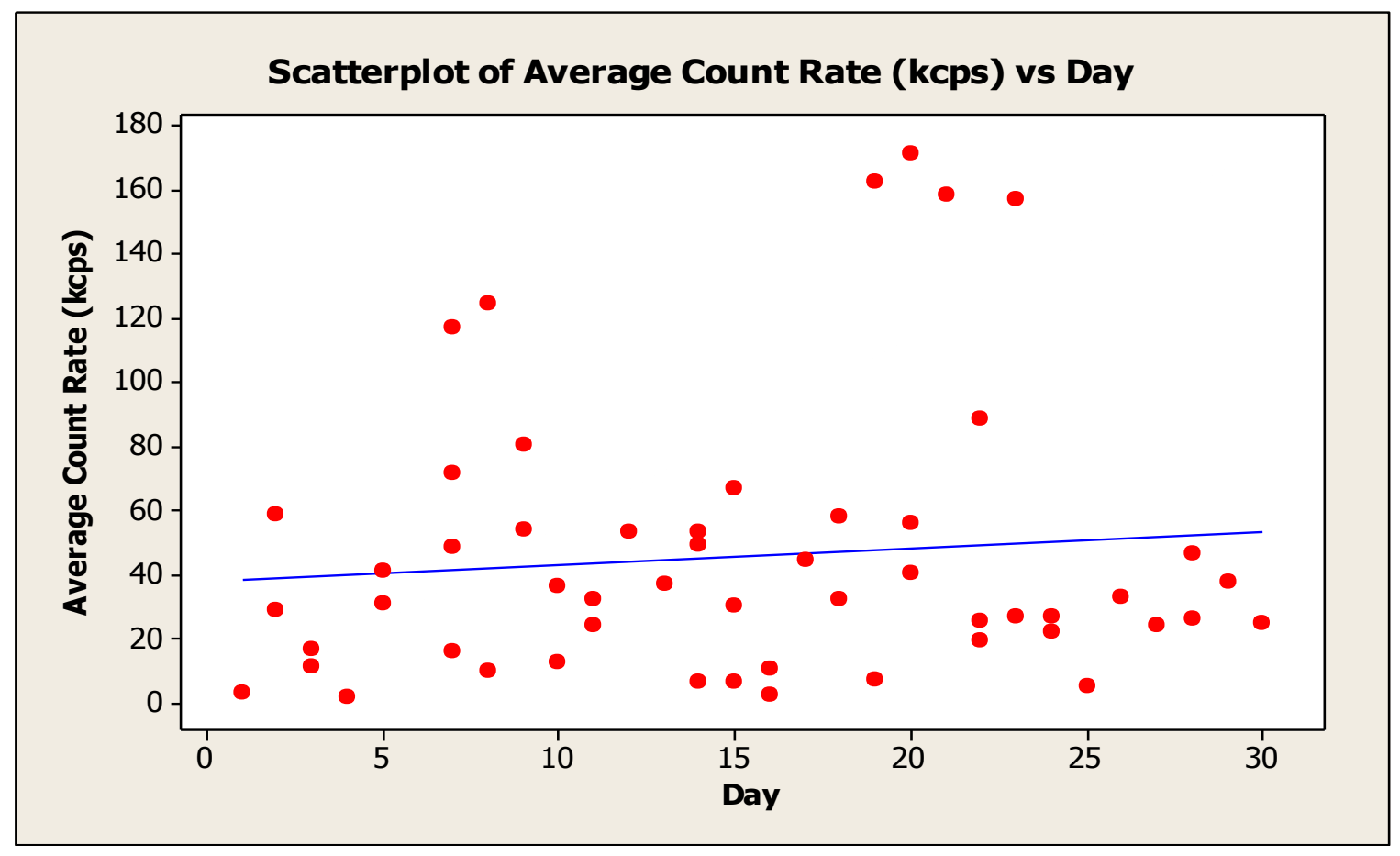

Figure 20. Daily SBR particles in solution without adjustment. 
Another ANOVA was run factoring in the dilution to determine whether the count rate was constant or increased on a daily basis. If the count rate is constant, then the rubber degradation rate is constant as the solution diffuses into the rubber. However if the count rate increases with time, then the degradation of rubber increases as the solution diffuses into the rubber sample. The ANOVA results indicated a constant degradation rate. Figure 21 shows the scatterplot with regression factoring in the dilution.

The dilution factor does lead to normalization of the data. This could cause possible correlation between factors and particle count rate to be removed. This would lead to slight misinterpretation of the data.

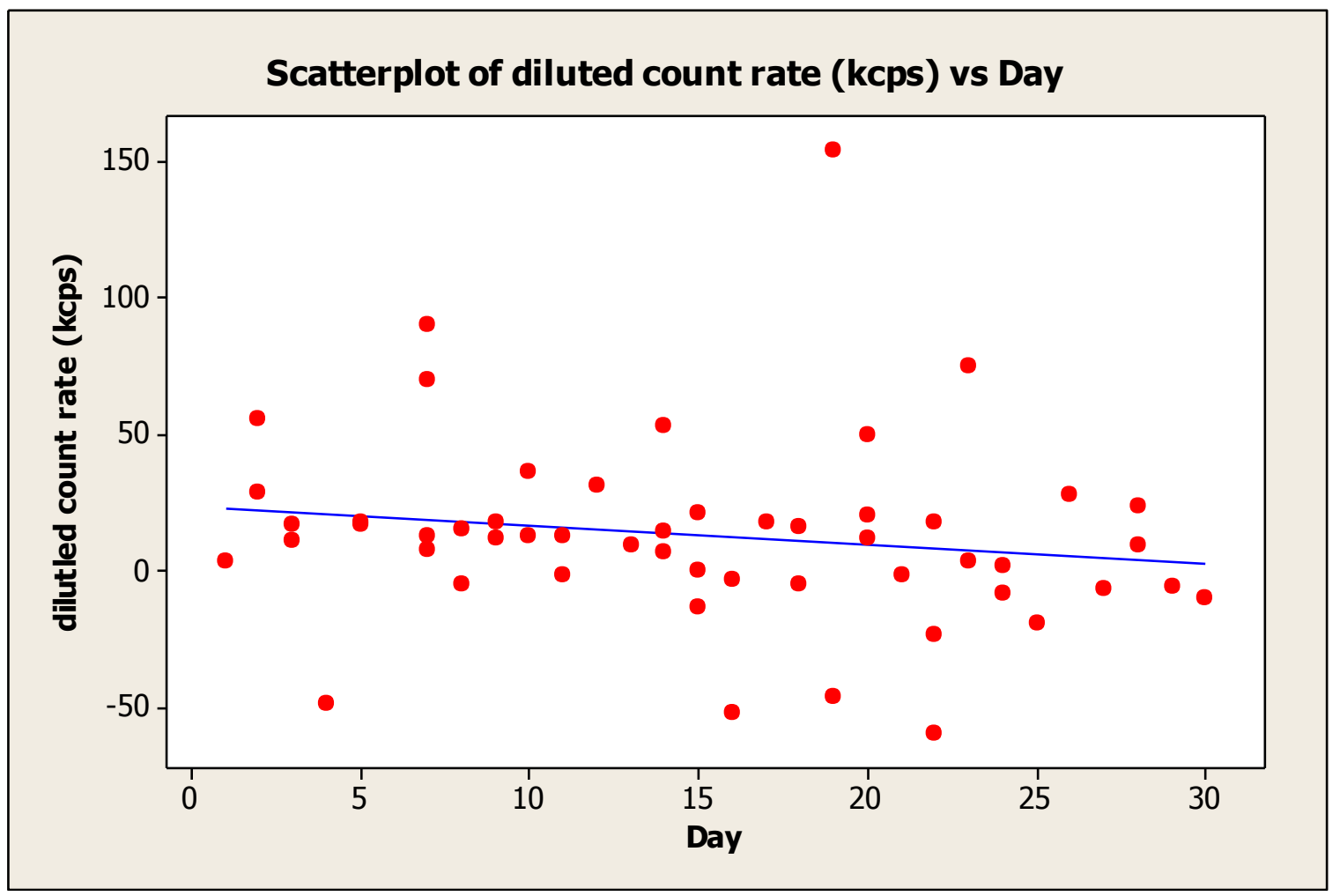

Figure 21. Daily SBR particles in solution with adjustment. 
Although the ANOVA indicated no correlation between concentration, temperature, or time to the particles in solution, Figure 22 shows the count rate across each of the factor levels.

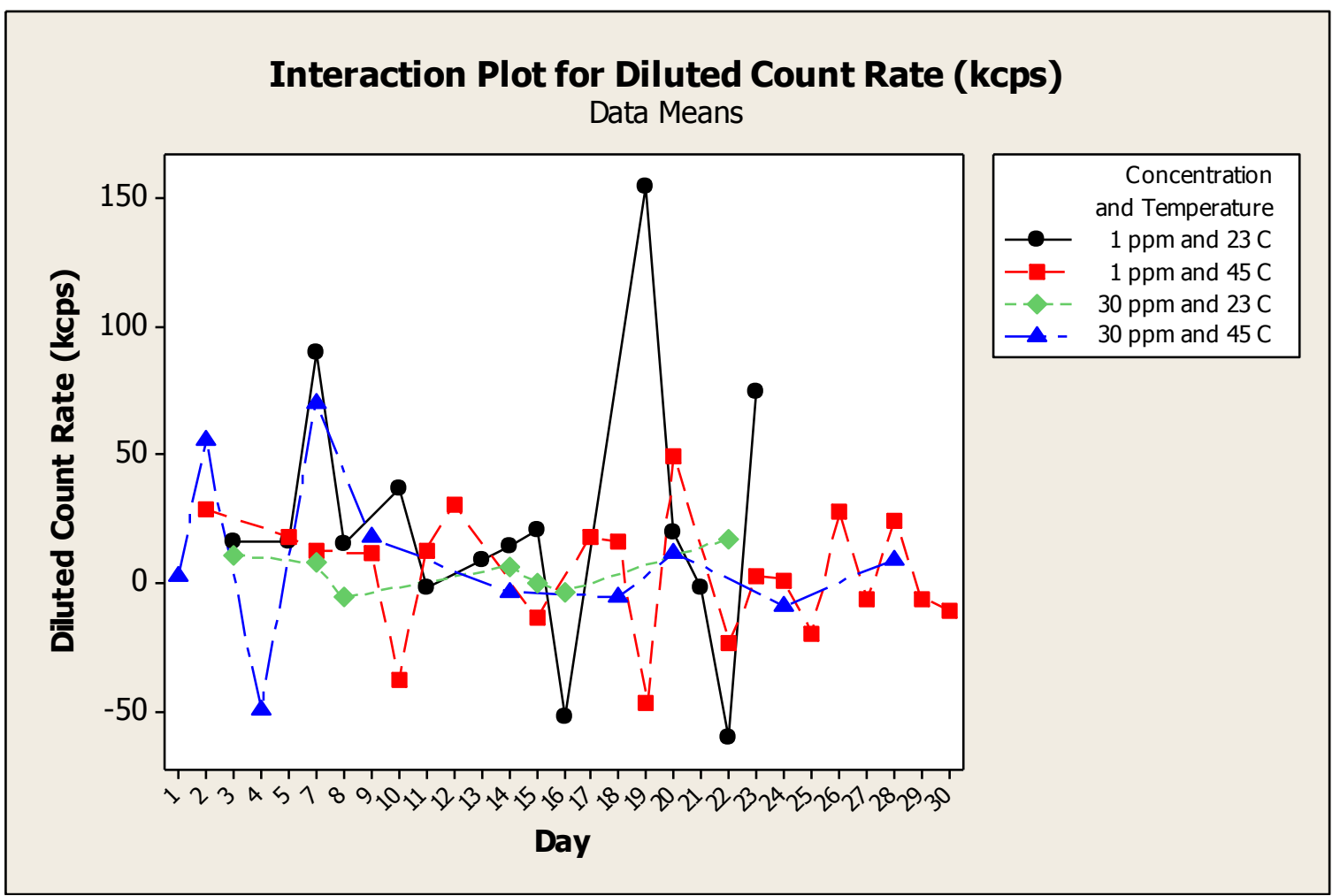

Figure 22. SBR Interaction plot of Time, Temperature, and Concentration on Diluted Count Rate.

All factor level combinations shown in Figure 22 indicate a constant degradation rate. Although $1 \mathrm{ppm}$ concentration at $23^{\circ} \mathrm{C}$ shows higher fluctuation than the other factor levels, the ANOVA found the degradation rate to be constant. The high fluctuation is likely caused by slight errors in the Particle Sizing Device as explained previously. 
b. NR

Before factoring in the dilution, NR had high correlation between time, concentration, and temperature. However, after factoring in the dilution factor, NR showed no correlation between the count rate of particles and the factor levels. Figure 23 and Figure 24 show scatterplots of the NR count rate before and after using the dilution factor.

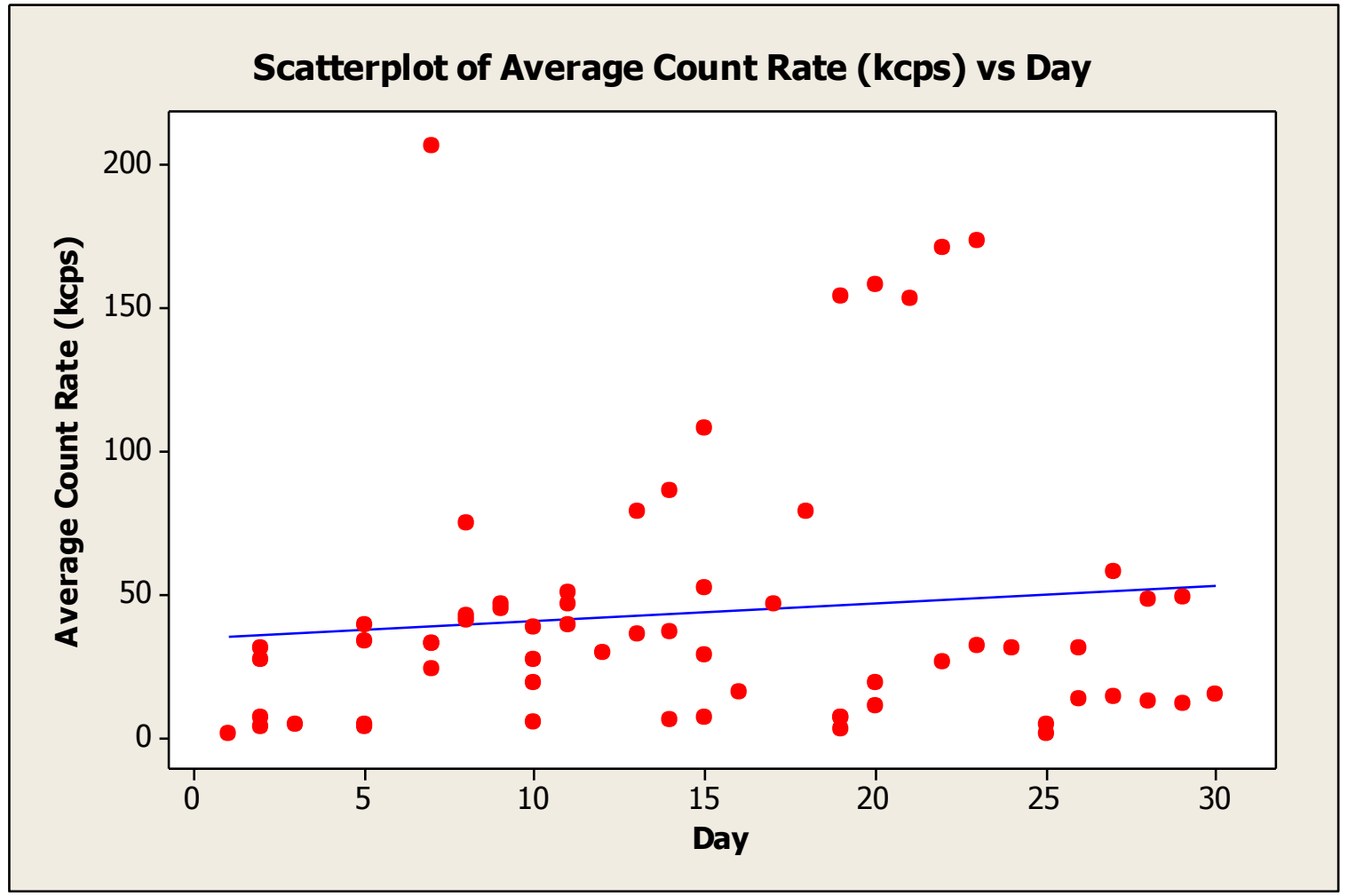

Figure 23. Daily NR particles in solution without adjustment. 


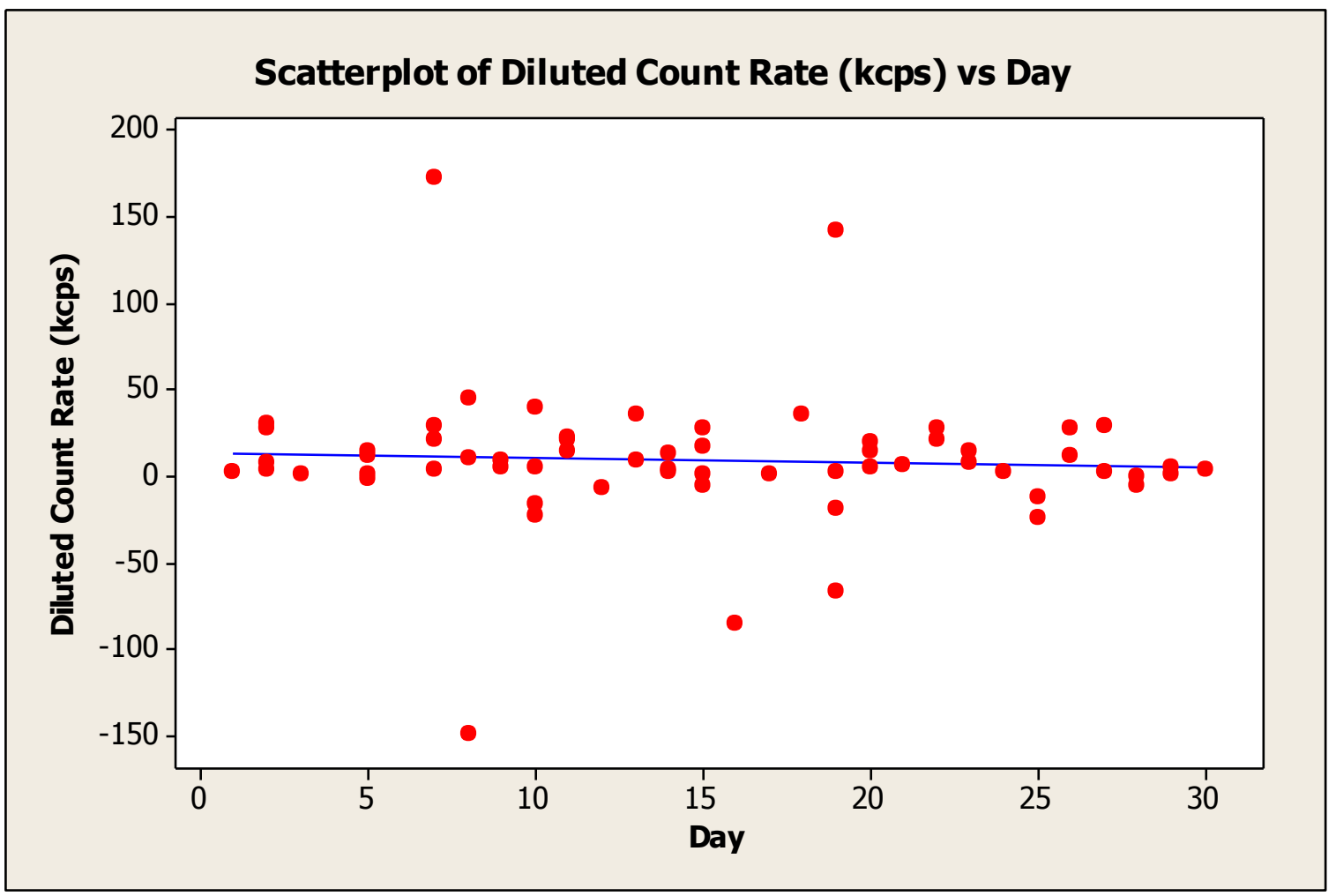

Figure 24. Daily NR particles in solution with adjustment.

Although the ANOVA indicated no correlation between concentration, temperature, or time to the particles in solution, Figure 25 shows the count rate across each of the factor levels. 


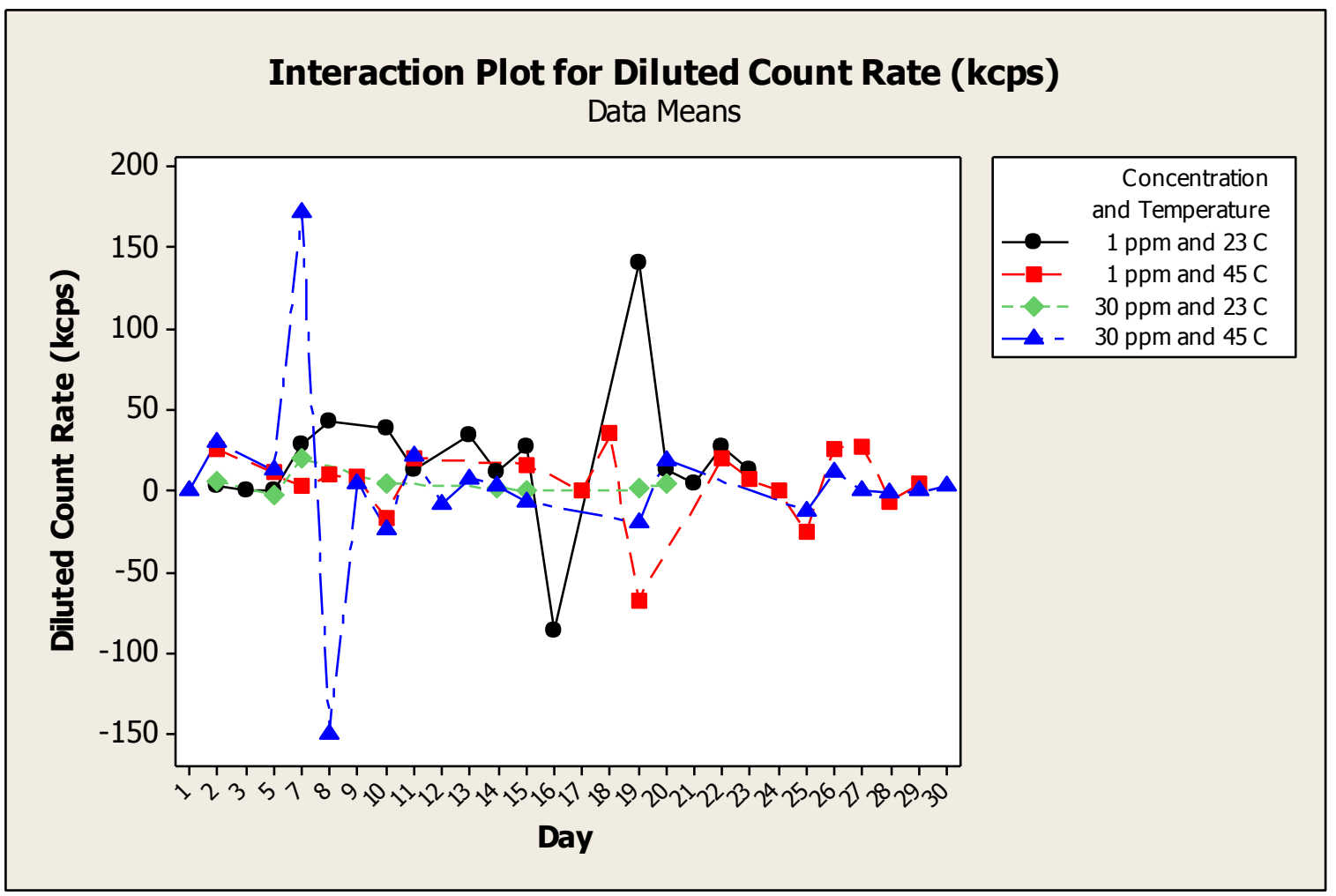

Figure 25. NR Interaction plot of Time, Temperature, and Concentration on Diluted Count Rate.

All factor level combinations shown in Figure 25 indicate a constant degradation rate.

Although $1 \mathrm{ppm}$ concentration at $23^{\circ} \mathrm{C}$ and $30 \mathrm{ppm}$ concentration at $45^{\circ} \mathrm{C}$ show higher fluctuation then the other factor levels, the ANOVA found the degradation rate to be constant. The high fluctuation is likely caused by slight errors in the Particle Sizing Device as explained previously.

\section{c. EPDM-P}

EPDM-P indicated no correlation between factor changes and the count rate of particles. This result was expected given the type of rubber being used. EPDM-P is 
highly resistant to chloramine degradation. Thus it is unlikely to have an increasing count rate over time.

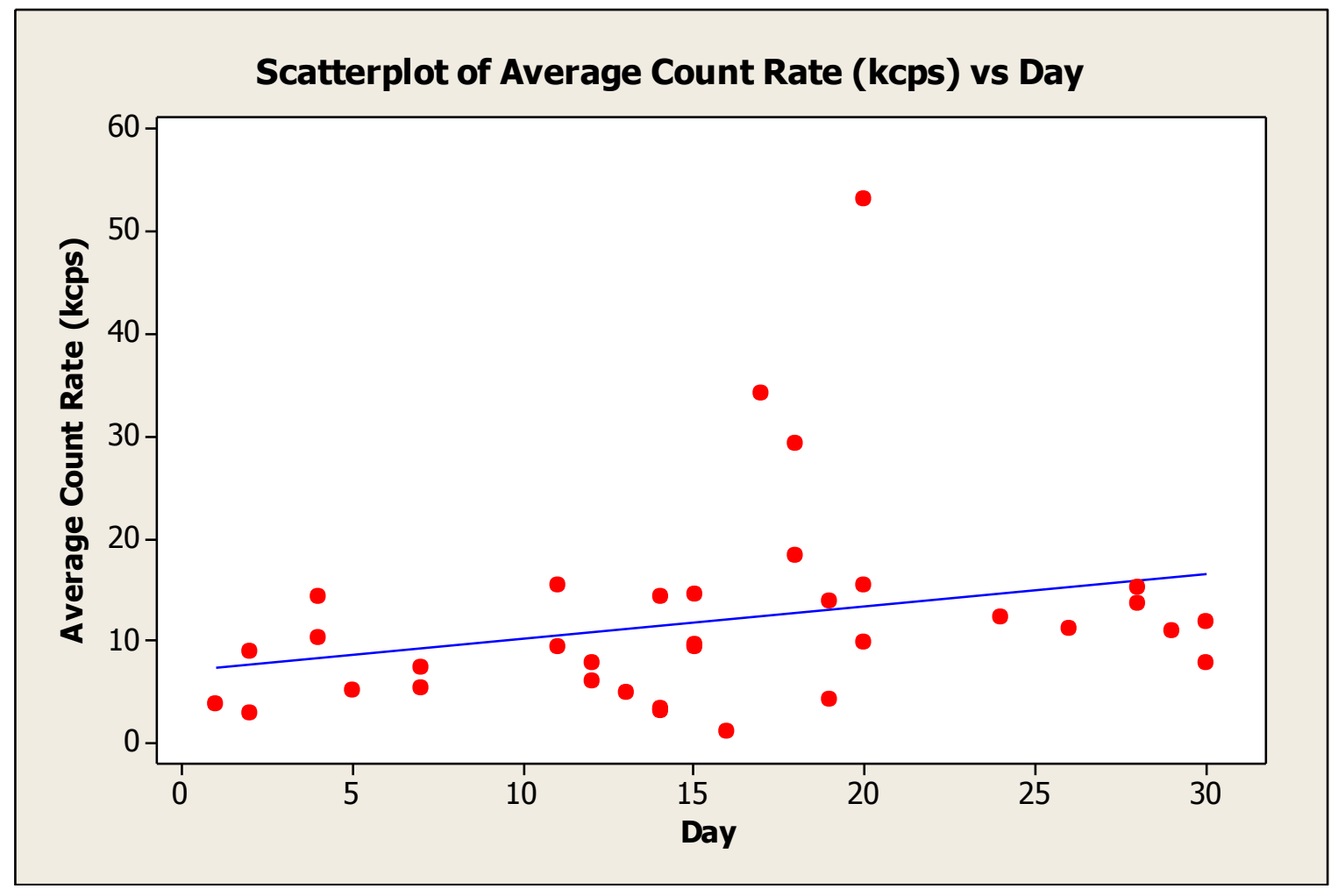

Figure 26. Daily EPDM-P particles in solution without adjustment.

Another ANOVA was run factoring in the dilution to be sure about the low correlation to factor levels and the count rate. EPDM-P still showed no sign of correlation. 


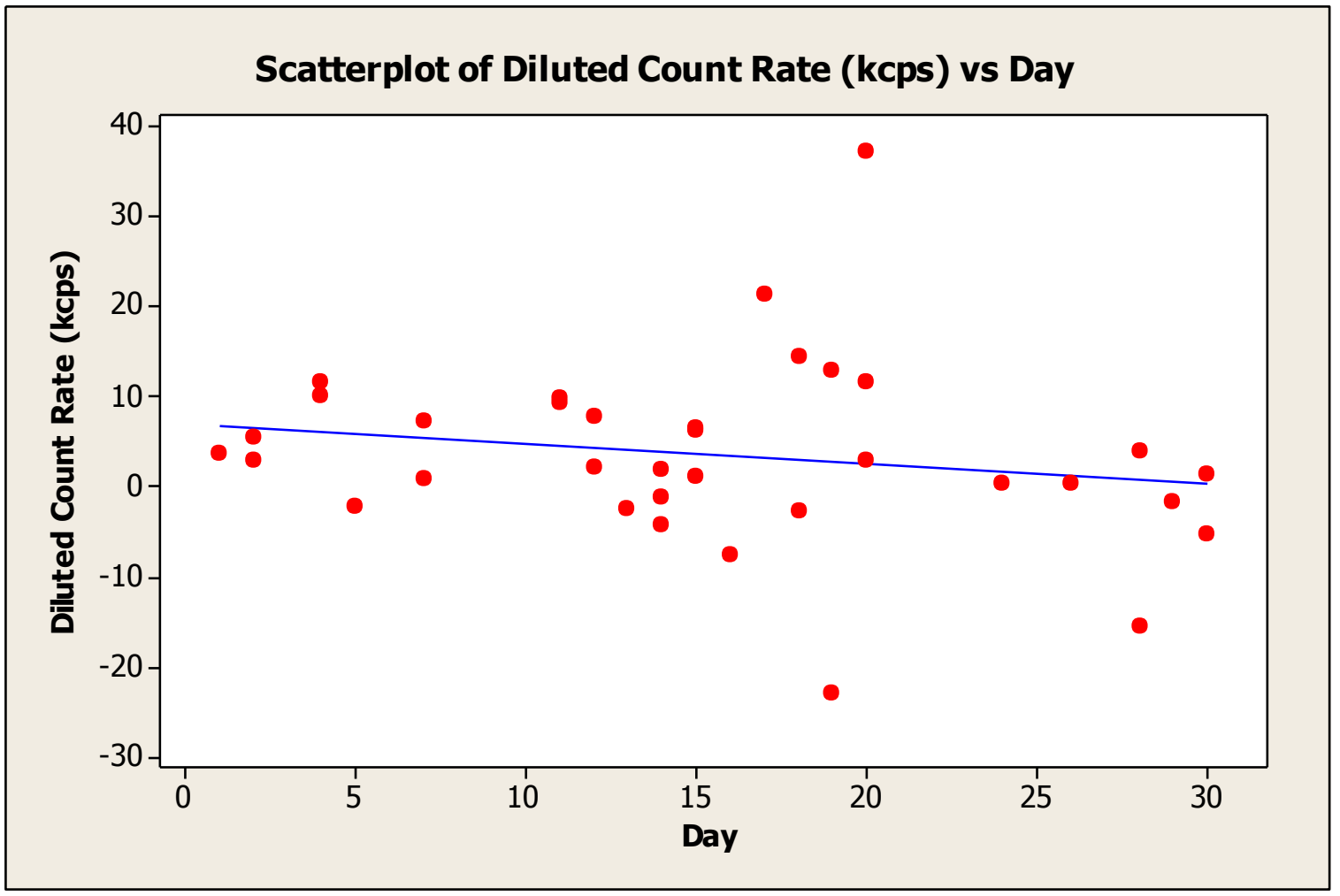

Figure 27. Daily EPDM-P particles in solution with adjustment.

Although the ANOVA indicated no correlation between concentration, temperature, or time to the particles in solution, Figure 28 shows the count rate across each of the factor levels. 


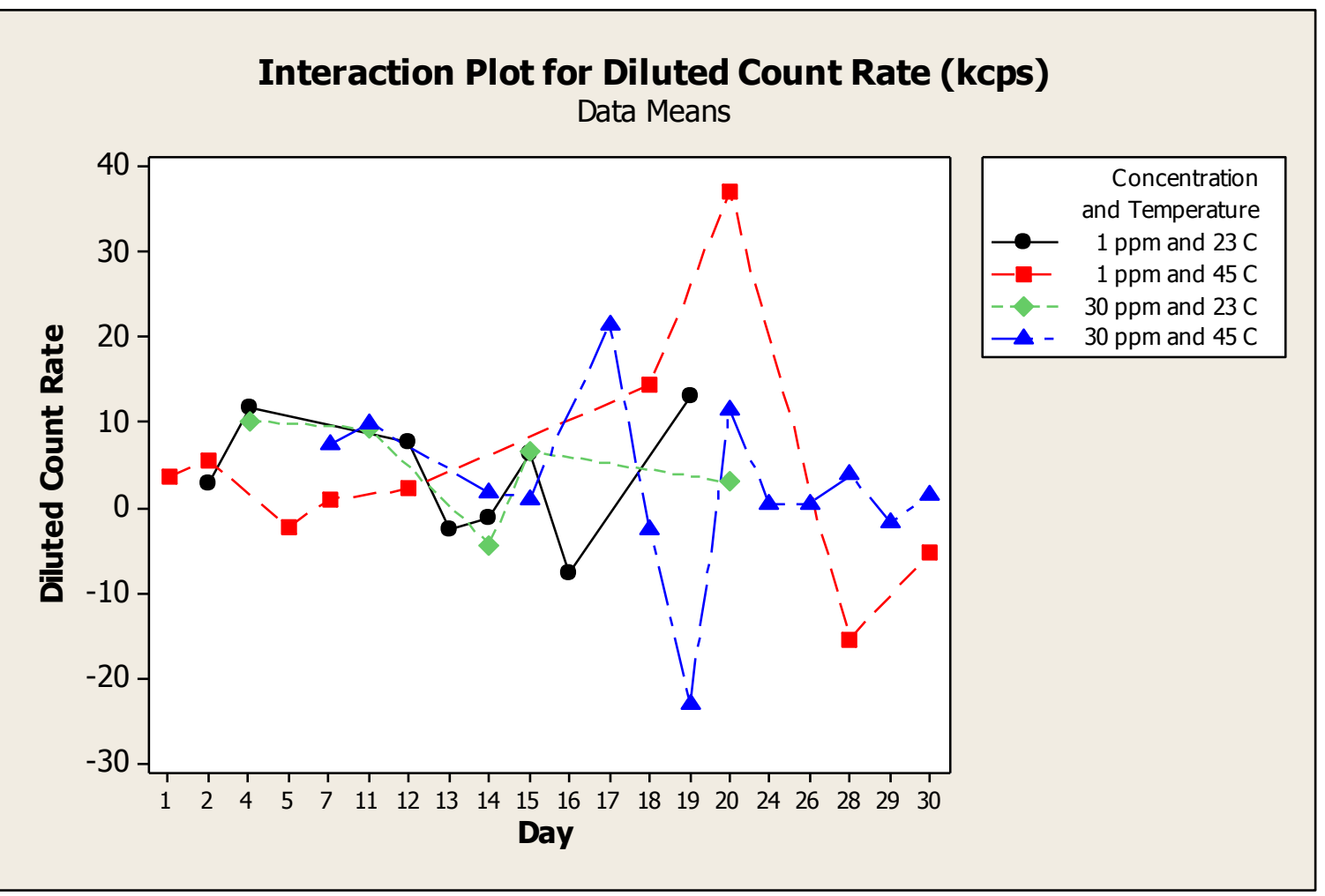

Figure 28. EPDM-P Interaction plot of Time, Temperature, and Concentration on Diluted Count Rate.

All factor level combinations shown in Figure 28 indicate a constant degradation

rate. Although $1 \mathrm{ppm}$ concentration at $45^{\circ} \mathrm{C}$ shows higher fluctuation then the other factor levels, the ANOVA found the degradation rate to be constant. The high fluctuation is likely caused by slight errors in the Particle Sizing Device as explained previously.

\section{Peak Cluster}

The Particle Sizing Analyzer, when processing a sample, would give a range of particle sizes. The particle diameters were calculated using a weighted average of the peaks. Along with particle diameter, it is important to demonstrate how the particle size ranges changed throughout the experiment. If the size ranges increased over time, then 
the chloramine solution was likely degrading the rubber and degrading the carbon black particles suspended in solution. However, if the size ranges remained fairly constant throughout the duration of the experiment, then the chloramine solution only degraded the rubber samples.

\section{a. SBR}

SBR showed no changes in the particle ranges throughout the experiment. Figure 29 shows the peak ranges for each sample. It is noticeable that some samples have larger ranges then others, however, there is no correlation between the factors and peak ranges.

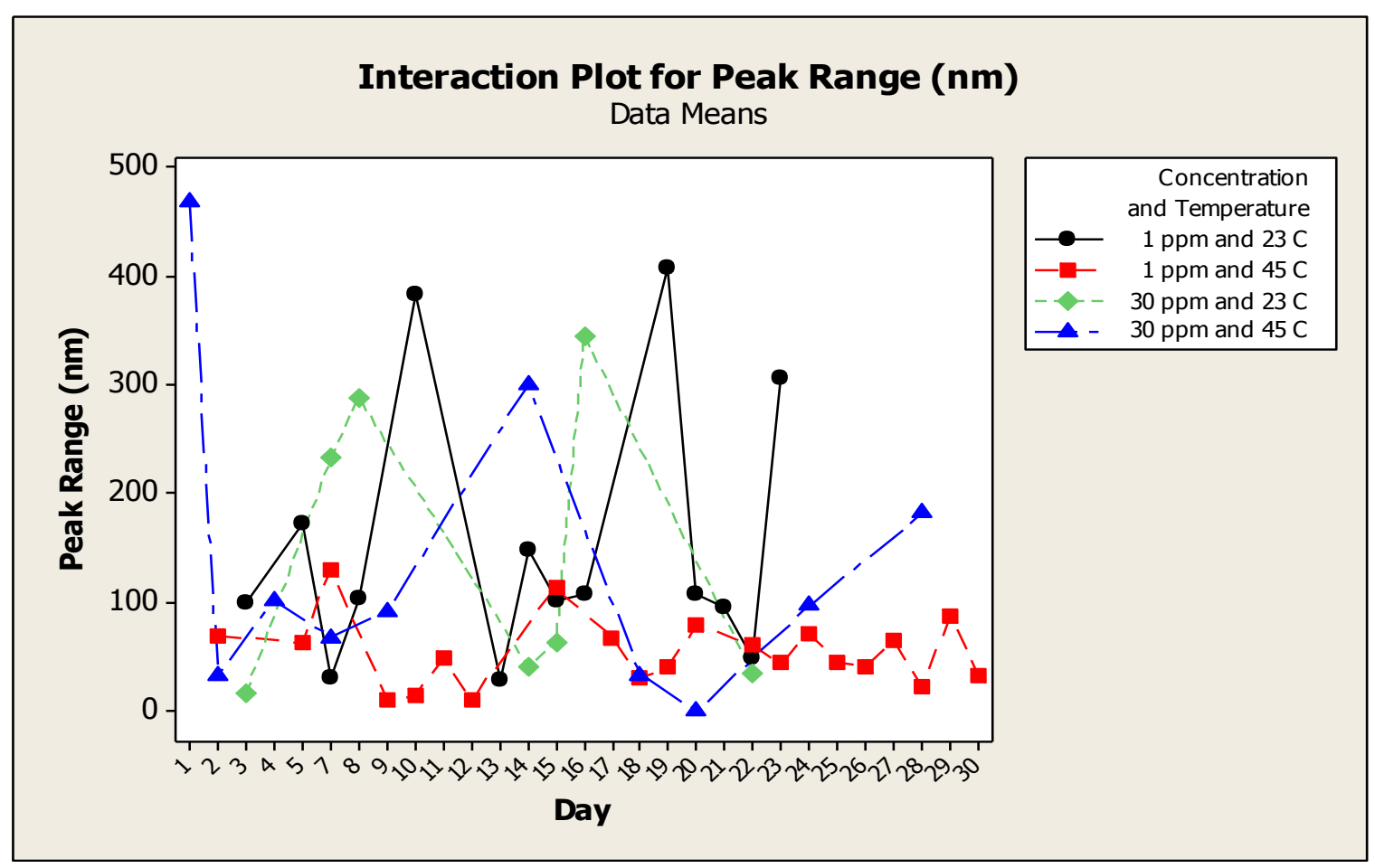

Figure 29. SBR Peak Ranges 
b. NR

NR showed high correlation to altering peak ranges throughout the experiment.

NR Showed high correlation with time, concentration, and temperature. Figure 30 shows the peak ranges for each sample.

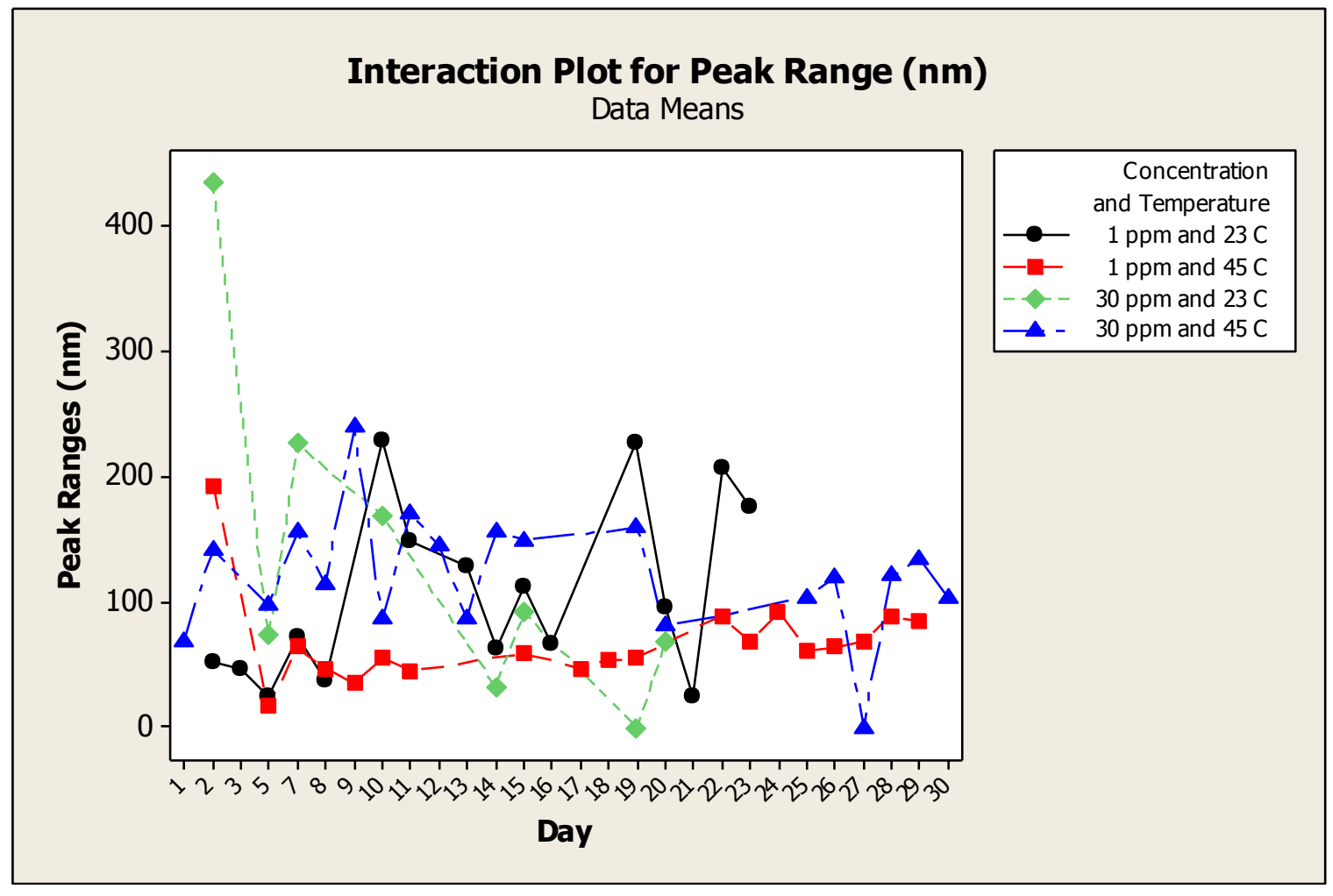

Figure 30. NR Peak Ranges

There is a slight increase in the peak ranges over time for most of the samples.

The $1 \mathrm{ppm}$ at $45^{\circ} \mathrm{C}$ sample showed the lowest values in peak range. The others showed slight increases in the peak range. To better understand how each factor level changes peak range, a regression equation was made.

$$
\begin{array}{r}
P R=2.32+11.30(D)+17.04(C)+1.38(T)-1.44(D * C) \\
-0.25(D * T)-0.32(C * T)+.03(D * C * T)
\end{array}
$$


Where $\mathrm{PR}$ is the peak range, $\mathrm{D}$ is the day, $\mathrm{C}$ is the concentration and $\mathrm{T}$ is the temperature. The regression equation shows the role each factor level has in predicting the peak ranges. Although the interaction coefficients are negative, the positive coefficients for day, concentration, and temperature easily outweigh them. Meaning day, concentration, and temperature have a positive effect on the peak range.

\section{c. EPDM-P}

EPDM-P showed no changes in the particle ranges throughout the experiment.

Figure 31 shows the peak ranges for each sample. It is noticeable that unlike SBR, all the samples have similar ranges. This is due to EPDM-P having high resistance to chloramine degradation.

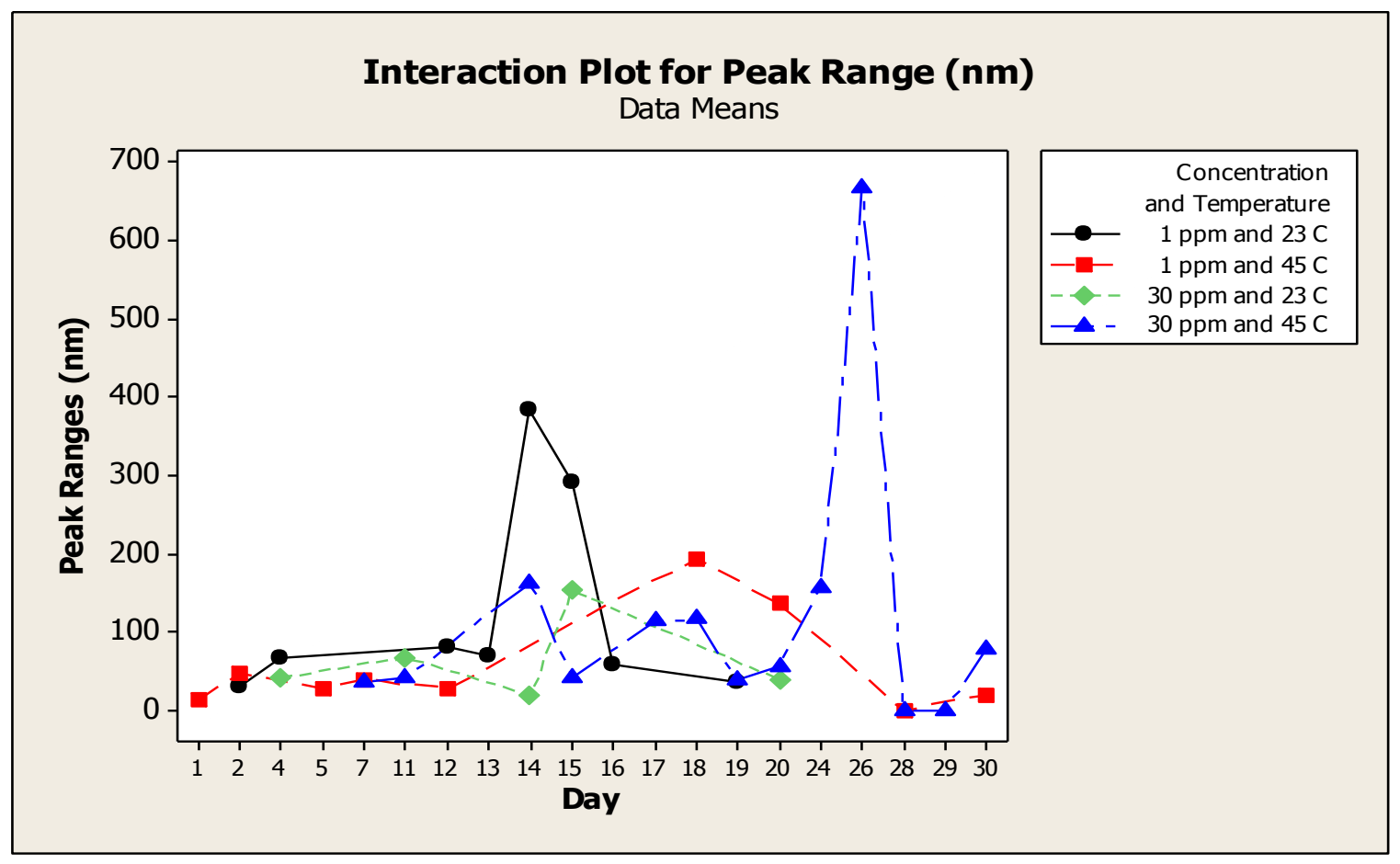

Figure 31. EPDM-P Peak Ranges 


\section{E. Turbidity}

Turbidity is the cloudiness or haziness of a liquid caused by inorganic or organic particles suspended in solution. (Tolgyessy, 1993) This serves as a rough measurement for the amount of carbon black released into the sample over time. The graphs below demonstrate the turbidity of the samples throughout the experiment. Distilled was used as a control and any deviation indicates chloramine degradation of the rubber.

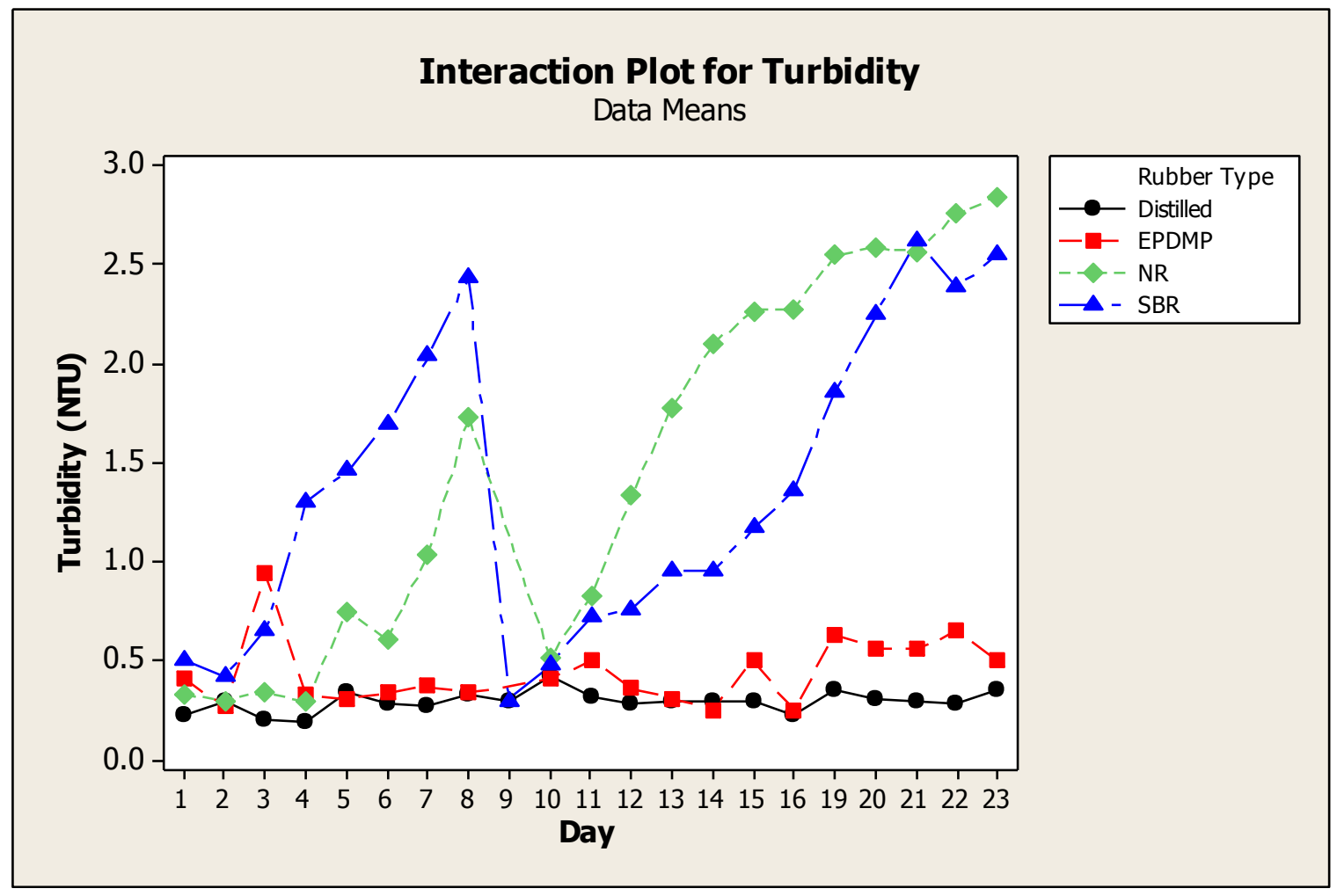

Figure 32 . Turbidity at $1 \mathrm{ppm}$ and $23^{\circ} \mathrm{C}$ (Solution was changed on Day 9 to switch from DI water to Distilled)

DI water was originally used in the experiment but was exchanged for distilled water. The DI water was taken from a reverse osmosis filter while the distilled water was taken from a water distiller. The change was due to DI water displaying odd peaks on the particle size analyzer. Figure 32 illustrates high degradation for SBR and NR and low degradation for EPDM-P compared to the control. 


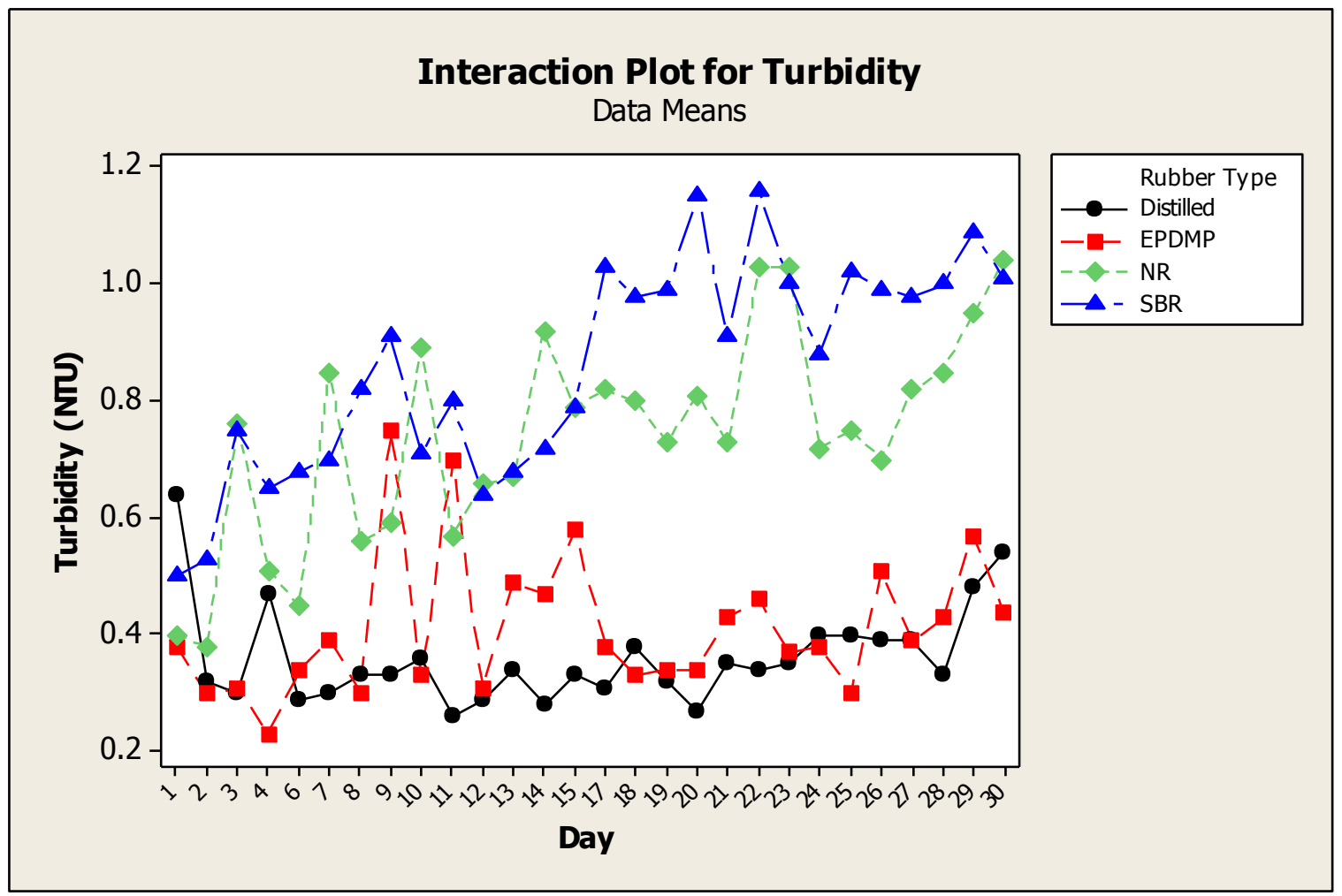

Figure 33. Turbidity at $1 \mathrm{ppm}$ and $45^{\circ} \mathrm{C}$

The samples held at $45^{\circ} \mathrm{C}$ used distilled water throughout the experiment and was never fully exchanged. Figure 33 shows high degradation for SBR and NR and low degradation for EPDM-P. However the degradation for EPDM-P is slightly greater than the experiment run at $1 \mathrm{ppm}$ and $23^{\circ} \mathrm{C}$. This is likely due to temperature increasing the diffusion and chloramine reaction rate. 


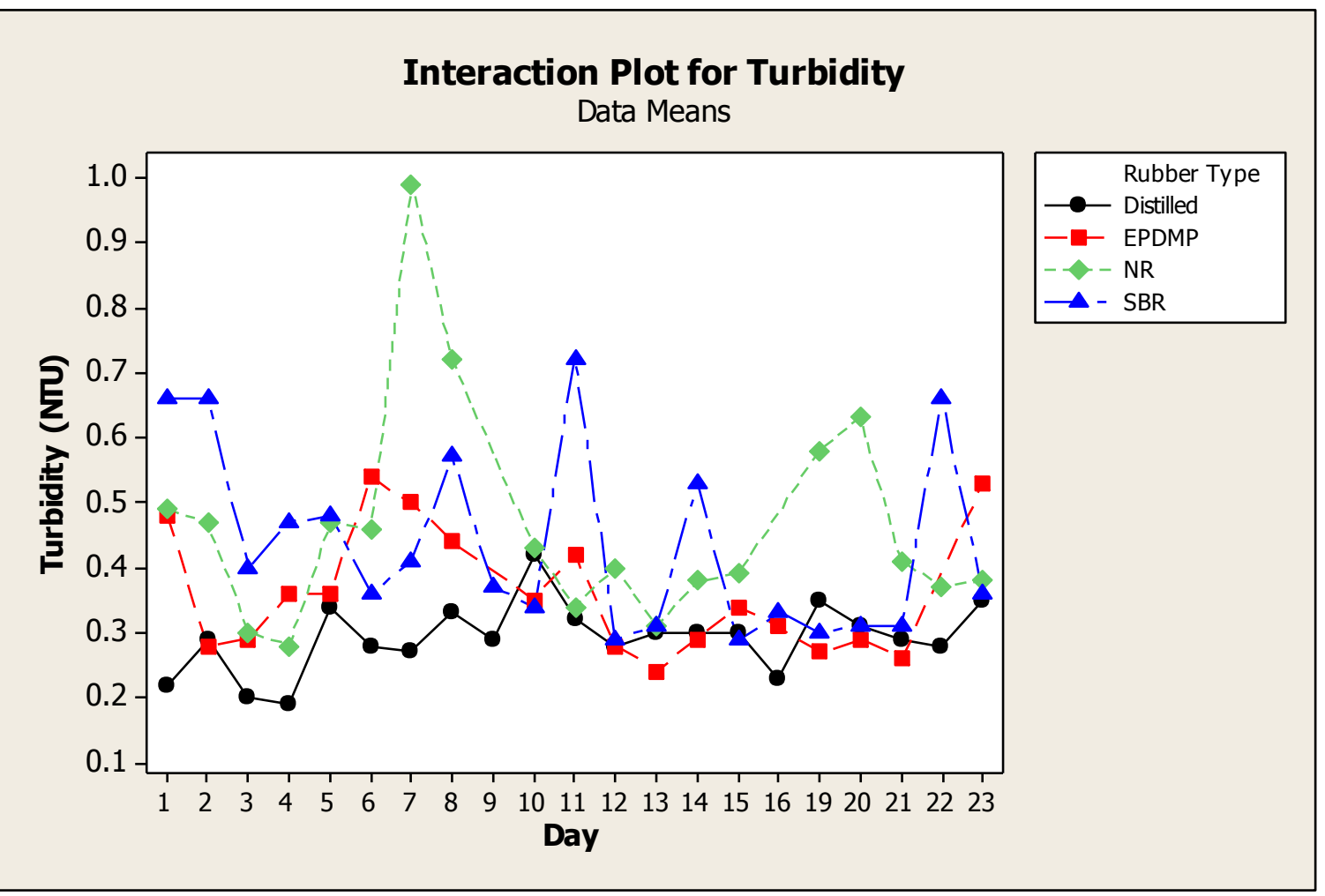

Figure 34. Turbidity at $30 \mathrm{ppm}$ and $23^{\circ} \mathrm{C}$ (Solution was changed on Day 9 to switch from DI water to Distilled)

The chloramine solution was switched out on day 9. Figure 34 shows moderate degradation for SBR and NR and low degradation for EPDM-P. Overall the degradation at $30 \mathrm{ppm}$ and $23^{\circ} \mathrm{C}$ was below that of the previous experiments. This is likely caused by concentration having a minor effect on diffusion and chloramine reaction rate. 


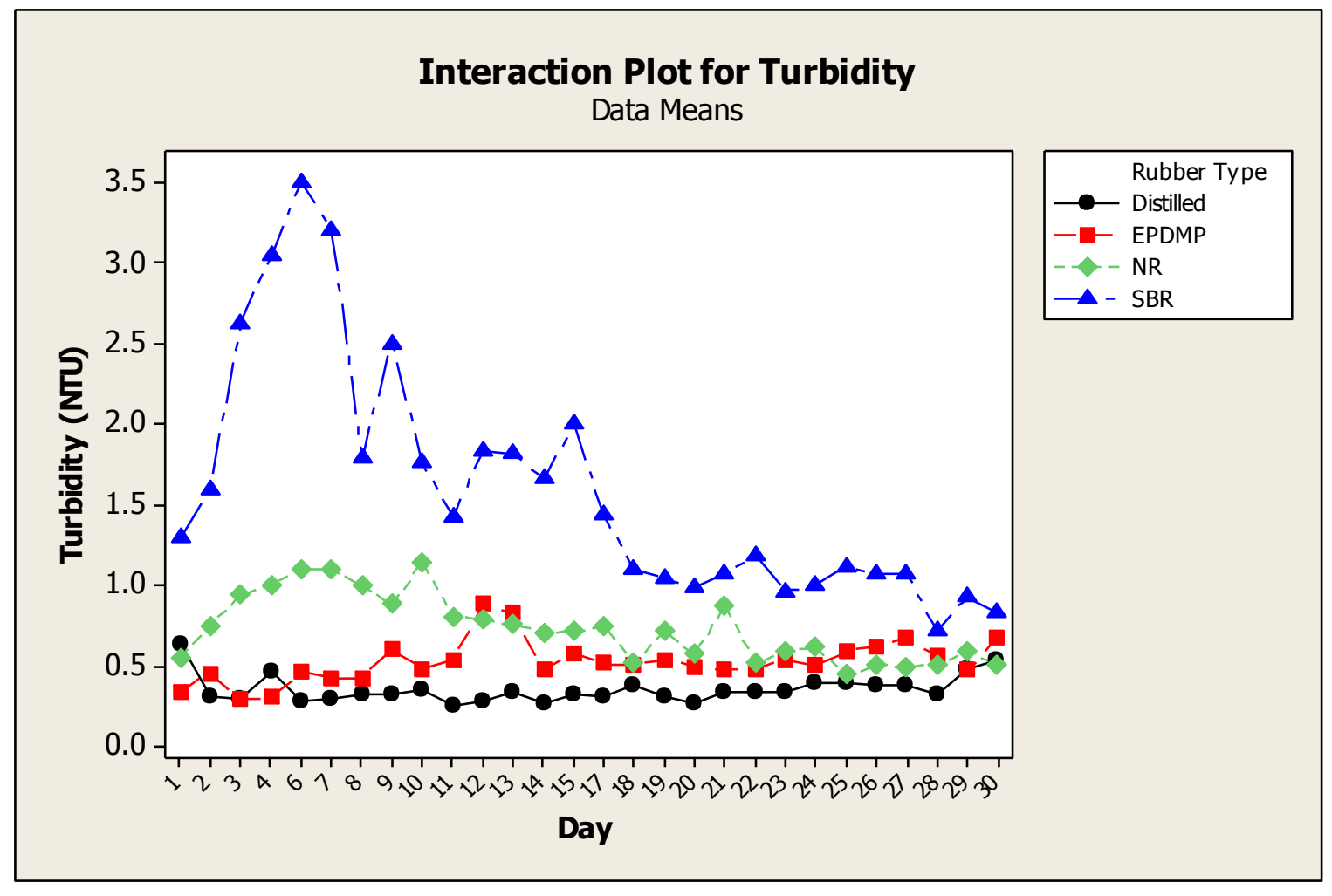

Figure 35 . Turbidity at $30 \mathrm{ppm}$ and $45^{\circ} \mathrm{C}$

The solution was kept throughout the experiment. Figure 35 displays high initial degradation for SBR and NR and low degradation for EPDM-P. Unlike the other experiments, $30 \mathrm{ppm}$ and $45^{\circ} \mathrm{C}$ had high degradation and then slowly decreased over time. This is likely due to the high concentration and temperature of the sample. Initially high amounts of carbon black particles were released from the rubber into the suspension. This causes the increase in turbidity initially. However, due to the high concentration and temperature of this suspension, the carbon black aggregates were broken apart into smaller aggregates or individual particles. Due to the wavelength of light, the smaller particles would become too small to be seen and would no longer contribute to the 
turbidity. Over time, as the particle aggregates are continuously broken apart, the sample would become clearer since the light is unobstructed by the small particles.

\section{F. Comparisons to Previous Research}

This research was based on two previous studies. The first is, "Elastomeric Compounds Degradation and Associated Water Quality Concerns in Drinking Water Distribution Systems" by Raja Nagisetty in 2009. The second is, "Performance of Elastomeric Components in Contact with Potable Water" by Rockaway et al in 2007.

The Nagisetty dissertation focused on mechanical properties associated with elastomer degradation by chloramines. These mechanical properties were hardness, swelling, and tensile strength. The major conclusions from the research were 1)Temperature demonstrates higher impact on elastomer degradation as compared to concentration, 2)EPDM-P was found to be least susceptible to chloramine degradation followed by SBR and NR, and 3)For longer-term performance predictions of elastomeric compounds in drinking water systems, accelerating the degradation by increased chloramine concentration is thought to be better service conditions degradation representative than the increased temperature acceleration.

Comparing the conclusions from the Nagisetty dissertation to those made in this research, similar conclusions were made. Based on the particle diameter and particle count rate results, temperature demonstrated higher impact on elastomer degradation. EPDM-P also showed low susceptibility to chloramine degradation followed by SBR and 
NR. However, time-temperature tables were only done in the Nagisetty research. Thus no comparison about the third conclusion can be made.

In the Rockaway et al. report, the chloramine and chlorine diffusion rate into rubber was calculated for SBR, NR, and EPDM-sulfur cured rubber samples. The experiment determined the diffusion rate by examining the rate and depth at which carbon black was removed from the rubber sample. This was done using an atomic force microscopy. The major conclusions from the research were: 1) The diffusion of the penetrating liquid into the sample was likely responsible for the loss of carbon black. 2) Samples exposed to conditions of accelerated aging showed an overall loss of carbon black material and a decrease in the average particle size as fluids penetrated the sample. 3) Chloramine-induced erosion of the carbon black particles is a strong factor in the decrease in elastomer performance over time.

Comparing the conclusions from the Rockaway et al. report to those made in this research, similar conclusions were made. Based on the changes in particle diameter and particle count rate, diffusion of chloramine was likely responsible for the loss of carbon black. Similar to this research, samples exposed to accelerated aging such as higher concentration or temperature showed an overall loss of carbon black and average particle size decrease over time. However, elastomer performance was not performed in this research so similarities could not be made about elastomer performance. 


\section{CONCLUSIONS}

The conclusions that can be drawn from the results of this research are promising. The 30 day test results indicated that higher temperatures and lower concentrations lead to a smaller average particle size for SBR and NR. This is likely due to temperature affecting the diffusion into the rubber and rubber degradation reaction rate in an exponential manner. The concentration affects the diffusion and rubber degradation rate in a linear manner. However, both temperature and concentration have a positive proportionality with the diffusion and rubber degradation rate. EPDM-P was unaffected by changes in temperature and concentration on the carbon black particle sizes identified. This is likely due to EPDM-P's highly resistant nature to chloramine degradation.

All three rubber types tested indicated little change at the number of particles suspended in solution as temperature and concentration changed. Since the SBR and NR particle sizes decreased with temperature and concentration, it is likely that the rubber degradation rate is only modestly changed with temperature and concentration changes. Instead, the diffusion rate is highly increased allowing the chloramine solution to penetrate further into the rubber samples. Based on how the rubber is synthesized, larger carbon black aggregates are likely to be present on the outer surface of the rubber sample 
while the smaller carbon black aggregates or single particles are likely to be further in the rubber. The increase in temperature and concentration allows the chloramine solution to reach the smaller carbon black particles and degrade the rubber bonds surrounding them. Thus it suspends smaller carbon black particles into solution.

The peak ranges or the size range of the carbon black particles remained fairly consistent throughout the 30 day testing period for all three types of rubber tested. This shows that the chloramine solution is unlikely degrading the carbon black aggregates. Otherwise it would be expected to see the particle size ranges change over time. The turbidity behaves similar to that of previous studies whereas the turbidity starts low and increases vastly as the experiment continues. 


\section{RECOMMENDATIONS}

The chloramine and rubber interaction causes several byproducts to be formed. A major byproduct formed is chloroform. Chloroform is carcinogenic and poses a serious health risk in high quantities. It is recommended that experiments are run to determine the chloroform production rate. This would allow a health risk assessment to be done to determine the hazards it may have in the water system. The experimental setup would include a reaction vessel where the chloramine solution would react with a rubber compound. SBR is a good candidate due to its high use in the water sanitation industry. The vapor space should then be bubbled through a solution with high chloroform solubility. Acetone, methanol, and ethanol have high chloroform solubility (Linke, 1958). Acetone is recommended due to its boiling point. Samples of the acetone/chloroform solution can be run on a gas chromatography device allowing the user to receive concentration of chloroform over time data. This would allow easy calculation of the chloroform production rate.

It is also recommended to run this experiment again except by completely changing out the solutions daily. By only diluting the chloramine solution, the degraded rubber remained in solution. This would decrease the diffusion into the rubber since the 
gradient between the solution and rubber would be decreased. By changing the entire solution out daily, it is possible to see higher rubber degradation over the 30 day period. Switching the solution daily would also decrease the amount of degraded elastomer sulfur bonds in solution and allow better operation of the particle sizing analyzer.

The last recommendation would be to run the carbon black under SEM, Scanning Electron Microscopy. This test allows the user to take high resolution photos of nanoparticles. By comparing the carbon black removed from the rubber during the reaction to the carbon black used to make the rubber, the user can see whether the chloramine solution is degrading the carbon black. 


\section{REFERENCES CITED}

Donnet, Jean-Baptiste, and Andries Voet. Carbon Black: Physics, Chemistry, and Elastomer Reinforcement. New York: M. Dekker, 1976. Print.

EPA Guidance Manual. "Chloramines." Water.epa.gov. Environmental Protection Agency, n.d. Web. 8 Dec. 2012. <http://water.epa.gov/lawsregs/rulesregs/sdwa/mdbp/upload/2001_01_12_mdbp_ alter_chapt_6.pdf>.

Faust, Samuel D., and Osman M. Aly. Chemistry of Water Treatment. Boston: Butterworth, 1983. Print.

Haynes, William M. CRC Handbook of Chemistry and Physics: A Ready-reference Book of Chemical and Physical Data. 93rd ed. Boca Raton, FL: CRC, 2012. Print.

Hsieh, H. L.; Wagner, P. H.; Wilder, C. R. Synthetic Rubber. Encyclopedia of Chemical Processing and Design 1994.

Instruction Manual for 90Plus/BI-MAS Multi Angle Particle Sizing Option. New York: Brookhaven Instruments Corporation, 1995. PDF.

Kirmeyer, G.J., G.W. Foust, G.L. Pierson, J.J. Simmler, and M.W. LeChevallier. 2003. Optimizing Chloramine Treatment. $2^{\text {nd }}$ ed. Denver, Colo.: AwwaRF.

Kreyszig, Erwin, Herbert Kreyszig, and E. J. Norminton. Advanced Engineering Mathematics. 10th ed. Hoboken, NJ: Wiley, 2011. Print.

Kroeger, Patrick D. "THE FEASIBILITY OF USING MONOCHLORAMINE IN RECYCLING VULCANIZED STYRENE BUTADIENE RUBBER." Thesis. University of Louisville, 2013. Print.

Lide, David R. CRC Handbook of Chemistry and Physics. Boca Raton: CRC, 2005. Print.

Linke, William F., and Atherton Seidell. Solubilities, Inorganic and Metal Organic Compounds; a Compilation of Solubility Data from the Periodical Literature. Princeton, NJ: Van Nostrand, 1958. Print.

Lower, Stephen. "Gibbs Free Energy." Gibbs Free Energy. N.p., 14 Oct. 2010. Web. 08 Dec. 2012.

Nagisetty, R. M., Rockaway, T. D. and Willing, G. A. (2010), Aqueous chloramine diffusion into elastomers. J. Appl. Polym. Sci., 117: 2597-2611. doi: 10.1002/app.30970 
Nagisetty, Raja M. "Elastomeric Compounds Degradation and Associated Water Quality Concerns in Drinking Water Distribution Systems." Diss. University of Louisville, 2009. Print.

Perry, Robert H., and Don W. Green. Perry's Chemical Engineers' Handbook. 8th ed. New York: McGraw-Hill, 2008. Print.

Rockaway, Thomas D., Gerold A. Willing, Raymond M. Schreck, and Kenneth R. Davis. "Performance of Elastomeric Components in Potable Water." AWWA Research Foundation (2007): n. pag. Print.

Sarai, Darshan Singh. Basic Chemistry for Water and Wastewater Operators. Denver, CO: American Water Works Association, 2002. Print.

Seader, J. D., Ernest J. Henley, and D. Keith. Roper. Separation Process Principles: Chemical and Biochemical Operations. Hoboken, NJ: Wiley, 2011. Print.

Smith, J. M., Ness H. C. Van, and Michael M. Abbott. Introduction to Chemical Engineering Thermodynamics. 7th ed. Boston: McGraw-Hill, 2005. Print.

The Department of health. (2008). Chlorination of Drinking Water. http://www.doh.wa.gov/ehp/dw/Publications/331253_chlorination_of_drinkingjwater_5-24-04.pdf. Last visited August 2008.

Tölgyessy, Juraj. Chemistry and Biology of Water, Air, and Soil: Environmental Aspects. Amsterdam: Elsevier, 1993. Print.

"What Is an ANOVA." What Is an ANOVA. Washington State University, 14 Aug. 2000. Web. 05 Dec. 2013. 


\section{APPENDIX}

\section{TABLE XI}

\section{SBR RAW DATA}

\begin{tabular}{|c|c|c|c|c|c|c|c|c|}
\hline $\begin{array}{l}\text { Rubber } \\
\text { Type }\end{array}$ & Day & $\begin{array}{l}\text { Concentration } \\
(\mathrm{ppm})\end{array}$ & $\begin{array}{l}\text { Temperature } \\
\left({ }^{\circ} \mathrm{C}\right)\end{array}$ & $\begin{array}{l}\text { Average Count } \\
\text { Rate (kcps) }\end{array}$ & $\begin{array}{l}\text { Weighted Particle } \\
\text { Diameter }(\mathrm{nm})\end{array}$ & $\begin{array}{l}\text { Diluted Count } \\
\text { Rate (kcps) }\end{array}$ & $\begin{array}{l}\text { Turbidity } \\
\text { (NTU) }\end{array}$ & $\begin{array}{l}\text { Peak Range } \\
(\mathrm{nm})\end{array}$ \\
\hline SBR & 1 & 30 & 45 & 3.2 & 433.8 & 3.2 & 1.30 & 468.4 \\
\hline SBR & 2 & 1 & 45 & 28.7 & 159.2 & 28.7 & 0.53 & 69.9 \\
\hline SBR & 2 & 30 & 45 & 58.5 & 289.2 & 55.5 & 1.60 & 32.2 \\
\hline SBR & 3 & 1 & 23 & 16.5 & 259.9 & 16.5 & 0.65 & 98.9 \\
\hline SBR & 3 & 30 & 23 & 11.2 & 40.0 & 11.2 & 0.40 & 16.7 \\
\hline SBR & 4 & 30 & 45 & 1.8 & 6696.5 & -49.2 & 3.04 & 102.6 \\
\hline SBR & 5 & 1 & 23 & 31.1 & 401.0 & 16.7 & 1.46 & 172.2 \\
\hline SBR & 5 & 1 & 45 & 41.2 & 231.3 & 17.9 & & 63.3 \\
\hline SBR & 7 & 1 & 23 & 117.1 & 80.9 & 90.0 & 2.04 & 29.9 \\
\hline SBR & 7 & 30 & 23 & 16.3 & 323.6 & 7.8 & 0.41 & 233.1 \\
\hline SBR & 7 & 1 & 45 & 48.4 & 8304.3 & 12.5 & 0.70 & 131.1 \\
\hline SBR & 7 & 30 & 45 & 71.5 & 316.7 & 70.0 & 3.20 & 68.1 \\
\hline SBR & 8 & 1 & 23 & 124.4 & 356.1 & 15.1 & 2.44 & 103.6 \\
\hline SBR & 8 & 30 & 23 & 9.8 & 213.3 & -5.4 & 0.57 & 288.3 \\
\hline SBR & 9 & 1 & 45 & 53.8 & 59.5 & 11.6 & 0.91 & 10.0 \\
\hline SBR & 9 & 30 & 45 & 80.1 & 6116.5 & 17.8 & 2.50 & 90.9 \\
\hline SBR & 10 & 1 & 23 & 36.5 & 771.3 & 36.5 & 0.48 & 384.0 \\
\hline SBR & 10 & 1 & 45 & 12.6 & 34.7 & -37.6 & 0.71 & 14.9 \\
\hline
\end{tabular}




\begin{tabular}{|c|c|c|c|c|c|c|c|c|}
\hline SBR & 11 & 1 & 23 & 32.1 & 675.4 & -2.0 & 0.72 & 2524.6 \\
\hline SBR & 11 & 1 & 45 & 24.2 & 54.3 & 12.4 & 0.80 & 48.2 \\
\hline SBR & 12 & 1 & 45 & 53.6 & 69.7 & 31.0 & 0.64 & 10.6 \\
\hline SBR & 13 & 1 & 23 & 37.0 & 1081.4 & 9.0 & 0.96 & 27.9 \\
\hline SBR & 14 & 1 & 23 & 49.0 & 411.4 & 14.5 & 0.96 & 149.0 \\
\hline SBR & 14 & 30 & 23 & 6.8 & 126.8 & 6.8 & 0.53 & 41.7 \\
\hline SBR & 14 & 30 & 45 & 53.3 & 737.5 & -3.4 & 1.67 & 300.6 \\
\hline SBR & 15 & 1 & 23 & 66.9 & 174.7 & 21.2 & 1.17 & 101.5 \\
\hline SBR & 15 & 30 & 23 & 6.6 & 3896.7 & 0.3 & 0.29 & 62.5 \\
\hline SBR & 15 & 1 & 45 & 30.5 & 75.9 & -13.1 & 0.79 & 113.5 \\
\hline SBR & 16 & 1 & 23 & 10.6 & 364.1 & -51.8 & 1.36 & 108.3 \\
\hline SBR & 16 & 30 & 23 & 2.7 & 669.1 & -3.5 & 0.33 & 345.7 \\
\hline SBR & 17 & 1 & 45 & 44.7 & 52.8 & 18.1 & 1.03 & 67.3 \\
\hline SBR & 18 & 1 & 45 & 57.7 & 24.8 & 16.0 & 0.98 & 30.3 \\
\hline SBR & 18 & 30 & 45 & 32.6 & 133.4 & -5.1 & 1.11 & 33.4 \\
\hline SBR & 19 & 1 & 23 & 162.5 & 761.5 & 153.9 & 1.86 & 408.9 \\
\hline SBR & 19 & 1 & 45 & 7.3 & 44.9 & -46.6 & 0.99 & 40.9 \\
\hline SBR & 20 & 1 & 23 & 171.5 & 419.1 & 19.8 & 2.25 & 107.5 \\
\hline SBR & 20 & 1 & 45 & 56.2 & 7598.2 & 49.4 & 1.15 & 79.5 \\
\hline SBR & 20 & 30 & 45 & 40.5 & 123.1 & 12.1 & 0.99 & 0.0 \\
\hline SBR & 21 & 1 & 23 & 158.4 & 246.6 & -1.7 & 2.62 & 95.3 \\
\hline SBR & 22 & 1 & 23 & 88.3 & 158.6 & -59.5 & 2.39 & 49.1 \\
\hline SBR & 22 & 30 & 23 & 19.4 & 1447.8 & 17.6 & 0.66 & 33.9 \\
\hline SBR & 22 & 1 & 45 & 25.6 & 67.3 & -23.4 & 1.16 & 60.5 \\
\hline SBR & 23 & 1 & 23 & 157.0 & 526.1 & 74.6 & 2.55 & 305.6 \\
\hline SBR & 23 & 1 & 45 & 27 & 50.2 & 3.1 & 1.00 & 43.9 \\
\hline SBR & 24 & 1 & 45 & 26.6 & 58.4 & 1.4 & 0.88 & 71.5 \\
\hline SBR & 24 & 30 & 45 & 22.1 & 9968.5 & -8.6 & 1.00 & 97.0 \\
\hline SBR & 25 & 1 & 45 & 5.1 & 37.2 & -19.7 & 1.02 & 45.8 \\
\hline SBR & 26 & 1 & 45 & 32.8 & 63.1 & 28.0 & 0.99 & 40.9 \\
\hline
\end{tabular}




\begin{tabular}{|l|l|l|l|l|l|l|l|l|}
\hline SBR & 27 & 1 & 45 & 24.3 & 82.5 & -6.3 & 0.98 & 64.8 \\
\hline SBR & 28 & 1 & 45 & 46.6 & 60.2 & 23.9 & 1.00 & 22.4 \\
\hline SBR & 28 & 30 & 45 & 26.1 & 360.3 & 9.3 & 0.73 & 182.2 \\
\hline SBR & 29 & 1 & 45 & 37.7 & 73.2 & -5.8 & 1.09 & 87.1 \\
\hline SBR & 30 & 1 & 45 & 24.8 & 52.0 & -10.4 & 1.01 & 33.0 \\
\hline
\end{tabular}

\section{TABLE XII}

\section{NR RAW DATA}

\begin{tabular}{|c|c|c|c|c|c|c|c|c|}
\hline $\begin{array}{l}\text { Rubber } \\
\text { Type }\end{array}$ & Day & $\begin{array}{l}\text { Concentration } \\
(\mathrm{ppm})\end{array}$ & $\begin{array}{l}\text { Temperature } \\
\left({ }^{\circ} \mathrm{C}\right)\end{array}$ & $\begin{array}{l}\text { Average Count } \\
\text { Rate (kcps) }\end{array}$ & $\begin{array}{l}\text { Weighted Particle } \\
\text { Diameter }(\mathrm{nm})\end{array}$ & $\begin{array}{l}\text { Diluted Count } \\
\text { Rate (kcps) }\end{array}$ & $\begin{array}{l}\text { Turbidity } \\
\text { (NTU) }\end{array}$ & $\begin{array}{l}\text { Peak Range } \\
(\mathrm{nm})\end{array}$ \\
\hline NR & 1 & 30 & 45 & 1.4 & 128.8 & 1.4 & 0.6 & 67.9 \\
\hline NR & 2 & 1 & 23 & 3.6 & 170.4 & 3.6 & 0.3 & 51.6 \\
\hline NR & 2 & 30 & 23 & 7 & 280.1 & 7.0 & 0.5 & 434.3 \\
\hline NR & 2 & 1 & 45 & 27.1 & 253.9 & 27.1 & 0.4 & 191.7 \\
\hline NR & 2 & 30 & 45 & 31.5 & 233.4 & 30.2 & 0.8 & 142.2 \\
\hline NR & 3 & 1 & 23 & 4.3 & 137.9 & 0.9 & 0.3 & 46.1 \\
\hline NR & 5 & 1 & 23 & 4.6 & 65.3 & 0.9 & 0.8 & 25.4 \\
\hline NR & 5 & 30 & 23 & 3.5 & 140.3 & -2.2 & 0.5 & 74.2 \\
\hline NR & 5 & 1 & 45 & 33.8 & 39.3 & 11.8 & & 17.2 \\
\hline NR & 5 & 30 & 45 & 39.5 & 141.5 & 13.9 & & 98.4 \\
\hline NR & 7 & 1 & 23 & 32.6 & 172.3 & 28.6 & 1.0 & 71.6 \\
\hline NR & 7 & 30 & 23 & 24 & 514.6 & 21.0 & 1.0 & 226.3 \\
\hline NR & 7 & 1 & 45 & 32.5 & 70.8 & 3.1 & 0.9 & 64.2 \\
\hline NR & 7 & 30 & 45 & 206.4 & 289.3 & 172.0 & 1.1 & 155.3 \\
\hline NR & 8 & 1 & 23 & 74.5 & 112.4 & 44.1 & 1.7 & 38.3 \\
\hline NR & 8 & 1 & 45 & 40.5 & 76.1 & 10.2 & 0.6 & 47.2 \\
\hline NR & 8 & 30 & 45 & 42.8 & 166.4 & -149.8 & 1.0 & 114.8 \\
\hline
\end{tabular}




\begin{tabular}{|c|c|c|c|c|c|c|c|c|}
\hline NR & 9 & 1 & 45 & 46.6 & 53.2 & 8.8 & 0.6 & 35.3 \\
\hline NR & 9 & 30 & 45 & 45 & 489.2 & 5.1 & 0.9 & 240.0 \\
\hline NR & 10 & 1 & 23 & 38.8 & 919.0 & 38.8 & 0.5 & 228.2 \\
\hline NR & 10 & 30 & 23 & 5.2 & 346.5 & 5.2 & 0.4 & 169.2 \\
\hline NR & 10 & 1 & 45 & 27.5 & 68.3 & -16.0 & 0.9 & 55.6 \\
\hline NR & 10 & 30 & 45 & 19.1 & 154.3 & -22.9 & 1.2 & 86.6 \\
\hline NR & 11 & 1 & 23 & 50.6 & 360.5 & 14.4 & 0.8 & 149.4 \\
\hline NR & 11 & 1 & 45 & 46.5 & 80.3 & 20.8 & 0.6 & 44.8 \\
\hline NR & 11 & 30 & 45 & 39.4 & 299.2 & 21.6 & 0.8 & 170.5 \\
\hline NR & 12 & 30 & 45 & 29.6 & 149.1 & -7.2 & 0.8 & 145.2 \\
\hline NR & 13 & 1 & 23 & 78.9 & 211.9 & 34.8 & 1.8 & 128.3 \\
\hline NR & 13 & 30 & 45 & 35.7 & 206.2 & 8.1 & 0.8 & 87.7 \\
\hline NR & 14 & 1 & 23 & 86 & 125.7 & 12.4 & 2.1 & 62.6 \\
\hline NR & 14 & 30 & 23 & 6.4 & 83.4 & 2.5 & 0.4 & 32.8 \\
\hline NR & 14 & 30 & 45 & 37.1 & 259.1 & 3.8 & 0.7 & 156.2 \\
\hline NR & 15 & 1 & 23 & 108.1 & 238.5 & 27.8 & 2.3 & 112.2 \\
\hline NR & 15 & 30 & 23 & 6.7 & 135.6 & 0.7 & 0.4 & 92.1 \\
\hline NR & 15 & 1 & 45 & 52.2 & 94.0 & 16.9 & 0.8 & 59.3 \\
\hline NR & 15 & 30 & 45 & 29.1 & 233.9 & -5.5 & 0.7 & 149.7 \\
\hline NR & 16 & 1 & 23 & 15.6 & 162.2 & -85.3 & 2.3 & 67.5 \\
\hline NR & 17 & 1 & 45 & 46.3 & 56.0 & 0.8 & 0.8 & 47.4 \\
\hline NR & 18 & 1 & 45 & 79 & 71.3 & 35.8 & 0.8 & 54.2 \\
\hline NR & 19 & 1 & 23 & 154.1 & 588.5 & 141.4 & 2.6 & 227.2 \\
\hline NR & 19 & 30 & 23 & 6.8 & 133.4 & 1.7 & 0.6 & 0.0 \\
\hline NR & 19 & 1 & 45 & 6.8 & 59.8 & -66.9 & 0.7 & 55.7 \\
\hline NR & 19 & 30 & 45 & 2.9 & 331.3 & -19.2 & 0.7 & 159.6 \\
\hline NR & 20 & 1 & 23 & 158.2 & 290.2 & 14.4 & 2.6 & 95.1 \\
\hline NR & 20 & 30 & 23 & 11 & 265.0 & 4.7 & 0.6 & 69.2 \\
\hline NR & 20 & 30 & 45 & 19.3 & 2738.6 & 19.3 & 0.6 & 81.0 \\
\hline NR & 21 & 1 & 23 & 153.5 & 68.3 & 5.8 & 2.6 & 25.4 \\
\hline
\end{tabular}




\begin{tabular}{|l|l|l|}
\hline NR & 22 & 1 \\
\hline NR & 22 & 1 \\
\hline NR & 23 & 1 \\
\hline NR & 23 & 1 \\
\hline NR & 24 & 1 \\
\hline NR & 25 & 1 \\
\hline NR & 25 & 30 \\
\hline NR & 26 & 1 \\
\hline NR & 26 & 30 \\
\hline NR & 27 & 1 \\
\hline NR & 27 & 30 \\
\hline NR & 28 & 1 \\
\hline NR & 28 & 30 \\
\hline NR & 29 & 1 \\
\hline NR & 29 & 30 \\
\hline NR & 30 & 30 \\
\hline
\end{tabular}

\begin{tabular}{|l|l|}
\hline 23 \\
\hline 45 \\
\hline 23 \\
\hline 45 \\
\hline 45 \\
\hline 45 \\
\hline 45 \\
\hline 45 \\
\hline 45 \\
\hline 45 \\
\hline 45 \\
\hline 45 \\
\hline 45 \\
\hline 45 \\
\hline 45 \\
\hline 45
\end{tabular}

\begin{tabular}{|l|l|}
\hline 170.7 & 463.0 \\
\hline 26.5 & 73.0 \\
\hline 173.1 & 357.3 \\
\hline 32.1 & 102.4 \\
31.4 & 113.6 \\
\hline 4.6 & 114.8 \\
\hline 1.5 & 154.8 \\
\hline 31.4 & 85.2 \\
\hline 13.4 & 6006.4 \\
\hline 57.6 & 109.3 \\
\hline 14.1 & 91.8 \\
\hline 48 & 113.1 \\
\hline 12.6 & 6476.5 \\
49.3 & 118.1 \\
\hline 12.1 & 137.0 \\
\hline 15 & 265.4 \\
\hline &
\end{tabular}

\begin{tabular}{|l|l|l|}
\hline 27.4 & 2.8 & 207.1 \\
\hline 21.0 & 1.0 & 89.1 \\
\hline 13.8 & 2.9 & 176.7 \\
\hline 7.4 & 1.0 & 69.0 \\
\hline 1.4 & 0.7 & 91.5 \\
\hline-24.7 & 0.8 & 61.4 \\
\hline-12.2 & 0.5 & 103.9 \\
\hline 27.1 & 0.7 & 64.6 \\
\hline 12.0 & 0.5 & 119.1 \\
\hline 28.3 & 0.8 & 69.1 \\
\hline 1.6 & 0.5 & 0.0 \\
\hline-5.8 & 0.9 & 89.3 \\
\hline-0.6 & 0.5 & 120.9 \\
\hline 4.5 & 1.0 & 84.4 \\
\hline 0.3 & 0.6 & 134.0 \\
\hline 3.7 & 0.5 & 104.1 \\
\hline & & \\
\hline
\end{tabular}

TABLE XIII

EPDM-P RAW DATA

\begin{tabular}{|l|l|l|l|l|l|l|l|l|}
\hline $\begin{array}{l}\text { Rubber } \\
\text { Type }\end{array}$ & Day & $\begin{array}{l}\text { Concentration } \\
(\mathrm{ppm})\end{array}$ & $\begin{array}{l}\text { Temperature } \\
\left({ }^{\circ} \mathrm{C}\right)\end{array}$ & $\begin{array}{l}\text { Average Count } \\
\text { Rate }(\mathrm{kcps})\end{array}$ & $\begin{array}{l}\text { Weighted Particle } \\
\text { Diameter }(\mathrm{nm})\end{array}$ & $\begin{array}{l}\text { Diluted Count } \\
\text { Rate }(\mathrm{kcps})\end{array}$ & $\begin{array}{l}\text { Turbidity } \\
(\mathrm{NTU})\end{array}$ & $\begin{array}{l}\text { Peak Range } \\
(\mathrm{nm})\end{array}$ \\
\hline $\begin{array}{l}\text { EPDM- } \\
\mathrm{P}\end{array}$ & 1 & 1 & 45 & 3.7 & 54.5 & 3.7 & 0.4 & 14.0 \\
\hline $\begin{array}{l}\text { EPDM- } \\
\mathrm{P}\end{array}$ & 2 & 1 & 23 & 2.9 & 81.1 & 2.9 & 0.3 & 29.9 \\
\hline EPDM- & 2 & 1 & 45 & 9.0 & 155.7 & 5.5 & 0.3 & 48.4 \\
\hline
\end{tabular}




\begin{tabular}{|c|c|c|c|c|c|c|c|c|}
\hline $\mathrm{P}$ & & & & & & & & \\
\hline $\begin{array}{l}\text { EPDM- } \\
\mathrm{P}\end{array}$ & 4 & 1 & 23 & 14.2 & 255.4 & 11.7 & 0.3 & 67.6 \\
\hline $\begin{array}{l}\text { EPDM- } \\
\mathrm{P}\end{array}$ & 4 & 30 & 23 & 10.2 & 126.5 & 10.2 & 0.4 & 41.7 \\
\hline $\begin{array}{l}\text { EPDM- } \\
P\end{array}$ & 5 & 1 & 45 & 5.1 & 69.9 & -2.2 & & 26.7 \\
\hline $\begin{array}{l}\text { EPDM- } \\
\mathrm{P}\end{array}$ & 7 & 1 & 45 & 5.4 & 117.2 & 1.0 & 0.4 & 39.4 \\
\hline $\begin{array}{l}\text { EPDM- } \\
\mathrm{P}\end{array}$ & 7 & 30 & 45 & 7.3 & 113.4 & 7.3 & 0.4 & 35.3 \\
\hline $\begin{array}{l}\text { EPDM- } \\
\mathrm{P}\end{array}$ & 11 & 30 & 23 & 9.3 & 255.4 & 9.3 & 0.4 & 67.6 \\
\hline $\begin{array}{l}\text { EPDM- } \\
\mathrm{P}\end{array}$ & 11 & 30 & 45 & 15.5 & 126.4 & 10.0 & 0.5 & 41.7 \\
\hline $\begin{array}{l}\text { EPDM- } \\
\mathrm{P}\end{array}$ & 12 & 1 & 23 & 7.8 & 178.7 & 7.8 & 0.4 & 80.9 \\
\hline $\begin{array}{l}\text { EPDM- } \\
\mathrm{P}\end{array}$ & 12 & 1 & 45 & 6.0 & 71.3 & 2.2 & 0.3 & 27.9 \\
\hline $\begin{array}{l}\text { EPDM- } \\
\mathrm{P}\end{array}$ & 13 & 1 & 23 & 4.8 & 148.3 & -2.5 & 0.3 & 68.7 \\
\hline $\begin{array}{l}\text { EPDM- } \\
\mathrm{P}\end{array}$ & 14 & 1 & 23 & 3.4 & 675.7 & -1.1 & 0.3 & 384.5 \\
\hline $\begin{array}{l}\text { EPDM- } \\
P\end{array}$ & 14 & 30 & 23 & 3.2 & 25.5 & -4.4 & 0.3 & 18.5 \\
\hline $\begin{array}{l}\text { EPDM- } \\
\mathrm{P}\end{array}$ & 14 & 30 & 45 & 14.4 & 445.3 & 1.8 & 0.5 & 162.5 \\
\hline $\begin{array}{l}\text { EPDM- } \\
\mathrm{P}\end{array}$ & 15 & 1 & 23 & 9.4 & 459.2 & 6.2 & 0.5 & 290.5 \\
\hline EPDM- & 15 & 30 & 23 & 9.6 & 458.0 & 6.6 & 0.3 & 152.8 \\
\hline
\end{tabular}




\begin{tabular}{|c|c|c|c|c|c|c|c|c|}
\hline $\mathrm{P}$ & & & & & & & & \\
\hline $\begin{array}{l}\text { EPDM- } \\
\mathrm{P}\end{array}$ & 15 & 30 & 45 & 14.5 & 127.1 & 1.1 & 0.6 & 41.7 \\
\hline $\begin{array}{l}\text { EPDM- } \\
P\end{array}$ & 16 & 1 & 23 & 1.1 & 227.3 & -7.7 & 0.3 & 57.1 \\
\hline $\begin{array}{l}\text { EPDM- } \\
P\end{array}$ & 17 & 30 & 45 & 34.1 & 266.4 & 21.5 & 0.5 & 114.0 \\
\hline $\begin{array}{l}\text { EPDM- } \\
\mathrm{P}\end{array}$ & 18 & 1 & 45 & 18.4 & 629.9 & 14.4 & 0.3 & 193.2 \\
\hline $\begin{array}{l}\text { EPDM- } \\
\mathrm{P}\end{array}$ & 18 & 30 & 45 & 29.2 & 565.7 & -2.6 & 0.5 & 116.3 \\
\hline $\begin{array}{l}\text { EPDM- } \\
\mathrm{P}\end{array}$ & 19 & 1 & 23 & 13.9 & 60.1 & 13.0 & 0.6 & 35.9 \\
\hline $\begin{array}{l}\text { EPDM- } \\
\mathrm{P}\end{array}$ & 19 & 30 & 45 & 4.2 & 124.0 & -23.1 & 0.5 & 38.7 \\
\hline $\begin{array}{l}\text { EPDM- } \\
\mathrm{P}\end{array}$ & 20 & 30 & 23 & 9.8 & 79.0 & 3.0 & 0.3 & 39.0 \\
\hline $\begin{array}{l}\text { EPDM- } \\
\mathrm{P}\end{array}$ & 20 & 1 & 45 & 53.3 & 255.5 & 37.3 & 0.3 & 136.3 \\
\hline $\begin{array}{l}\text { EPDM- } \\
\mathrm{P}\end{array}$ & 20 & 30 & 45 & 15.5 & 193.6 & 11.6 & 0.5 & 56.3 \\
\hline $\begin{array}{l}\text { EPDM- } \\
P\end{array}$ & 24 & 30 & 45 & 12.2 & 318.3 & 0.4 & 0.5 & 157.8 \\
\hline $\begin{array}{l}\text { EPDM- } \\
P\end{array}$ & 26 & 30 & 45 & 11.1 & 308.5 & 0.5 & 0.6 & 667.3 \\
\hline $\begin{array}{l}\text { EPDM- } \\
\mathrm{P}\end{array}$ & 28 & 1 & 45 & 15.2 & 629.9 & -15.5 & 0.4 & 0.0 \\
\hline $\begin{array}{l}\text { EPDM- } \\
\mathrm{P}\end{array}$ & 28 & 30 & 45 & 13.6 & 38.8 & 3.9 & 0.6 & 0.0 \\
\hline EPDM- & 29 & 30 & 45 & 11.0 & 124.0 & -1.7 & 0.5 & 0.0 \\
\hline
\end{tabular}




\begin{tabular}{|l|l|l|l|l|l|l|l|}
\hline $\mathrm{P}$ & & & & & & & \\
\hline $\begin{array}{l}\text { EPDM- } \\
\mathrm{P}\end{array}$ & 30 & 1 & 45 & 7.9 & 49.4 & -5.3 & 0.4 \\
\hline $\begin{array}{l}\text { EPDM- } \\
\mathrm{P}\end{array}$ & 30 & 30 & 45 & 11.8 & 170.3 & 1.5 & 0.7 \\
\hline
\end{tabular}

TABLE XIV

\section{CONTROL RAW DATA}

\begin{tabular}{|l|l|l|l|l|l|l|}
\hline $\begin{array}{l}\text { Rubber } \\
\text { Type }\end{array}$ & Day & $\begin{array}{l}\text { Concentration } \\
(\mathrm{ppm})\end{array}$ & $\begin{array}{l}\text { Temperature } \\
\left({ }^{\circ} \mathrm{C}\right)\end{array}$ & $\begin{array}{l}\text { Average Count Rate } \\
(\mathrm{kcps})\end{array}$ & $\begin{array}{l}\text { Weighted Particle } \\
\text { Diameter }(\mathrm{nm})\end{array}$ & $\begin{array}{l}\text { Turbidity } \\
(\mathrm{NTU})\end{array}$ \\
\hline DI & 1 & 0 & 23 & 11.7 & 255.5 & 0.2 \\
\hline DI & 4 & 0 & 23 & 8.1 & 343.0 & 0.2 \\
\hline DI & 5 & 0 & 23 & 2.3 & 310.8 & 0.3 \\
\hline Distilled & 8 & 0 & 45 & 8.0 & 326.1 & 0.3 \\
\hline Distilled & 10 & 0 & 23 & 4.4 & 880.7 & 0.4 \\
\hline Distilled & 10 & 0 & 45 & 3.2 & 113.6 & 0.4 \\
\hline Distilled & 12 & 0 & 23 & 10.3 & 199.9 & 0.3 \\
\hline Distilled & 13 & 0 & 23 & 6.5 & 126.4 & 0.3 \\
\hline Distilled & 13 & 0 & 45 & 6.0 & 409.7 & 0.3 \\
\hline Distilled & 15 & 0 & 23 & 6.6 & 355.3 & 0.3 \\
\hline Distilled & 15 & 0 & 45 & 7.3 & 86.1 & 0.3 \\
\hline Distilled & 17 & 0 & 45 & 15.1 & 266.3 & 0.3 \\
\hline Distilled & 18 & 0 & 45 & 9.6 & 1452.1 & 0.4 \\
\hline Distilled & 19 & 0 & 23 & 10.3 & 926.2 & 0.4 \\
\hline Distilled & 19 & 0 & 45 & 1.4 & 117.4 & 0.3 \\
\hline Distilled & 20 & 0 & 23 & 10.2 & 197.5 & 352.0 \\
\hline Distilled & 22 & 0 & 23 & 9.1 & & 0.3 \\
\hline Distilled & 23 & 0 & 45 & 5.6 & & 0.4 \\
\hline
\end{tabular}




\begin{tabular}{|l|l|l|l|l|l|l|}
\hline Distilled & 24 & 0 & 45 & 6.1 & 106.4 & 0.4 \\
\hline Distilled & 30 & 0 & 45 & 1.8 & 252.6 & 0.5 \\
\hline
\end{tabular}


VITA

NAME:

ADDRESS:

DOB:

EDUCATION:

WORK EXPERIENCE:
William Calvin Hunter III

6006 Trappers Ridge Circle

Louisville, KY 40216

September 20, 1989

B.S., Chemical Engineering University of Louisville 2008-2012

M. Eng., Chemical Engineering University of Louisville 2012-2013

Ashland Specialty Ingredients

Process Engineering Co-op

2010-2011

Kroger Pharmacy

Pharmacy Technician

2008-2009

PROFESSIONAL SOCIETIES:

American Institute of Chemical Engineers 